\title{
The mechanism of action of heparin in purified systems and in plasma
}

Citation for published version (APA):

Pieters, J. J. S. M. (1989). The mechanism of action of heparin in purified systems and in plasma.

[Doctoral Thesis, Maastricht University]. Rijksuniversiteit Limburg. https://doi.org/10.26481/dis.19890224jp

Document status and date:

Published: 01/01/1989

DOI:

10.26481/dis.19890224jp

Document Version:

Publisher's PDF, also known as Version of record

\section{Please check the document version of this publication:}

- A submitted manuscript is the version of the article upon submission and before peer-review. There can be important differences between the submitted version and the official published version of record.

People interested in the research are advised to contact the author for the final version of the publication, or visit the DOI to the publisher's website.

- The final author version and the galley proof are versions of the publication after peer review.

- The final published version features the final layout of the paper including the volume, issue and page numbers.

Link to publication

\footnotetext{
General rights rights.

- You may freely distribute the URL identifying the publication in the public portal. please follow below link for the End User Agreement:

www.umlib.nl/taverne-license

Take down policy

If you believe that this document breaches copyright please contact us at:

repository@maastrichtuniversity.nl

providing details and we will investigate your claim.
}

Copyright and moral rights for the publications made accessible in the public portal are retained by the authors and/or other copyright owners and it is a condition of accessing publications that users recognise and abide by the legal requirements associated with these

- Users may download and print one copy of any publication from the public portal for the purpose of private study or research.

- You may not further distribute the material or use it for any profit-making activity or commercial gain

If the publication is distributed under the terms of Article $25 \mathrm{fa}$ of the Dutch Copyright Act, indicated by the "Taverne" license above, 
THE MECHANISM OF ACTION OF HEPARIN

IN PURIFIED SYSTEMS AND IN PLASMA 
Druk: Wibro Dissertatiedrukkerij, Helmond Omslag: Janine Voncken 


\title{
The Mechanism of Action of Heparin
}

\section{in Purified Systems and in Plasma}

\author{
Proefschrift
}

\begin{abstract}
ter verkrijging van de graad van doctor
aan de Rijksuniversiteit Limburg te Maastricht, op gezag van Rector Magnificus, Prof. Dr. F.I.M. Bonke, volgens het besluit van het College van Dekanen, in het openbaar te verdedigen op vrijdag 24 februari 1989 om 16.00 uur
\end{abstract}

door

Jean Joseph Servais Marie Pieters

geboren te Heerlen 


\section{Promotor:}

Prof. Dr. H.C. Hemker

\section{Co-promotor:}

Dr. T. Lindhout

\section{Beoordelingscommissie:}

Prof, Dr. H.A.J. Struyker Boudier, Rijksuniversiteit Limburg, Maastricht (voorzitter)

Prof. Dr. U. Abildgaard, Universiteit van Oslo, Noorwegen

Prof. Dr. F. Duckert, Universiteit van Basel, Zwitserland

Prof. Dr. P.B. Soeters, Rijksuniversiteit Limburg, Maastricht

Prof. Dr. M.A. Allessie, Rijksuniversiteit Limburg, Maastricht

The Netherlands Heart Foundation contributed to the printing costs of this thesis. 
"In de wetenschap gelijken wij op kinderen, die aan de oever der kennis hier en daar een steentje oprapen, terwijl de wijde oceaan van het onbekende zich voor onze ogen uitstrekt."

John Newton 



\section{Contents}

Chapter I Introduction.

Chapter II Neutralization of heparin by prothrombin activation products. [Thromb Res 45:573, 1987]

Chapter III Inhibition of factor IX $_{\mathrm{a}}$ and factor $\mathrm{X}_{\mathrm{a}}$ by antithrombin III/heparin during factor $\mathrm{X}$ activation. [J Biol Chem 263:15313, 1988]

Chapter IV The limited importance of factor $\mathrm{X}_{\mathrm{a}}$ inhibition to the anticoagulant property of heparin in thromboplastin-activated plasma. [Blood, in press]

Chapter $\mathrm{V} \quad$ Factor $\mathrm{XI}_{\mathrm{a}}$ catalyzed generation of factor $\mathrm{IX}_{\mathrm{a}}$ in human plasma. Regulation by plasma proteinase inhibitors. [Submitted]

Chapter VI In situ generated thrombin is the only enzyme that effectively activates factor VIII:C and factor $\mathrm{V}$ in plasma. [Submitted]

Chapter VII General discussion.

Summary 


\section{ABBREVIATIONS}

\begin{tabular}{|c|c|}
\hline AT III & antithrombin III \\
\hline DEAE & diethylaminoethyl \\
\hline EDTA & ethylenediaminetetraacetic acid \\
\hline FPLC & fast protein liquid chromatography \\
\hline GLA & $\gamma$-carboxyglutamic acid \\
\hline HA-heparin & high affinity heparin \\
\hline $\mathrm{MW}$ & molecular weight \\
\hline PC & phosphatidylcholine \\
\hline PS & phosphatidylserine \\
\hline PPACK & Phe-Pro-Arg-chloromethylketone \\
\hline RVV & Russell's viper venom \\
\hline SDS & sodium dodecyl sulfate \\
\hline SDS-PAGE & polyacrylamide gel electrophoresis with SDS \\
\hline STI & soybean trypsin inhibitor \\
\hline S2238 & D-Phe-(Pipecolyl)-Arg-p-nitroanilide \\
\hline$\$ 2337$ & N-Benzoyl-Ile-Glu-(Piperidyl)-Gily-Arg-p-nitroanilide \\
\hline Tris & tris(hydroxymethyl)aminomethane \\
\hline UFH & unfractionated heparin \\
\hline
\end{tabular}




\section{Chapter I}

\section{Introduction}

In this chapter we will provide some background information on the process of blood coagulation, its initiation and its regulation. First of all, we will briefly discuss the historical events which lead to our present understanding of blood coagulation. After presenting a pathway for the initiation of coagulation, we will discuss the regulatory/inhibitory reactions occurring in plasma, with the emphasis on the antithrombin III/heparin system. In a last section we introduce the subsequent chapters of this thesis.

\section{The Early Years}

More than 300 years ago, in 1666, Malpighi (1) isolated white fibrous strands by washing clotted blood. This event represents the first written evidence of interest in the mysteries of blood coagulation (2).

About 100 years later, Hewson (3) localized the source of these fibrous strands to the plasma, rather than to the blood corpuscles, and by the middle-nineteenth century the formation of this fibrous material, named fibrin, became subject to investigations, which led to the beginning of the study of blood coagulation. 


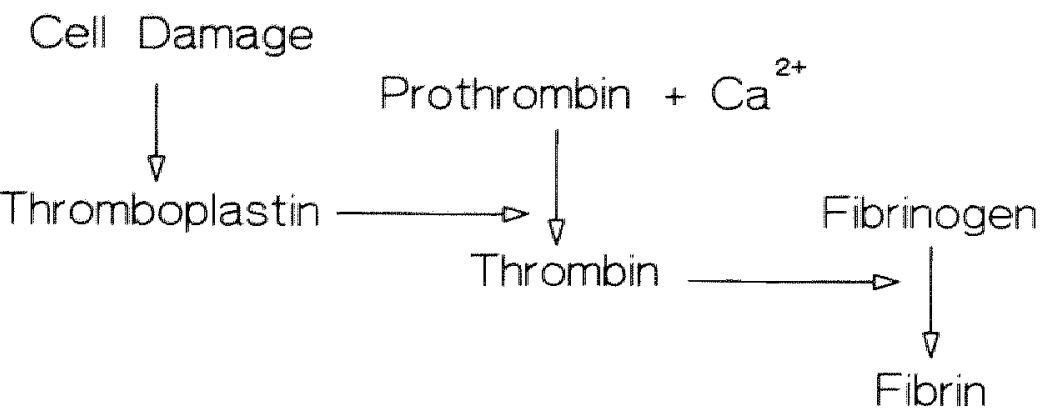

Figure 1. The "four factor" theory of blood clotting (taken from reference 23).

In 1845 , Buchanan (5) showed the ability of a serum component to induce blood coagulation. This component was initially named thrombin by Schmidt (6), but he later postulated that it was derived during clotting from a precursor in plasma, prothrombin.

It is now well established (7) that the discovery of prothrombin was due to the work of Pekelharing (8).

The next important observation was made by de Blainville (9): he saw that intravenous injection of a suspension of brain tissue led to immediate death, caused by total occlusion of the blood vessels by clots. Buchanan (5) confirmed that a variety of tissue's could induce clot formation, and initially it was thought that bodily tissue's contained thrombin. However, Schmidt (10), and later Morawitz (11) found that these tissue extracts did not clot fibrinogen directly, but rather by converting prothrombin into thrombin with the necessary presence of calcium ions. Therefore these clot-promoting substances were called tissue thromboplastin.

These results led to the so-called classical theory, also named the "four-factor" theory of blood clotting, which is schematically depicted in Figure 1. In this theory, tissue thromboplastin, in the presence of calcium ions first converts prothrombin into thrombin, which then in turn converts fibrinogen into fibrin. This theory held strong for almost half a century and persisted in the textbooks even longer. 


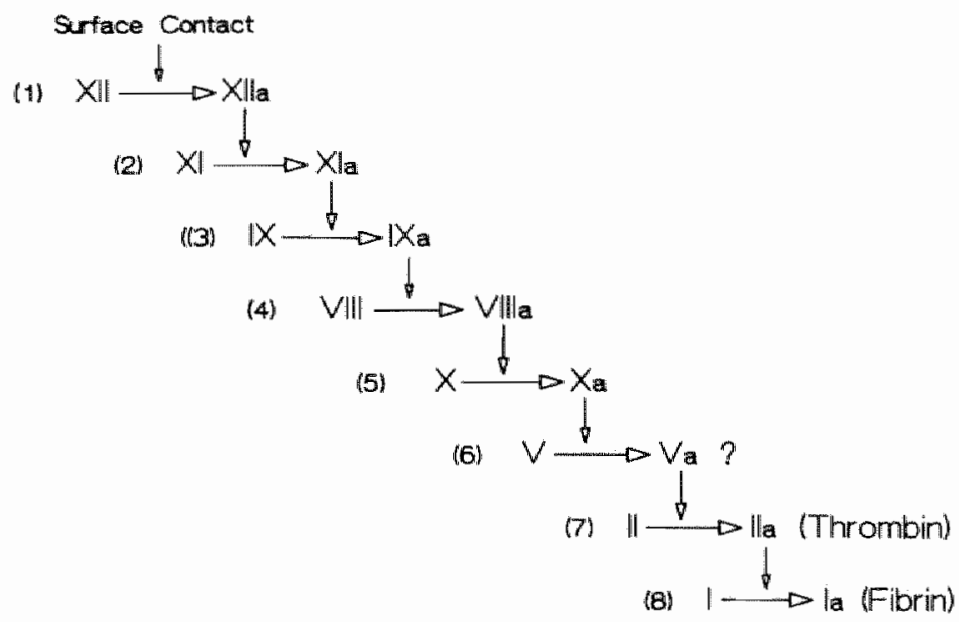

Figure 2. The enzyme cascade in the blood coagulation mechanism as published by MacFarlane in 1964. This reaction sequence originally represented what is now known the intrinsic pathway of coagulation. These reactions proceed upon exposure of blood to foreign surfaces (modified from reference 45)

In the late thirties several experiments suggested that the conversion of prothrombin into thrombin required participation of additional factors (12-14), and three additional factors were postulated.

In 1947, work from Owren (16) on a family with a congenital bleeding tendency gave the first clear indication of the existence of an additional clotting factor. He named it factor $\mathrm{V}$, being the fifth clotting factor discovered, but renamed it later in "proaccelerim" (17).

Several investigators suggested that there existed a serum component important for the conversion of prothrombin into thrombin $(18,19,20)$. Koller et. al. finally performed experiments on a familiar bleeding tendency from which they inferred the existence of a procoagulant plasma protein which they called factor VII, and that appeared to be identical with the serum component (23)

In 1956, studies of two patients with an abnormal one stage prothrombin time that was corrected by serum, revealed that the factor VII preparations then available contained a second procoagulant factor, as predicted earlier by Duckert $(24,25)$. This factor was named Stuart-Prower factor (factor X) $(26,27)$, after the surnames of the affected individuals. 
However, at the time of Morawitz classical theory, studies of Nolf (33) and Bordet and Gengou (34) laid the basis for the understanding of what is now known as the intrinsic pathway of coagulation. They demonstrated that blood depleted of cells clotted in glass tubes. Originally it was thought that such plasma contained thromboplastic substances (35). This was believed until Conley's classic experiment, that clearly demonstrated plasma to clot upon exposure to glass in the absence of tissue thromboplastin (42).

At that time, mostly by means of the occurrence of people with a bleeding disorder, and who appeared to be deficient in a clotting factor, factor XII (37), factor XI (38) and the antihaemophilic factor (factor VIII) $(39,40)$ were discovered.

In 1947, Pavlovsky's observation of a second type of haemophilia (41) led to the discovery of factor IX $(42,43,44)$.

This completed the view on blood coagulation in the early sixties, and resulted in publications of the so-called "cascade" (45) or "waterfall" (46) hypothesis of the blood coagulation system (see Figure 2).

The interaction of components of the blood clotting systemj with phospholipid vesicles was first demonstrated by Hanahan and Papahadjopoulos in 1964 (30). In 1967, Hemker et al performed experiments on the conversion of prothrombin into thrombin in a purified system, and proposed a kinetic model in which phospholipid provided a surface on to which coagulant proteins bind, in order to form a complex (31). It was also shown that for the activation of factor $\mathrm{X}$ into factor $\mathrm{X}_{\mathrm{a}}$ a complex of phospholipid, calcium, activated factor IX and VITI:C was responsible (32).

\section{A Modern View}

Nowadays, 25 years after the cascade or waterfall hypothesis was presented, this reaction sequence still forms the backbone of most reviews on blood coagulation. As was described in the previous section, this model was based on two historical findings, first, the observation of de Blainville (9), leading to the evidence that tissue factor promotes blood coagulation, and second, the experiments of Conley (36), showing the clotting of plasma upon exposure to glass. This division in extrinsic (tissue factor) and intrinsic (glass contact) pathways for coagulation was of considerable practical significance for the clinic in testing the integrity of 
the blood coagulation pathway: The one-stage prothrombin time (PT) is used to screen the extrinsic pathway (15), while the partial thromboplastin time (PTT) screens the intrinsic pathway $(14,47)$.

However, in this section we would like to formulate an alternative scheme for the blood coagulation cascade. To do this, we will first have to briefly recapitulate the most important features of the separate blood coagulation factors who will form part of the scheme; after discussing tissue factor we will mention the vitamin-K dependent clotting factors (i.e. factor VII, factor IX, factor $\mathrm{X}$ and prothrombin), and then we will present some information on the non-enzymatic protein cofactors factor VIII and factor V. Finally, a pathway for the initiation of coagulation as we think it proceeds in plasma under physiological circumstances is proposed.

\section{A. Components of the Blood Coagulation Scheme}

\section{Tissue Factor}

TF is a protein present on the plasma membranes of many cells. Especially brain, lung and placenta tissue display a high activity in TF. It is a 53,000 dalton glycoprotein, rich in carbohydrates $(56,57)$. Purification of TF requires removal of phospholipids by extraction with organic solvents (58). The resultant purified TF is devoid of proteolytic activity and has an absolute requirement for phospholipids to express its coagulant activity $(58,59)$. Recently, an inhibitor of the TF:factor VII(a) complex was identified $(59,60$; see the section on factor VII). Also it was suggested that the carbohydrate moiety of TF provides a regulatory mechanism, as it was reported that concanavalin $\mathrm{A}$ binds to and inhibits TF $(58,61,62)$.

No deficiencies of TF are known, indicating the possibility that absence of TF is incompatible with life (62).

\section{The Vitamin-K Dependent Coagulation Factors}

In 1935, the necessity of vitamin-K for normal hemostasis was recognised by Dam (63). Many years later it was shown that vitamin-K was necessary for the biological activity of prothrombin and factors VII, IX and X (64-66). It is now known that vitamin-K provides a post-translational carboxylation of glutamic 
acid residues to yield the $\gamma$-carboxyglutamic acid residues (Gla's) (67). These Gla's are thought to bind calcium ions, thereby promoting the association of these proteins to lipid membranes. Calcium ions act as "bridges" in this model, by interacting with negatively charged sites at the phospholipid on the one hand and the Gla residues on the protein on the other hand (68).

However, the role of Gla-residues may extend beyond $\mathrm{Ca}^{2+}$-mediated, protein-lipid association. Factor VII for example, binds via calcium ions to a very hydrophilic domain in TF that contains no Gla's (69). Also the activation of factor $X$ by Russel's viper venom occurs in the absence of phospholipid, but in the presence of calcium, where intact factor $\mathrm{X}$ is activated much faster than factor $\mathrm{X}$ from which the Gla-domain has been removed (70). Another example of a calcium dependent, non-phospholipid dependent reaction is the activation of factor IX by activated factor XI (71). Moreover, for the activation of factor X by factor VII $a / T F$ in the presence of phospholipid, it was demonstrated that the concentration of factor $X$ in solution controls the reaction velocity, rather that the concentration of phospholipid-bound factor X (72).

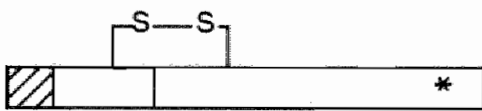

Factor VII MW 48,000

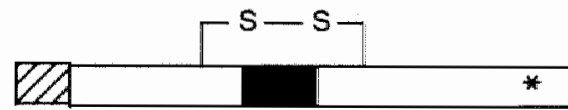

Factor DX MW 57.000

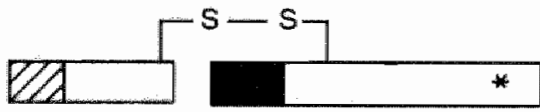

Factor $\times$ MW 55,000

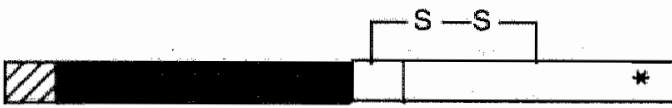

Factor $\|$ MW 72,000

Figure 3. The four vitamin- $K$ dependent coagulation factors. The shadow shaded part represents the amino terminal Gla-containing region. the active site serine on the carbaxyterminal part of the zymogen is symbolized with an asterisk. Activated peptides released upon activation of the zymogens are shown by solid bars. 
Thus, as there apparently is no a priori reason to invoke protein-phospholipid binding to explain $\mathrm{Ca}^{2+}$-and Gla-mediated acceleration of reactions in which vitamin-K dependent coagulation factors are involved, it is speculated that a Giamediated, $\mathrm{Ca}^{2+}$-induced conformational change may cause the observed acceleration of these reactions (48).

Which of these possibilities, calcium induced "bridge" formation, calcium induced conformational change, or both, causes the biological activity of these proteins, remains to be established. The Gla-containing, vitamin-K dependent proteins are schematically depicted in Figure 3.

\section{Factor VII}

Factor VII is a single chain glycoprotein ( $M W=48,000$ dalton), present in plasma at the very low concentration of $10 \mathrm{nM}$ (73). Factor VII is unique among the coagulation enzymes in that the zymogen factor VII has intrinsic activity (74). Nevertheless, factor VII clotting activity is some 100-fold increased by proteolytic cleavage into its two chain derivate, factor $\mathrm{VII}_{\mathrm{a}}$. This is catalyzed most rapidly by factor $\mathrm{X}_{\mathrm{a}}$ and at a slow rate by factor $\mathrm{IX}_{\mathrm{a}}(75,76)$. Factor $\mathrm{XII}_{\mathrm{a}}$ has also been reported to activate factor VII $(77,78)$.

Unti.l recently, no inhibitors of factor VII(a) were described. In 1987, Rao et al found that an inhibitor, requiring the presence of TF, factor VII(a) and factor $\mathrm{X}_{\mathrm{a}}$ could inhibit the TF:factor VII(a) activity, probably by the formation of an inert TF:VII(a): $X_{a}:$ inhibitor complex in the presence of calcium $(59,60)$. Indeed we have shown that when plasma is triggered with a relatively high concentration of thromboplastin, the activated factor $\mathrm{X}$ is able to back-inactivate the activating $\mathrm{TF}: \mathrm{VII}_{\mathrm{a}}$ complex, thus providing a regulation of its own generation (79).

Deficiencies in factor VII(a) activity have been described, some patients having serious bleeding difficulties, others quite moderate or mild (80).

\section{Factor $D X$}

Factor IX (Christmas factor) is a single chain glycoprotein with a molecular weight of 57,000 dalton $(81,82)$. Its plasma concentration is about $80 \mathrm{nM}$. Factor IX is activated into two chain factor IX $\mathrm{X}_{\mathrm{a}}$ by TF:VII(a), as mentioned above, and by factor $\mathrm{XI}_{\mathrm{a}}$, as we shall discuss in a later section $(83,84)$.

The inhibition of factor $\mathrm{IX}_{\mathrm{a}}$ is accomplished by antithrombin III $(84,85)$, and this is stimulated by heparin (see later). In a purified system, this stimulation is quite moderate (86), however, we and others showed that the action of heparin on the antithrombin III/factor IX reaction in plasma is tremendous (87-89).

Deficiency of factor IX results in hemophilia B, a sex linked, recessive bleeding disorder (90). About $10 \%$ of the patients have normal plasma levels of immunologically detectable factor IX $\left(\mathrm{CRM}^{+}\right)$, and the remaining $90 \%$ can be derived into two groups: those with reduced levels of factor IX $\left(\mathrm{CRM}^{\mathrm{red}}\right)$ and 
those with no detectable levels of factor IX (CRM) (90-92). Hemophilia B occurs in a severe, moderate or mild form according to the level of factor IX activity in plasma; Patients with severe hemophilia B have less than $1 \%$ factor IX; the patients possessing 5-25\% of normal factor IX activity have only mild symptoms.

\section{Factor $X$}

Factor X (Stuart-Prower factor) is a two chain glycoprotein of 55,000 dalton $\mathrm{MW}$, circulating in plasma at a concentration of about $160 \mathrm{nM}(93,94)$. Factor $\mathrm{X}$ is converted to $\alpha$-factor $\mathrm{X}_{\mathrm{a}}$ by the complex of factor $\mathrm{LX}_{\mathrm{a}}$, factor $\mathrm{VIII}_{\mathrm{a}}, \mathrm{Ca}^{2+}$ and phospholipids, or by the TF:VII(a) complex. This product can than autocatalytically be converted to a lower molecular weight form, $\beta$-factor $X_{a}$. Factor $X_{a}$ is also able to convert factor $X$ autocatalytically into $\beta$-factor $X$ and $\beta$-factor $X_{a}$ (95).

Factor $\mathrm{X}_{\mathrm{a}}$ is inactivated by antithrombin III, $\alpha 2$-macroglobulin and $\alpha 1$-antitryp$\sin (84,96,97)$.

To our present knowledge, no patients with a severe factor $\mathrm{X}$ deficiency were described. Because activated factor $\mathrm{X}$ is the only known physiological activator of prothrombin, factor $X$ deficient patients possibly die in utero at the first signs of microtraumatation (98).

\section{Prothrombin}

Prothrombin (factor II) is a single chain glycoprotein of a molecular weight of 72,000 dalton, circulating in plasma at concentration of about $1.5 \mu \mathrm{M}(99)$. Upon activation by factor $X_{\mathrm{a}}$ into thrombin, the Gla-containing activation peptide (fragment 1.2) is released (100) (see Figure 3). The activation peptide of prothrombin is almost half of the molecule, which suggests that it might be more then a mere activation peptide. Its function has been subject to many investigations. It was found to play a role in $\mathrm{Ca}^{2+}$ mediated binding to membranes, thus enhancing the factor $\mathrm{X}_{\mathrm{a}}$-induced activation $(101,102)$. It also seems to be involved in the binding of the non-enzymatic protein cofactor of prothrombin activation, factor $V_{a}$ (see later) $(50,102)$. The activation fragment has been found to regulate the activation of prothrombin (103) and to neutralize heparin (103), although the in vivo importance of these last two findings remain to be established.

The thrombin formed is inhibited by antithrombin III, $\alpha 2$-macroglobulin, $\alpha_{2}-$ antiplasmin and heparin cofactor II (105-108).

No patients lacking factor II were described, indicating the importance of this factor for normal hemostasis. 


\section{Factor VIII and Factor V}

The non-enzymatic protein cofactors VIII and V have a lot in common. Both of these cofactors accelerate the activation of a Gla-containing substrate (factor $\mathrm{X}$ or prothrombin) by a Gla-containing enzyme (factor $\mathrm{LX}_{\mathrm{a}}$ or factor $\mathrm{X}_{\mathrm{a}}$ ). Both require calcium ions and a lipid surface for optimal activity (109). Another similarity is that both factor VIII and factor V activity is regulated by limited proteolysis; both cofactors circulate as inactive proteins and are activated by serine proteases such as thrombin or factor $X_{\mathrm{a}}$, and are inactivated by another Gla-containing serine protease, namely activated protein C (110). These inactivation reactions also require a Gla-containing cofactor (protein S), $\mathrm{Ca}^{2+}$ and a lipid surface. Deficiency in factor VIII or factor V result in respectively hemophilia A (111) or parahemophilia (112) which represent mild to severe bleeding disorders. Also a combined deficiency of factors VIII and V was described (113).

\section{Factor VIII}

Factor VIII clotting activity occurs principally in plasma as a complex with von Willebrand factor (114). Factor VIII procoagulant protein is indicated as factor VIII:C, to distinguish from von Willebrand factor. Due to its very low concentration (about 1-1.5 nM) in plasma (115) and the fact that in plasma it circulates as an inactive cofactor tightly bound to von Willebrand factor, it was extremely difficult to purify. However, the isolation of full length cDNA's coding for human factor VIII:C, and its expression in mammalian cells (116-119), led to an explosion of knowledge about the structure and function of factor VIII:C. This cDNA codes for a peptide with a MW of 265,000 .

As already mentioned, factor VIII:C must be activated by thrombin (5153,120 ), factor $X_{a}(121)$ or factor $I_{\mathrm{a}}(122)$, although thrombin must be considered to be the physiologic activator in plasma.

The inactivation of factor VIII: $\mathrm{C}$ is, as already mentioned, accomplished by the protein C/protein $\mathrm{S}$ pathway, which is further discussed in a later section.

Deficiency of factor VIII:C (hemophilia A) results in hemorrhage and hematoma's. As for hemophilia B, the patients can be divided in severe (1\%), moderate $(1-5 \%)$ or mild $(5-25 \%)$, according to the relative amount of factor VIII:C activity in plasma (109)

\section{Factor $V$}

Factor $\mathrm{V}$ is a plasma glycoprotein that circulates in plasma at a concentration of $30 \mathrm{nM}$ in a single chain form (123). It was isolated and purified from human plasma in 1980 (124), whereas platelet factor $V$ has also been isolated. Bovine aortic endothelial, cells were also found to contain factor $\mathrm{V}$ activity $(125,126)$. 
Factor $\mathrm{V}$ is activated by thrombin and factor $\mathrm{X}_{\mathrm{a}}(127,128)$. Activated factor $\mathrm{V}$ changes the reaction pathway and the intermediate generated during thrombin formation. In the absence of factor $V_{a}$, the intermediate prethrombin 2 is generated, whereas in its presence meizothrombin is the principal intermediate $(129,130)$. Both intermediates are then converted to the same thrombin species.

The inactivation of factor $\mathrm{V}_{\mathrm{a}}$ proceeds also through the protein $\mathrm{C} /$ protein $\mathrm{S}$ mechanism (131), as will be described later.

Deficiency in factor $V$ results in parahemophilia, either caused by low levels of factor $V$ or dysfunctional forms of factor $V(132,133)$. The bleeding of these patients is usually milder and more easily controlled than the bleeding associated with hemophilia A. (112).

\section{Factor XI}

Human factor XI (plasma thromboplastin antecedent, PTA) circulates in plasma non-covalently associated with high molecular weight kininogen (HMWK) (134). It is present at a concentration of approximately $30 \mathrm{nM}$ (135) and occurs as two identical disulphide-linked polypeptide chains of 80,000 dalton $\mathrm{MW}$ each (136). Factor $\mathrm{XI}$ is activated by proteolysis due to factor $\mathrm{XII}_{\mathrm{a}}$. Factor $\mathrm{XI}_{\mathrm{a}}$ is composed of two heavy chains and two light chains held together by disulphide bonds (137).

Factor $\mathrm{XI}_{\mathrm{a}}$ is inhibited by $\alpha 1$-antitrypsin, antithrombin III, C1-inhibitor and $\alpha 2$ antiplasmin. It is not clear whether $\alpha 1$-antitrypsin, or the combined action of $\alpha 1$ antitrypsin, antithrombin III and $\alpha 2$-antiplasmin are responsible for the rapid inactivation of factor $\mathrm{XI}_{\mathrm{a}}$ in plasma $(89,138,139)$.

Factor XI deficiencies are sometimes associated with a bleeding disorder (38), suggesting a possible physiological role for factor XI in normal hemostasis.

\section{B. Initiation of Blood Coagulation}

Now we would like to discuss in more detail the modern wiews on blood coagulation. Especially the initiation of blood coagulation was a subject of debate during the recent years. Some investigators stress the importance of the contact activation for the initiation of blood coagulation, others deny it. We would like to defend the position in the following part that indeed, the contact factors are not needed to explain normal and abnormal haemostasis.

Due to the intrinsic activity of factor VII and the fact that TF requires no proteolytical processing for its activity, the initial step in coagulation could be accomplished by the mere physical complexation of tissue factor with factor 
VII(a) (48). (As factor VII zymogen is thought to have activity, factor VII(a) is used when both enzyme and zymogen is referred to (48)). It is interesting to note that none of the usual inhibitory proteins is active against factor VII(a). Recently, an inhibitor of the factor VII(a):TF complex was found. However, this socalled extrinsic pathway inhibitor (EPI, 60), becomes active by its association with factor $X_{a}$, i.e. after coagulation already has started.

Once the active TF:factor VII is formed, this complex activates factor $\mathrm{X}$, giving rise to small amounts of activated factor $\mathrm{X}$. This factor $\mathrm{X}_{\mathrm{a}}$ then converts the $z \mathrm{y}$ mogen factor VII into its activated form, which possesses a 100-fold increased activity. This enzymatic complex of TF:factor $\mathrm{VII}_{\mathrm{a}}$ activates enough factor $\mathrm{X}$ to produce the amount of factor $X_{\mathrm{a}}$ necessary to convert some prothrombin to yield trace amounts of thrombin. These traces of thrombin can trigger the platelets to expose their procoagulant activity and activate factor V. Only then sufficient amounts of thrombin are generated to ensure proper coagulation $(54,55)$.

However, in this course of events the antihemophilic factors, factor IX and factor VIII:C, seem not to be involved, although they must play a significant role in normal hemostasis. To explain their action, we have to go back to 1965 , the year in which Josso showed that factor VIII:C and factor IX are essential for thrombin formation induced by diluted thromboplastin (140).
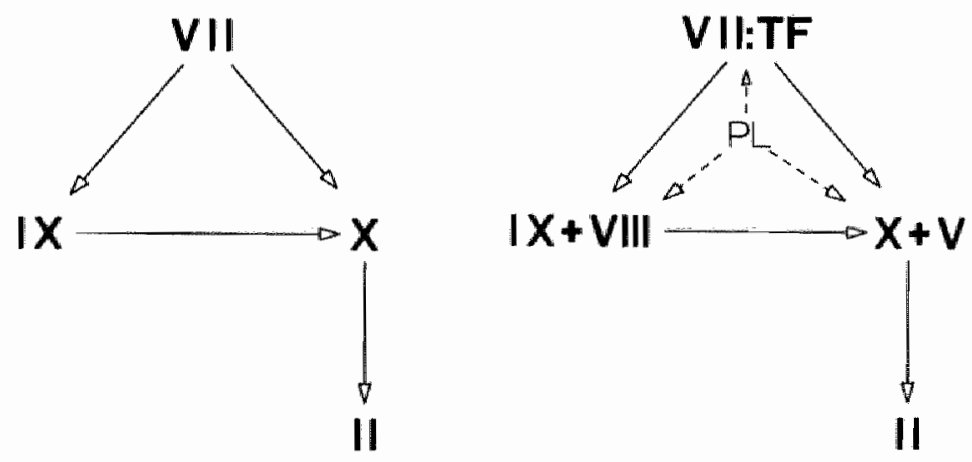

Figure 4. The Josso-loop. A: Factor VII (a) activates both factor $I X$ and factor $X$, after which the generated activated factor $X$ converts prothrombin into thrombin. $B$ : The completed Josso-loop. Her, also the non enzymatic cofactors and phospholipid surface are indicated (taken from reference 98). 
Because usually, all experiments in which the TF:factor VII initiation was involved, were carried out with extremely high concentrations of thromboplastin, it was not until the late seventies that this alternative pathway via factor IX got enough attention. By that time Osterud and Rapaport demonstrated clearly that besides factor $X$, also factor IX is activated in considerable amounts by TF:factor VII(a) $(49,141)$. The generation of factor $\mathrm{IX}_{\mathrm{a}}$ activity may become important if clotting is started by diluted thromboplastin, then providing a reinforcement loop in the generation of factor $\mathrm{X}_{\mathrm{a}}$. This reinforcement loop, which was proposed to be named the "Josso loop", after its discoverer (98), is depicted in Figure $4 \mathrm{a}_{\text {. }}$

Thus, besides producing directly factor $\mathrm{X}_{\mathrm{a}}$, the TF:factor VII(a) complex also provides an indirect activation of factor $\mathrm{X}$ by activating factor IX. As mentioned above, the first traces of thrombin activate factor VIII:C, leading to a view on thrombin formation as depicted in Figure $4 \mathrm{~b}$. The reinforcement loop via the antihemophilic factors, the Josso loop, will become more important the less thromboplastin is present. This might explain the fact that hemophiliacs tend to bleed in thromboplastin poor organs. In general, it is very likely that the in vivo

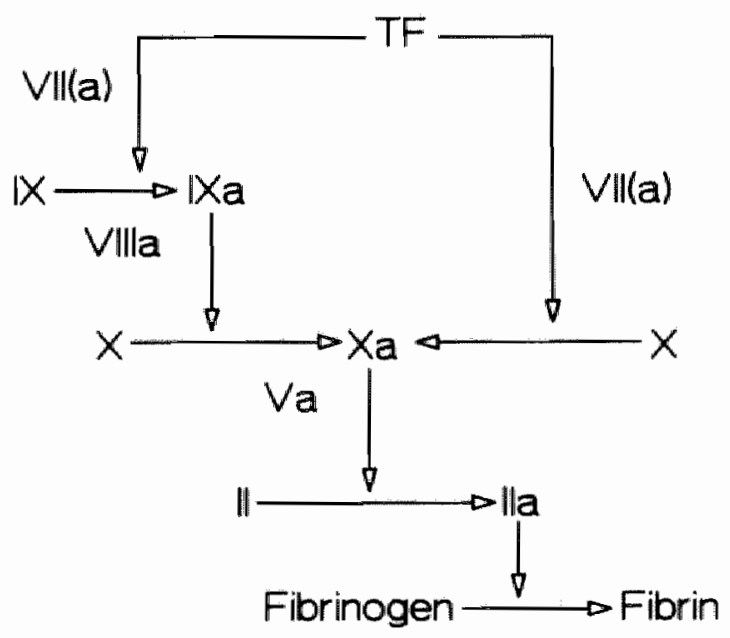

Figure 5. A modern view on blood coagulation. Upon the exposure of tissue factor, the complex of factor VII(a):TF activates as well as factor $I X$ as factor $X$, leading to the generation of factor $X_{\mathrm{a}}$, this activated factor $X$ than converts prothrombin into thrombin, leading to the generation of fibrin (modified from reference 48). 
coagulation starts upon exposure of very small amounts of tissue factor, equivalent to highly diluted thromboplastin. Indeed, already in 1834 de Blainville demonstrated that high concentrations of thromboplastin completely knocked out the hemostatic balance: the animals he injected with tissue extracts died through total occlusion of the blood vessels with clots (9)!

A modern vieuw on blood coagulation as explained above is schematically presented in Figure 5.

Now, what about the role of the contact factors in hemostasis? It is significant that people deficient in a contact factor are entirely asymptomatic (142). Also, the contact activation reactions are linked to several other proteolytic plasma systems $(62,143)$. Finally, the initiation of blood coagulation by negatively charged surfaces such as kaolin, sulfatides or glass must be considered extremely rare in a physiological situation. Instead of regarding contact activation as an alternative pathway for initiating blood coagulation, one could rather suspect the use of glass material in the early years of coagulation research to be a historical error!

However, one problem remains to be solved. In the above presented view on coagulation, no role for factor XI was considered, although factor XI deficient patients clearly show bleeding problems in a certain (unknown) percentage of the cases. Now their are 2 possibilities: Either the bleeding problems observed in those patients are not the consequence of the decreased factor XI levels (alone), or factor XI does play a role in normal hemostasis. Because the activation of factor $\mathrm{IX}$ by factor $\mathrm{XI}_{\mathrm{a}}$ does not require a cofactor or a surface for optimal activity, the factor $\mathrm{XI}_{\mathrm{a}}$ catalyzed activation of factor $\mathrm{IX}$ could possibly play a role in those situations in which no tissue factor is available.

\section{The Regulation of the Coagulation Cascade}

Uninhibited thrombin formation would lead to an uncontrolled explosive thrombin generation that would cause lethal thrombosis at the slightest provocation. As already mentioned throughout the previous section, the reaction sequence leading to the generation of thrombin is controlled at various levels by several inhibitory mechanisms. In this section we will discuss a number of these inhibitory mechanisms, who can be divided into four groups. 


\section{A. The Protein C/Protein S Pathway}

The protein $\mathrm{C} /$ protein $\mathrm{S}$ pathway provides an inhibitory mechanism for the activities of factor VIII: $\mathrm{Ca}_{\mathrm{a}}(120)$ and factor $\mathrm{V}_{\mathrm{a}}(144)$. Protein $\mathrm{C}$ is a vitamin-K dependent glycoprotein with a molecular weight of about 62,000 dalton and occurring in plasma at a concentration of $63 \mathrm{nM}(62,145)$. Upon proteolysis by thrombin, protein $C$ is activated at a very slow rate (146) and this activation process is further inhibited by physiological calcium concentrations (147). However, the endothelial cell was found to posses cofactor activity, now known to be caused by the presence of thrombomodulin at its surface (148), which forms a 1:1 complex with thrombin. This complex then rapidly activates protein $\mathrm{C}$ in a $\mathrm{Ca}^{2+}$ dependent reaction (149). In 1983 it was found that the factor $\mathrm{V}_{\mathrm{a}}$ molecule also possesses cofactor activity for the activation of protein $C$ by thrombin $(150,151)$.

Activated protein $\mathrm{C}$ requires the presence of phospholipid, calcium ions and protein $\mathrm{S}$, a vitamin- $\mathrm{K}$ dependent protein that functions as a cofactor for optimal inhibitory activity towards activated factors $V$ and VIII:C (152).

Activated protein $\mathrm{C}$ is inhibited by activated protein $\mathrm{C}$ inhibitor (APC-inhibitor $(153,154))$.

The importance of the protein $\mathrm{C} /$ protein $\mathrm{S}$ pathway in the regulation of blood coagulation might be indicated by the fact that deficiencies of protein $\mathrm{C} /$ protein $\mathrm{S}$ are associated with thrombotic disorders (155). It is significant that for thrombomodulin to be present so that the protein C/protein S mechanism can get started, intact endothelium is required.

\section{B. Inhibitors of Surface Binding}

This group of anticoagulants comprises a variety of compounds, all interfering with the blood coagulation factor-surface binding. This group can be divided into several subgroups (156), of which a first group is formed by the phospholipases, who bind to a phospholipid surface bilayers and hydrolyses various of its components. Thus, they occupy the surface and change its properties (157).

The second group consists of the lupus anticoagulant, a heterogenous group of acquired immunoglobulins which bind to the procoagulant surface (158). The lupus anticoagulant has been found to act as an inhibitor of in vitro clotting tests (159), and is associated with thrombosis (159), although the relationship between these phenomena remains to be established.

In a third group we mention the Gla-containing activation fragments of prothrombin and factor $X$, who inhibit in a competitive manner the tissue factor dependent activation of factor $\mathrm{X}(160)$ and the factor $\mathrm{X}_{\mathrm{a}}$-catalyzed prothrombin activation (103). Also a Gla-containing peptide derived from factor $\mathrm{X}$ was found to inhibit surface mediated reactions (161). 
As a last member of this group we name the vascular anticoagulant (VAC) discovered by Reutelingsperger in 1985 (162). This protein, devoid of Gla-residues, binds in a calcium-dependent way with high affinity to negatively charged phospholipids, thus interfering with the coagulant factor phospholipid interaction.

\section{The Extrinsic Pathway Inhibitor}

In 1985, Sanders et al observed an inhibition of the factor VII $/ \mathrm{TF}$ activity during coagulation in plasma (163). This inhibitor which they called the extrinsic pathway inhibitor (EPI), apparently required the presence of the TF: $\mathrm{VII}_{\mathrm{a}}$ complex and factor $X_{\mathrm{a}}$, thus providing a control mechanism in the initial steps of coagulation, triggered by the exposure of TF.

\section{Serpins}

The last group of naturally occurring inhibitors comprises the serpins, the serine protease inhibitors. This includes antiplasmin, $\alpha 1$-antitrypsin, heparin cofactor II and antithrombin III (164). These are structurally homologous plasma proteins, while their functional diversity is determined by their reactive site amino acids. The molecular weight of these proteins ranges from 40,000 to 100,000 dalton. These serpins function as suicidal proteins in that they form a tight 1:1 complex with their target protease, after which these complexes are removed from the circulation and catabolized.

As the major part of this thesis deals with the effect of antithrombin III and heparin (a mucopolysaccharide greatly enhancing the activity of antithrombin III) on several activated blood coagulation factors, we dedicate a separate section to this protein inhibitor.

\section{The Antithrombin III-Heparin System}

\section{Antithrombin III}

Antithrombin III is one of the most important physiological inhibitors of blood coagulation. Its inhibitory action is directed against thrombin and factor $\mathrm{X}_{\mathrm{a}}$, whereas factor $\mathrm{LX}_{\mathrm{a}}$, factor $\mathrm{XI}_{\mathrm{a}}$ and factor $\mathrm{XII}_{\mathrm{a}}$ were also shown to be liable to in- 
hibition (for a recent review see reference 165). The inhibition of factor $\mathrm{XI}_{\mathrm{a}}$ and factor $\mathrm{XII}_{\mathrm{a}}$, however, seems to be of no importance in plasma. The activity towards factor $\mathrm{X}_{\mathrm{a}}$ and factor $\mathrm{IX}_{\mathrm{a}}$ will be discussed further in this paragraph.

Antithrombin III, purified from plasma for the first time in 1968 (166), showed to be a single chain glycoprotein with a molecular weight of 55,000 dalton (167). Its plasma concentration is about $2.5 \mu \mathrm{M}(168,169)$. Two forms of antithrombin III were found in plasma, due to different carbohydrate composition $(170,171)$. The inhibitory activity of antithrombin III is greatly enhanced in the presence of heparin, as we shall discuss in a later section.

The interaction of antithrombin III with thrombin is extensively studied. Antithrombin III reacts with thrombin to form a 1:1 complex (172). In serum this complex was found to posses a molecular weight in the $180,000-200,000$ dalton range instead of the 90,000 dalton expected $(173,174)$. Marciniac et al, however, showed that this was due to aggregation (175). The formation of the antithrombin III thrombin complex involves the cleavage of a peptide bond in antithrombin III. The formed complex dissociates under physiological conditions spontaneously but very slowly (176), thus liberating active thrombin and proteolytically modified inactive antithrombin III (177). This modified two-chain antithrombin III is also formed by direct activation by thrombin, without complex formation (178).

As already mentioned, antithrombin III also inactivates factor $\mathrm{X}_{\mathrm{a}}$ and factor IX $X_{\mathrm{a}}$. The inactivation of factor $\mathrm{X}_{\mathrm{a}}$ by antithrombin III is analogous to the inhibition of thrombin. However, factor $\mathrm{X}_{\mathrm{a}}$ seems to be protected from inactivation by antithrombin III by the presence of $\mathrm{Ca}^{2+}$ /phospholipid or $\mathrm{Ca}^{2+} / \mathrm{Na}_{\mathrm{a}}$ phospholipid $(179,180,86)$. The inhibition of factor $\mathrm{IX}_{\mathrm{a}}$ by antithrombin III was found to be very slow in a purified system, and negligible in plasma. The addition of heparin caused a dramatic increase in inactivation rate of factor $\operatorname{IX}_{\mathrm{a}}(86,89)$.

Deficiencies in antithrombin III have been described, with antithrombin III levels varying from $40-70 \%$ of normal (165). These deficiencies are a result of either reduced antithrombin III levels (type I deficiency), or of abnormal variants (type II deficiency). Among type II deficiency, several different variants were identified, e.g. antithrombin III molecules with abnormal thrombin and factor $\mathrm{X}_{\mathrm{a}}$ inhibition and abnormal heparin binding (AT III "Budapest, AT III "Tokyo"); abnormal thrombin and factor $\mathrm{X}_{\mathrm{a}}$ inhibition but normal heparin binding (AT III "Vicenza", AT III "Denver"), and normal thrombin and factor $\mathrm{X}_{a}$ inhibition but abnormal heparin binding (AT III "Paris", AT III "Basel"). The occurance of this last variant with thrombosis shows that the binding of antithrombin III to heparin also in vivo probably plays a significant role. It has been suggested that the binding of antithrombin III to the heparin-like molecules (at the endothelial cell surface) in vivo must be important for its optimal activity as a coagulation inhibitor (165). 
Heparin

Heparin is a heterogenous, polydisperse glycosaminoglycan, with a molecular weight range from 5,000 to 30,000 dalton giving a mean molecular weight of 15,000 dalton. In mammalian species, this complex carbohydrate is widely distributed throughout a variety of organs, including liver, lungs, heart, kidney and intestine (181). Heparin is composed of individual mucopolysaccharide chains composed of a multitude of possible arrangements of uronic acid and glucosamine residues (165).

The antithrombin III binding sequence is an oligosaccharide segment that contains D-glucuronic acid and a unique trisulphated D-glucosamine residue, whereas the actual binding site for antithrombin III appears to be a pentasaccharide (182). The structure of this pentasaccharide is shown in Figure 6, and was reproduced by total synthesis by Choay et al (183). The chemical groups, most probably responsible for the binding to antithrombin III, are the 3-O-sulphate group and the 6-O-sulphate group on the $\mathrm{N}$-acetylated glucosamine unit.

However, only one third of the chains of unfractionated heparin contain this unique pentasaccharide sequence. The remaining two-third are essentially inactive as an anticoagulant, although not necessarily as an antithrombotic agent (165).

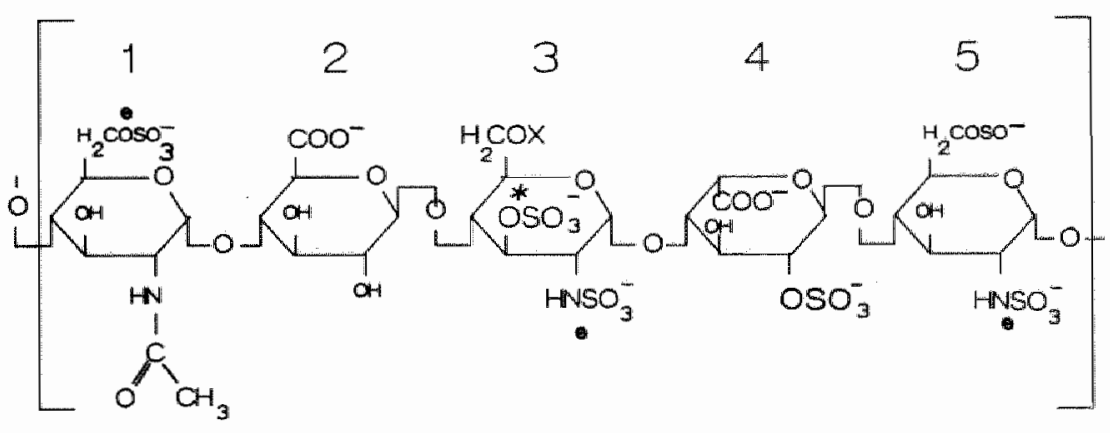

Figure 6. Structure of the antithrombin III binding pentasaccharide sequence. The3$O$-sulphate group of unit 3 (marked by an asteriks) is unique to the antithrombin III binding region of heparin, while each one of the sulphate groups indicated by $(e)$ is essential to the high affinity binding of antithrombin III (modified from reference 183). 
Because the administration of heparin, besides the desired antithrombotic effect, also causes non-desired side effects such as bleeding $(184,197)$ and platelet aggregation (185), one of the aims in heparin research over the past years was to isolate or synthesize heparin preparations that maximize the sequences with desirable activities, and minimize those sequences who probably cause the undesirable side effects (186). The preparation of heparin fractions is achieved either by fractionation, chemical modification, or synthesis.

Fractionation of heparin chains is done in various ways, including affinity chromatography with antithrombin III (187), gelfiltration (188) and precipitation with alcohols. Affinity chromatography with antithrombin III results in high affinity heparin fractions, containing the antithrombin III-binding sequence, and in low affinity heparin fractions. Gel filtration results in heparin fractions with different molecular weight. Because sulphated species are less soluble in alcohol then the less sulphated species, fractional precipitation with alcohol results in fractions with a different degree of sulphation.

Chemical modification is achieved mostly by removal of sulphate groups or controlled depolymerization, which produces fragments of the size of $8-30$ monosaccharide residues, ranging in molecular weight from 2,500 - 9,000 dalton. Fragments of $8-16$ monosaccharides that contain the antithrombin III binding pentasaccharide show very high anti- $\mathrm{X}_{\mathrm{a}}$ activities but are devoid of anti-thrombin activity.

The above mentioned discrimination in anti- $\mathrm{X}_{\mathrm{a}}$ and anti-thrombin activity of heparin was made because it was found that for the inhibition of thrombin, the binding of heparin to the protease is an absolute requirement $(189,190)$. In contrast, for the inactivation of factor $\mathrm{X}_{\mathrm{a}}$, the presence of the pentasaccharide sequence is sufficient to obtain a high inhibition of factor $X_{a}$ by antithrombin III $(191,192)$. Therefore a difference was made for heparins which exert high anti$\mathrm{X}_{\mathrm{a}}$ activity (i.e. low molecular weight heparins containing the pentasaccharide sequence) and heparins which exerted high anti-thrombin activity as well as antifactor $X_{a}$ activity (i.e. heparins containing at least $14-18$ saccharides $(193,194)$.

For the inhibition of factor $\mathrm{IX}_{\mathrm{a}}$ and factor $\mathrm{XI}_{\mathrm{a}}$ the same molecular weight dependence as for thrombin was shown by Holmer et al (189). However, we provided clear evidence that in plasma the inactivation of factor $\mathrm{IX}_{\mathrm{a}}$ is stimulated by pentasaccharide (see Chapter 5).

In the clinic, heparin is used for the prophylaxis of venous thrombosis, for the treatment of overt thrombosis, for the prophylaxis of recurrent thrombosis and for maintaining the fluidity of the blood in extracorporal circulations, such as in heart-lung machines and renal dialysis (195).

The prevention and treatment of these thrombotic events with classical unfractionated heparin is often accompanied with hemorrhage and sometimes with undesirable platelet interactions (196). Therefore, a number of years ago it was 
proposed that heparin preparations of low molecular weight would have advantages in anticoagulant therapy. Experiments in animal models suggested that with heparin fractions of about 5,000 dalton molecular weight, equal antithrombotic efficacy was obtained with less bleeding tendency as compared to classical unfractionated heparin $(197,198)$.

Also it was found that heparins with a mean molecular weight of between 4,000 and 6,000 dalton had relatively little effect on tests measuring overall clotting such as APTT, but maintained their potency as measured by anti- $\mathrm{X}_{\mathrm{a}}$ assay's $(199,200)$. Thus, it was suggested that heparins with high anti- $X_{d} / A P T T$ ratios (i.e. high anti- $\mathrm{X}_{\mathrm{a}} /$ anti-thrombin ratios) would maintain the efficacy of unfractionated heparin by exerting an antithrombotic effect through their preserved anti$\mathrm{X}_{\mathrm{a}}$ function, and cause less bleeding because of their reduced action on overall clotting $(201,202)$.

However, preparations of heparin in which the molecule is large enough to retain some thrombin blocking action appeared to be more effective as an antithrombotic agent (203). Nor have the clinical studies published so far convincingly demonstrated that low molecular weight heparins are safer and cause less bleeding than unfractionated heparin (204).

Another aspect is that although most clinical studies make use of the anti- $\mathrm{X}_{\mathrm{a}}$ activity of heparin/low molecular weight heparins to monitor their antithrombotic potency, the relationship between antithrombotic efficacy and anti- $X_{a}$ activity may severely be questioned (see chapter 4 and reference 205).

Some properties of the low molecular weight heparin, however, clearly overcome disadvantages of the classical unfractionated heparin preparations. First, low molecular weight heparins are eliminated from the blood more slowly than unfractionated heparin; its biological half life is about twice as long. Second, low molecular weight heparins apparently do not cross the placenta.

\section{The Present Investigation.}

This thesis describes a number of studies which deal with the regulatory (inhibitory) action of the heparin/antithrombin III system at several levels of the blood coagulation cascade. The reactions of the blood coagulation cascade and the interaction of heparin/antithrombin III on these reactions, are schematically drawn in Figure 7. As is shown, antithrombin III and heparin act as well on factors $\mathrm{XI}_{\mathrm{a}}$ and $\mathrm{IX}_{\mathrm{a}}$ as on factor $\mathrm{X}_{\mathrm{a}}$ and thrombin. 
However, because the reactions presented in Figure 7 are the result of studies mostly performed with isolated coagulation factors, the relative importance for the regulation of the in wivo haemostasis may severely be questioned. First of all, until now no information was available about the amounts of activated coagulation factors that were necessary for normal haemostasis. Secondly, the importance of a number of feed-back activation and inactivation reactions were not always recognized. To illustrate the first point: what good would it be for example to inhibit $95 \%$ of the generated factor $\mathrm{IX}_{\mathrm{a}}$ or factor $\mathrm{X}_{\mathrm{a}}$, if the remaining $5 \%$ could result in as adequate haemostatic processes as would $100 \%$ would? Also, coagulation factors which provide an amplification of the whole haemostatic mechanism by means of a number of feed-back reactions, of course are more important targets for regulation as are coagulation factors providing a single activation reaction.

With respect to these feed-back reactions, the role of thrombin can be considered as extremely important in blood coagulation. In Figure 8 the role of thrombin in a number of reactions leading to clot formation is depicted. Of course, thrombin is the enzyme that converts fibrinogen into fibrin, but, moreover, also is responsible for the activation of factor VIII:C and factor V, the essential protein cofactors for respectively factor $\mathrm{X}$ and prothrombin activation. Also the exposure of the platelet-procoagulant surface is the result of their activation by thrombin. Therefore, one can easily imagine the impact of thrombin inhibition on the overall process of blood coagulation.

An other aspect of the limited importance of results obtained from in vitro studies on purified factors to in vivo haemostasis is the fact that these results can

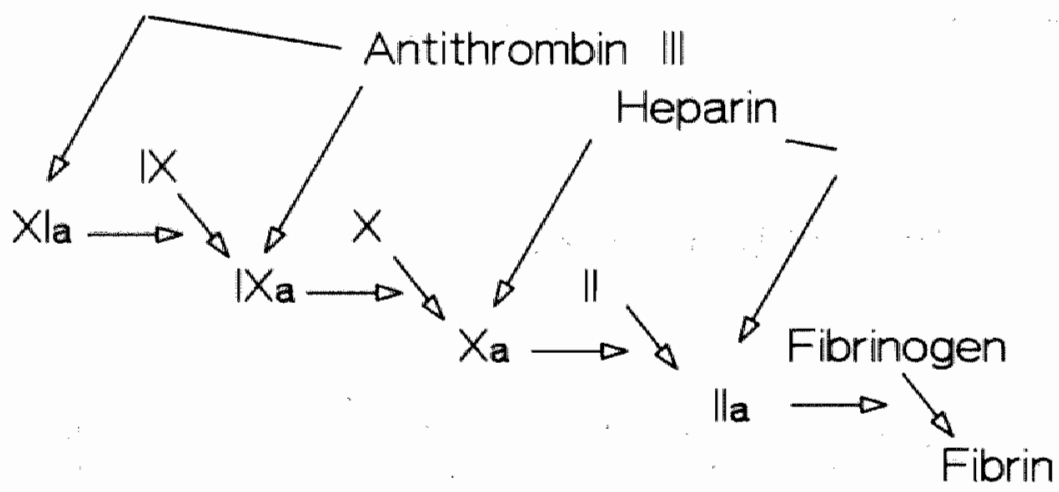

Figure T. Interaction of the antithrombin III/heparin system with activated clotting factors $X I_{\mathrm{a}}\left[X_{\mathrm{a}}, X_{\mathrm{a}}\right.$ and thrombin. 
Figure 7. Interaction of the antithrombin III/heparin system with activated clotting factors $\mathrm{XI}_{\mathrm{a}}, \mathrm{IX}_{\mathrm{a}}, \mathrm{X}_{\mathrm{a}}$ and thrombin.mostly not be extrapolated to the in vivo situation. For example, the reaction be

tween factor $\mathrm{X}_{\mathrm{a}}$ and antithrombin III in buffer has been described to be totally different from the reaction in which phospholipids and calcium are present. One can thus imagine what the effect of hundreds of plasma constituents are on such a reaction!

Therefore, in this thesis we gradually approach a situation which can de considered very near to the physiological one. The first two studies (chapters II and III) were performed in purified systems, whereas chapters IV, V and VI describe studies performed in whole plasma.

Chapter II describes studies performed with several activation products of prothrombin. We showed that meizothrombin, a major product during prothrombin activation did not bind to heparin, whereas thrombin does. Also, we showed that the activation peptides, which are released from prothrombin upon its activation, are able to neutralize heparin. These results might indicate an important role for

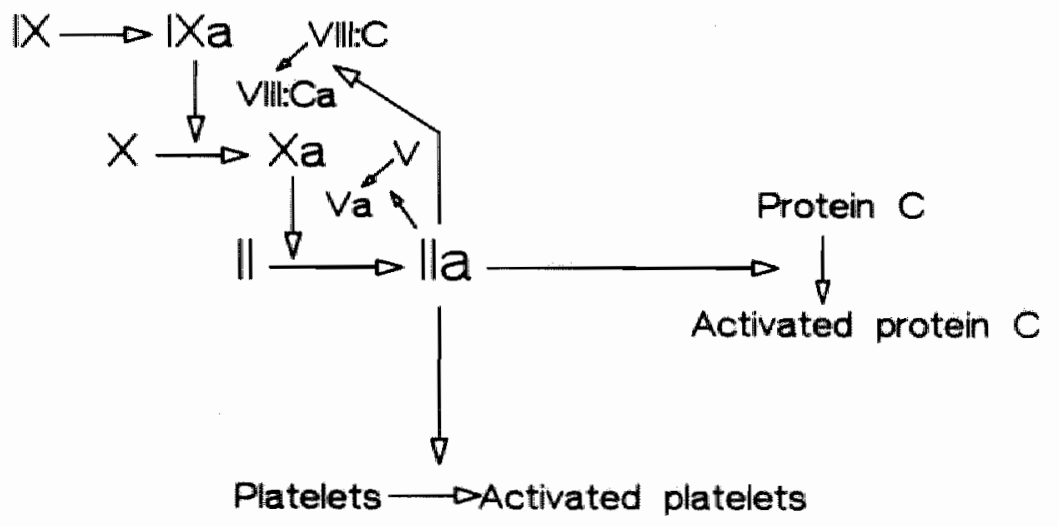

Figure 8. The central role of thrombin in the blood coagulation system. Thrombin is responsible for acceleration of its own generation by means of activation of the non enzymatic protein cofactors factor VIII:C and factor $V$, and by means of providing $a$ procoagulant surface by activating the platelets. thrombin is responsible for inhibition of its generation by activating protein $C$, an important inhibitor of factor VIII: $C_{\mathbf{a}}$ and factor $V_{\mathbf{a}}$ 
fragment 1.2 formation in the regulation of blood coagulation by competing with antithrombin III for the available heparin.

The following chapter (chapter III) deals with the action of antithrombin III/heparin on the activated coagulation factors during enzymatic conversion of factor $\mathrm{X}$ into factor $\mathrm{X}_{\mathrm{a}}$ by activated factor IX in the presence of phospholipids and calcium. We clearly demonstrated that under these more physiologic conditions, the kinetics of inactivation differ considerably from the kinetics of inhibition found for isolated, purified coagulation factors. For example, we found that factor $\mathrm{X}$ bound to phospholipid vesicles was able to protect factor $\mathrm{X}_{\mathrm{a}}$ from inhibition by antithrombin III, which may be an important mechanism for maintaining coagulation in vivo. Also, we unexpectedly found that calcium ions stimulated the heparin accelerated inhibition of factor $\mathrm{IX}_{\mathrm{a}}$ by antithrombin III.

Next we moved to whole plasma. To be able to measure specific activated coagulation factors in plasma without interference by other coagulation factors, we developed extremely serisitive bio-assay's, for factor $\mathbf{X}_{\mathbf{a}}$, factor $\mathbf{I X}_{\mathrm{a}}$, factor $\mathrm{V}_{\mathbf{a}}$ and factor VIII: $\mathrm{C}_{\mathrm{a} \text {. }}$ In chapter IV we demonstrated that for the anticoagulant effect of heparin in plasma, the inactivation of factor $X_{a}$ (and thus the anti- $X_{a}$ activity of heparin) is of no importance. Rather the ability of heparin to inhibit factor $V_{a}$ generation (via the inhibition of thrombin) causes the anticoagulant effect.

In chapter $V$ we investigated the kinetics of factor $I X_{a}$ catalyzed factor $I X$ activation in plasma. Furthermore, we studied the effect of heparin and the synthetic pentasaccharide on both the inactivation of factor $\mathrm{IX}_{\mathrm{a}}$ and factor $\mathrm{XI}_{\mathrm{a}}$ in plasma. Our results showed that the kinetics of factor $\mathrm{XI}_{\mathrm{a}}$ catalyzed factor $\mathrm{IX}$ activation were identical to those found in purified systems. Furthermore, in contrast to what was expected, heparin and pentasaccharide did have significant effects on factor IX $X_{a}$ generation in plasma.

In chapter VI finally we studied the activation of the non enzymatic protein cofactors factor $\mathrm{V}$ and factor VIII: $\mathrm{C}$ in thromboplastin-activated plasma. The enzymes in this system which possibly activate these cofactors are factor $\mathrm{X}_{\mathrm{a}}$ or thrombin. However, our results show that thrombin is the only enzyme capable of activating factor $\mathrm{V}$ and factor VIII:C under our conditions.

\section{References}

1. Malpighi M: De Polype Cordis. In Opera Omnia, London, 1686. Quoted from a reprint published by Almquist and Wiksells, Stockholm, 1953, pp 123-139 
2. Ratnoff $\mathrm{OD}$ : Blood clotting mechanisms: An overview, in Ogston $\mathrm{D}$, Bennet B (eds): Haemostasis: Biochemistry, Physiology, and Pathology. John Wiley \& Sons, 1977, pp 124

3. Hewson W: An experimental inquiry into the properties of blowd, with some remarks on its morbid appearances. Reprinted in The Works of William Hewson, F.R.S., Sydenham Society. London, $1846, p 40$

4. Chaptal HA: Annales de Chimie 21:284, 1797

5. Buchanan $A$ : on the coagulation of the blood and other fibrineferous liquids. London Med Gaz 1:617, 1845

6. Schmidt A: Zur blutlehre. F.C.W. Vogel Verlag, Leipzig, 1892, Quoted by Morawitz: Die chemie der blutgerrinung. Ergebn Physiol 4:307, 1905

7. Hemker CW: De ontdekking van het prothrombine. PhD Thesis, Rijksuniversiteit Limburg, Maastricht, The Netherlands, 19811, p 76

8. Pekelharing CA: Over den aard van het fibrineferment. Onderz $\vee$ h Phys Lab te Utrecht, 4e reeks, 1:77, 1891

9. de Blainwille H. In: Gaz Med Paris, Ser 2, 2:524, 1834

10. Schmidt A: Ueber den faserstoff und die ursache seiner gerinnung. Arch Anat Physiol Wissensch Medizin, 28:545, 1861

11. Morawitz P: Beitrage zur kenntnis der blutgerinnung. Deute hes Archiv Klin Med, 79:1, 1903

12. Warner ED, Brinkhous KM, Smith HP: The prothrombin conversionrate in various species Proc Soc Exp Biol Med 40:197, 1939

13. Quick AJ: On the constitution of prothrombin. Amer J Physiol 140:212, 1943

14. Warner ED, Brinkhous KM, Smith HP: A quantitative study on blood clotting. Prom thrombin fluctuates under experimental conditions. Amer J Physiol 114:667, 1936

15. Quick AJ: The nature of the bleeding in jaundice. Journ A M A, 110:1658, 1938

16. Owren PA: The coagulation of blood, investigations on a new clotting factor. I. Demonstration of a new factor in the coagulation process. Acta Med Scand, Suppl 194:1, 1947

17. Owren PA: The prothrombin activating complex and its clini cal significance. Report of the 3rd International Congress of Haematology, Grune and Stratton, New York, 1950, pp 379- 390

18. Owen CA, Bollman $\mathbb{~} \mathrm{L}$ : Prothrombin conversion factor of di coumarol plasma. Proc Soc Exp Biol N Y, 67:231, 1948

19. De Vries A, Alexander B, Goldstein R: A faclor in serum which accelerates the conversion of prothrombin to thrombin. I. Its determination and some physiologic and biochemical properties. Blood 4:247, 1949

20. Alexander $B$, De Vries A, Goldstein R: A factor in serum which accelerates the conversion of prothrombin to thrombin. II. Its evolution with special reference to the influence of conditions which affect blood coagulation. Blood 4:739, 1949

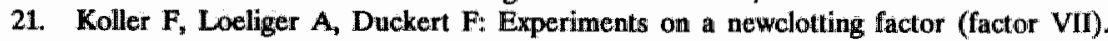
Acta Haematologica 6:1, 1951

22. Koller F, Loeliger A, Duckert F: Le facteur VII. Rev Hemat 7:156, 1952

23. MacFarlane RG: The theory of blood coagulation, in Biggs R (ed): Human Blood Coagulation, Haemostasis and Thrombosis. Blackwell Scientific Publishers, 1976, pp 131

24. Duckert $\mathbb{F}_{9}$ Fluckinger $\mathbf{P}$, Koller F:Le role du facteur $\mathbf{X}$ dans la formation de la thromboplastin sanguine. Rev Hemat 9:489, 1954

25. Duckert F, Fluckiger P, Matter M, Koller F: Clotting factor X. Physiologic and physicochemical properties. Proc Soc Exp Biol N Y, 90:17, 1955

26. Hougie C, Barrow EM, Graham JB: Stuart clotting defect. I. Segregation of an hered.itary hemorrhagic state from the heterogeneous group heretofore called "stable factor" (SPCA, proconvertin, factor VTI) deficiency. I Clin Invest, 36:485, 1957 
27. Telfer 'TP, Denson KW, Wright DR: A "new" coagulation defeet. Brit I Haemat 24308, 1956

28. Nemerson $\mathrm{Y}$ : The reaction between bovine brain tissue factor and factors VII and X. Biochemistry 5:601, 1966

29. Willams Wy, Norris DG: Purification of a bovine plasma protein (factor VII) which is required for the activity of lung microsomes in blood coagulation. J Bioll Chem 241:1847, 1966

30. Hanallan DI, Papahadjopoulos D: Interactions of phospholipids with coagulation factors. Thromb Diath Haemorrh suppl 17:71, 1965

31. Hemker HC, Esnouf MP, Hemker PW, Swart ACW, MacFarlane RG: Formation of prothrombin converting activity. Nature $215: 248,1967$

32. Varadi $\mathrm{K}$, Hemker $\mathrm{HC}$ Kinetics of the formation of the factor $\mathrm{X}$ activating enzyme of the blood coagulation system. Thromb Res 8303,1976

33. Noll P: The coagulation of the blood. Medicine 17:381, 1938

34. Bordet $J_{i}$ Gengou $O$ : Recherches sur la coagulation do sang et les serums anticoagulants. Ann Inst Pasteur 15:129, 1901

35. Morawitz P: Die chemie der blutgerrinung. Ergeb Physiol 4:307, 1905

36. Conley CL, Hartmann RC, Morse WI: The clotting behaviour of buman "platelet-free" plasma* eviddence for the existence of a "plasma thromboplastin". J Clin Invest 28:340, 1949

37. Ratrioff $O D$, Colopy JE: A familial hemorrhagic trait associated with a deficiency of a clot promoting fraction in plasma. J Clin Invest 34:602, 1955

38. Rosenthal RL, Dreskin OH, Rosenthal $\mathbb{N}$ : New hemophillia-like disease caused by deficiency of a third plasma thromboplas tin factor. Proc Soe Exp Biol N Y 82:171, 1953

39. Patek AJ, Stetson RP: Haemophilia. I. The abnormal coagulation of the blood and its relation to the blood platelets. J Clin Invest $15.531,1936$

40. Shanberge $\mathbf{J N}$, Gore I: Studies on the immunologic and physiologic activities of antihaemophilic factor (AHF). J Lab Clin Med 50:954, 1957

41. Pavlovsky A: Contribution to the pathogenesis of hemophilia. Blood 2:185, 1947

42. Aggeler PM, White SG, Glendening MB, Page EW, Leake TB, Bates G: Plasma thromboplastin component (PTC) deficiency: a new disease resembling hemophilia. Proc Soc Exp Biol N Y 79:692, 1952

43. Biggs R, Dougles AS, Macfarlane RG, Dacie JV, Pitney WR Merskey C, O'Brien JR: Christmas disease: a condition pre viously mistaken for haemophilia. Brit Med J 2:1378, 1952

44. Schulman $\mathbb{1}$, Smith $\mathrm{CH}$ : Hemorrhagic disease in an infant due to deficiency of a previouslis undescribed clotting factor. Blood 7,794, 1952

45. Macfarlane RG: An enzyme cascade in the blood clotting mechanism, and its function as a biochemical amplifier. Nature 202:498, 1964

46. Davie EW, Ratnoff OD: Waterfall sequence for intrinsic blood clotting. Science $145: 1310,1964$

47. Bennet B: Coagulation pathways: Intertelationships and control mechanisms. Seminars in Hematology 14:301, 1977

48. Nemerson Y: Tissue factor and hemostasis. Blood 71:1, 1988

49. Osterud B, Rapaport SI: Activation of factor IX by the reaction product of tissue factor and factor VII: Additional pathway for initiating blood coagulation. Proc Natl Acad Sci USA 74:5260, 1977

50. Jobin F, Esnouf MP: Studies on the formation on the prothrombin converting complex. Biochem J 102:666, 1967

S1. Rapaport SI, Schiffman S, Patch MJ, Ames SB:The importance of activation of antihemophilic globulin and proaccelerin by traces of thrombin in the generation of intrinsic prothrombistase activity. Blood 21:221, 1963 
52. Biggs R, Macfarlane RG, Denson KWE, Ash BJ: Thrombin and the interaction of factors VIII and IX. Brit I Haemat 11:276, 1965

53. Osterud B, Rapaport SI, Schiffrian S, Chang MMY: Formation of intrinsic factor X-aCtivator activity, with special reference to the role of thrombin. Br J Haematol 21:643, 1971.

54. Bailey K, Bettellheim FR, Lorand L, Middelbrook WR: Action of thrombin in the clotting of fibrinogen. Nature 167:233, 1951

55. Shuman MA, Majerus PW: The measurement of thrombin in clotting blood by radioimmunoassay. J Clin Invest 58:1249, 1976

56. Broze GJ, Leykam JE, Schwartz BD, Miletich JP; Purification of human tissue factor. J Biol Chem 260:10917, 1985

57. Guha A, Bach R, Konigsberg W, Nemerson Y: Affinity purification of human tissue factor: Interaction of factor VII and tissue factor in detergent micelles. Proc Natl Acad Sci USA 83:299, 1986

58. Zur $\mathrm{M}$, Nemerson $\mathrm{Y}$ : Tissue factor pathway of coagulation. in Bloom, Thomas (eds). Haemostasis and Thrombosis. Churchill Livingstone, 1981, pp 124-139

60. Rao LVM, Rapaport SI: Studies of a mechanism inhibiting the initiation of the extrinsic pathway of coagulation. Blood 69:645, 1987

61. Pitlich FA: Concanavalin A inhibits tissue factor coagulant activity. J Clin Invest 55:175, 1975

62. Lämmle B, Griffin JH: Formation of the fibrin clot: the balance of procoagulant and inhibitory factors. Clinics in Haematology $14: 281,1985$

63. Dam H: The antihaemorrhagic witamin of the chick. Biochem $J 29: 1273,1935$

64. Hemker HC, Veltkamp JJ, Hensen A, Loeliger EA: Nature of prothrombin biosynthesis: preprothrombinaemia in vitamin K-deficiency, Nature 200:589, 1963

65. Josso F, Lavergne JM, Gouault M, Prou-Wartelle O, Soulier JP: Différents étatsmoleculaires du facteur II (prothrombine). Leur étude à l'aide de la staphylocoagulase et d'anticorps anti-facteur II. Thromb Diath Haemorrh 20:88, 1968

66. Stenflo $\mathrm{J}_{*}^{*} \mathrm{~A}$ new vitamin $\mathrm{K}$-dependent protein. Purification from bovine plasma and prelimunary characterization. I Biol Chem 251:355, 1976

67. Suttie JW: Mechanism of action of vitamin K: Synthesis of -carboxyglutamic acid. CRC Crit Rev Biochem 8(2):189, 1980

68. Nelsestuen GL: Role of -carboxyglutamic acid. An unusual protein transition required for the calcium-dependent binding of prothrombin to phospholipid. J Biol Chem 251:5648,1976

69. Bach $\mathbf{R}$, Nemerson $\mathbf{Y}$, Konigsberg W: Purification of bovine tissue factor. J Biol Chem $256: 8324,1981$

70. Morita $T$, in Suttie (ed): Vitamin-K metabolism and vitamin-K dependent proteins, (University Park Press, Baltimore) 1979, pp 124-128

71. van der Graaf F, Greengard JS, Bouma BN, Kerbiriou DM, Griffin JH: Isolation and functional characterisation of the active light chain of activated human blood coagulation factor XI. J Bioll Chem 258:9669, 1983

72. Forman SD, Nemerson $Y$ : Membrane-cvoagulation reaction is dependent of the concentration of phopholipid-bound sub strate: Fluid phase factor $\mathrm{X}$ regulates the extrinsic system. Proc Natl Acad Sci USA 83:4675, 1986

73. Bajaj SP, Rapaport SI, Brown SF: lisolation and characterisation of human factor VII. Activation of factor VI by factor $X_{\mathrm{a}}$. J Biol Chem 256:253, 1981

74. Zar M, Nemerson $\mathrm{Y}$ : The esterase activity of coagulation factor VII. I Biol Chem 253:2203, 1978

75. Rao LVM, Rapaport SI, Bajaj SP: Activation of human factor VII in the initiation of tissue factor-dependent blood coagulation. Blood 68:685, 1986

76. Radcliffe R, Nemerson Y: Mechanism of activation of bovine factor VII. Products of cleavage by factor $X_{a .} J$ Biol Chem $251: 4797,1976$ 
77. Radeliffe $\mathbf{R}_{,}$Bagdasarian, Colman $\mathbf{R}$, Nemerson $\mathbf{Y}$ : Activation of bovine factor VII by Hageman fictor fragments. Blood 50:611, 1977

78. Selighson 1, Osterud $\mathrm{B}, \mathrm{Brown} \mathrm{SF}$, Griffin $\mathrm{JH}_{8}$, Rapaport SI: Activation of human factor VI in plasna and in purified systems. Rolles of activated factor $\mathbb{X}$, kallikrein, and ac tivated factor XII. Clin Invest 64:1056, 1979

79. Pieters $J$, Lindhout $T$ : The limited importance of the anti- $X_{\text {a }}$ activity of heparin in thromboplastin activated plasma. Blood, in press

80. Giles $A R$, Tinlin $S$, Brosseau $L$, Hoogendoorn $H$ : In vivo studies of the role of factor VII in Hemostasis. Blood 65: 1197, 1985

81. DiScipio RG, Kurachi K, Davie EW: Activation of human factor IX (Christmas Factor). J Clin linwest 61:1528, 1978

82. Osterud B, Bouma BN, Griffin JH: Human blood coagulation factor IX. Purification, properties, and mechanism of ac tivation by activated factor XI. J Biol Chem 253:5946, 1978

83. Ratnoff OD, Davie EW, Mallett DC: Studies on the action of Hageman Factor: Evidence that activated Hageman Factor in turn activates plasma thromboplastin antecedent J Clin Invest $40: 803,1961$

84. Rosenberg IS, McKenna PW, Rosenberg RD: Inhibition of human factor $\mathrm{IX}_{\mathrm{a}}$ by human antithrombin. J Biol Chem 250:8883, 1975

85. Kurachi $K_{n}$ Fujikawa $K$, Schmer $G_{*}$ Davie EW: Inhibition of factor $\mathbf{L X}_{a}$ and factor $\mathbf{X}_{\mathrm{s}} \beta$ by antithrombin III. Biochemistry 15:373, 1976

86. Pieters $\mathrm{J}$, Willems $\mathrm{G}$, Hemker HC, Lindhout $\mathrm{T}$ : Inactivation of factor $\mathrm{IX}_{\mathrm{a}}$ and factor $\mathrm{X}_{\mathrm{a}}$ during factor $X$ activation by antithrombin III/heparin. J Biol Chem 263:15313, 1988

87. Fuchs J, Trapp HG, Griffith MJ, Roberts HR, Pizzo SV: Re gulation of factor $\mathbf{I X}_{\mathrm{a}}$ in vitro in human and mouse plasma and in vivo in the mouse. J Clin Invest 73:1696, 1984

88. McNeely $T$, Griffith MJ: The anticoagulant mechanism of action of heparin in contactactivated plasma:Inhibition of factor X activation. Blood 65:1226, 1985

89. Pieters J, Soons $\mathrm{H}$, Willems G, Franssen J, Hemker HC, Lindhout T: Factor $\mathrm{XI}_{\mathrm{a}}$ catalyzed activation of factor IX in human plasma; Effect of heparin. Submitted for publication

90. Hedner U, Davie EW: Factor IX. in: Colman RW (ed): Hemostasis and thrombasis. Philadelphia JB Lippincott, 1982, pp 29

91. Roberts HR, Gross GP, Webster WP, Dejanov II, Penick GD: Acquired inhibitors of plasma factor IX. A study of their induction properties and neutralisation. Am J Med Sci 251:43, 1966

92. Thompson J: Factor IX antigen by radioimmunoassay. Abnormal factor IX protein in patients on warfarin therapy andf with hemophilia B. J Clin Invest 59:900, 1977

93. Fuijikawa K, Legaz ME, Davie EW: Bovine factor X1 (Stuart Factor). Mechanism of activation by a protein from Russel's viper wenom. Biochemistry 11:4882, 1972

94. Fair J, Plow EF, Edgington TS: Combined functional and immunochemical analysis of normal and abnormal factor X. J Clin Invest 64:884, 1979

95. Jesty J, Spencer AK, Nemerson Y: The mechanism of activation of factor X. Kinetic control of alternative pathways leading to the formation of activated factor $\mathrm{X}$. J Biol Chem 249: 5614,1974

96. Yin ET, Wessler $\mathbf{S}$, Stol』 PJ: Rabbit plasma inhibitor of the activated species of blood coagulation factor X. J Biol Chem 246:3694, 1971

97. Fuchs J, Pizzo SV: Regulation of factor $\mathbf{X}_{\mathrm{a}}$ in vitro in buman and mouse plasma and in vivo in the mouse. Role of the endothelium and plasma proteinase inhibiltors. $J$ Clin Invest $72: 2041,1983$

98. Hemker HC: In memory of François Josso. Why do hemophiliacs blleed? Scand J Haematol (Suppl 40) 33:11, 1984

99. Suttie JW, Jackson CM: Prothrombin structure, activation and biosynthesis. Physiol Rev 57:1, 1977 
100. Stenn $\mathbb{K S}$, Blout $\mathbb{E R}$ : Mechanism of bovine prothrombin activation by an insoluble

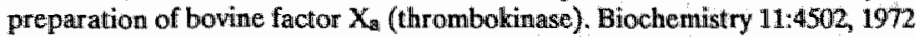

101. Esnouf MP, Jobin F: Lipids in prothrombin conversion. Thromb Diath Haemorrh $17: 103,1965$

102. Esmon CT, Owen WG, Jackso CM: A plausable mechanism for prothrombin activation by factor $X_{\text {a, }}$ factor $V_{a}$, phospholipids, and calcium ions. J Biol Chem 249:8045, 1974

103. Govers-Riemslag JWP, Speijer $\mathbb{H}_{\text {, }}$ Zwaal RFA, Rosing $J$ : The effects of prothrombin fragment 1 and fragment 1.2 on prothrombin actiwation. Thromb Res $38: 375,1985$

104. Pieters J, Franssen J, Visch $C$, Lindhout $T$ : Neutralization of heparin by prothrombin activation products. Thromb $\operatorname{Res} 45: 573,1987$

105. Abilgaard in The physiolical inhibitors of blood coagulation and fibrinolysis. Collen et al. (eds), Ansterdam, Elsevier/ North-Holland, 1979, pp 31-33

106. Steinbach Rev Françaice d"etudes cliniques et biologiques 13:179, 1968

107. Saito H, Goldsmith GH, Moroi M, Aoki N: Inhibition spectrum of a2-plasmin inhibitor. Proc Nat1 Acad Sci Usa 76:2013, 1979

108. Tollefsen DM, Majerus DW, Bllank MK: Heparin cofactor II.. Purification and proreties of a heparin-dependent inhibitor of thrombin in human plasma. J Biol Chem 257:2162, 1982

109. Kane WH, Davie EW: Blood coagulation V and VIII: Structural and functional similarities and their relationship to hemorrhagic and thrombotic disorders. Blood 71:539, 1988

110. Esmon CT: The regulation of natural anticoagulant pathways. Science $235 ; 1348,1987$

111. Sadler JE, Davie EW: Hemophilia A, hemophillia B and von Willebrand's disease, in Stamatoyannopoulos G, Nienhuis AW, Leder P, Majerus PW (eds): The molecular basis of blood diseases. Philadelphia, Saunders, 1987, p 575

112. Seeler RA: Parahemophilia. Factor V deficiency. Med Clin North Am 56:119, 1972

113. Soff GA, Levin J: Familial multiple coagulation factor deficiencies. Semin Thromb Hemost 7:112, 1981

114. Zimmerman TS, Fullcher CA: Factor VIII procoagulant protein. Clinics in hacmatology 14:343, 1985

115. Fulcher CA, Zimmerman TS: Characterization of the human factor VIII procoagulant protein with a heterologous precipitating antibody. Proc Natl Acad Sci Usa 79:1648, 1982

116. Toole JJ, Knopf JL, Wozney JM, Sultzman LA, Buecker JL, Pittman DD, Kaufman RJ, Brown, E, Shoemaker C, Orr EC, Amphlett GW, Foster WB, Coe ML, Knutson GJ, Fass DN, Hewick RM: Molecular cloning of a cDNA encoding human antihatmophilic factor, Nature 312:342, 1984

117. Gitscher J, Wood WI, Goralka TM, Wion KI, Chen EY, Eaton DH, Vehar GA, Capon DJ, LLawn RM: Characterization of the human factor VIII gene. Nature 312:326, 1984

118. Wood WI, Capon DJ, Simonsen CC. Eaton DL, Gitschier J, Keyt B, Seebyrg PH, Smith DH, Hollingshead P, Wion KL, Delwart E, Tuddenham EGD, Vehar GA, Lawn RM: Expression of active human factor VIII from recombinant DNA clones. Nature 312:330, 1984

119. Vehar GA, Keyt B, Eaton D, Rodriguez H, OB Bien DP, Roublat $F$, Oppermann $H_{\text {, }}$ Keck R, Wood WI, Harkins RN, Tuddenham EGD, 312:337, 1984

120. Vehar GA, Davie EW: Preparation and properties of bovine factor VIII (Antihemophilic Factor). Biochemistry 19:401, 1980

121. Eaton DL, Wood WI, Eaton D, Hass PI, Hollingshead $\mathrm{P}_{\text {, Wion }} \mathrm{K}_{\text {, Mather J, Lawn RM, }}$ Vehar GA, Gorman C: Constructionand characterization of an active factor Vill variant lacking the central one-third of the molecule. Biochemistry 25:505, 1986

122. Rick ME: Activation of factor VIII by factor $\mathbb{1 X}$ a. Blood 60:74, 1982

123. Tracy PB, Ride LL, Bowie EJW, Mann KG: Radioimmunoassay of factor $V$ in human plasma and platelets. Blood $60: 95,1982$ 
124. Dahlbec B: Human coagulation factor $\mathbf{V}$ purification and thrombin-catalyzed activation. I Clin Invest 66:583, 1980

125. Viskupp RW, Tracy PB, Mann KG: The isolation of human platelet factor V. Blood $69: 1188,1987$

126. Cerveny TJ, Fass DN, Mann KG: Synthesis of coagulation factor V by cultured aortic endothelium. Blood 63:1467, 1984

127. Suzuki $\mathrm{K}$, Dăhlbeck $\mathrm{B}$, Stenflo J: Thrombin-catalyzed acti vation of human coagulation factor V.J Biol Chem 257:6556, 1982

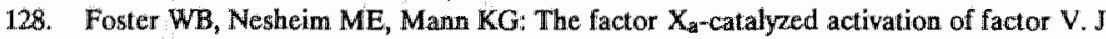
Biol Chem 258:13970, 1983

129. Krisnaswarny S, Mann KG, Nesheim ME: The prothrombinase- catalyzed actiwation of prothrombin proceeds through the intermediate meizothrombin in an ordered, sequential reac tion. J Biol Chem $261: 8977,1986$

130. Rosing J, Zwaal RFA, Tans G: Formation of meizothrombin as intermediate in factor $X_{a}$-catalyzed prothrombin activation. J Biol Chem 261:4224, 1986

131. Walker FJ, Sexton PW, Esmon CT: The inhibition of blood coagulation by activated protein $C$ through the selective inactivation of activated factor V. Biochim Biophys Acta $571: 333,1979$

132. Tracy PB, Mann KG: Abnormal formation of the prothrombinase complex Factor $\mathrm{V}$ deficiency and related disorders. Hum Pathol 18:162, 1987

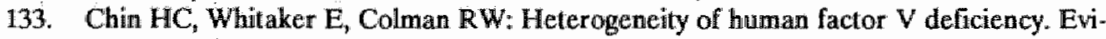
dence for the existence of antigen- positiwe variants. J Clin Invest 72:493, 1983

134. Thompson RE, Mandle R, Kaplan AP: Association of factor XI and high molesular weight kininogen in thuman plasma. J Clin Invest 60:1376, 1977

135. Saito H, Goldsmith GH Jr: Plasma Thromboplastin Antecedent (PTA), Factor XI): A specific and sensitive radioimmunoassay. Blood 50:377, 1977

136. Bouma BN, Griffin JH: Human blood coagulation factor XI. Purification, properties, and mechanism of activation by activated factor XII. J Biol Chem 252:6432, 1977

137. Kurachi K, Davie EW: Activation of human factor XI (Plasma Thromboplastin Antecedent) by factor $\mathrm{XII}_{\mathrm{a}}$ (Activated Hageman Factor). Biochemistry 16:5831, 1977

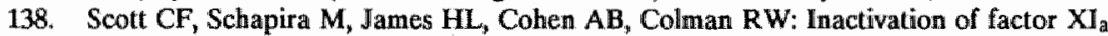
by plasma protease inhibitors. Predominant role of $\alpha 1$-protease inhibitor and protective effect ofheigh molecular weight kininogen. J Clin Invest 69:844,1982

139. Meijers JCM: Regulation of the blood coagulation mechanism by plasma proteinase in hibitors. Thesis at the University of Utrecht, Utrecht, the Netherlands, 1988

140. Josso F, Prou-Wartelle O: Interaction of tissuc factor and factor VII at the earliest phase of coagulation. Thromb Diathes Haemorrh 14(Suppl 17);35, 1965

141. Osterud B, Papaport SI: Activation of 125I-factor IX and 1251 -factor X: Effect of tissue factor and factor VII, factor $X_{\mathrm{a}}$ and thrombin. Scand $J$ Hacmatol $24: 213,1980$

142. Ratnoff OD, Saito $\mathrm{H}_{\text {: }}$ Surface-mediated reactions. Current topics in hematology 2:1, 1979

143. Kaplan AP, Silverberg M: The coagulation-kinin pathway of human plasma. Blood $70: 1,1987$

144. Kisiel W, Canfield WM, Ericsson LH, Davie EW: Anticoagulant properties of bovine plasma protein C following activation by thrombin. Biochemistry 16:5824, 1977

145. Griffin JH, Mosher DF, Zimmerman TS, Kleiss AJ: Protein C, an antithrom botic protein, is reduced in hospitalized patients with intravascular coagulation. Blood 60:261, 1982

146. Kisiel W: Human plasma protein C. Isolation, characterizazation and mechanism of activation by human $\alpha$-thrombin. J Clin Invest 64:761, 1979

147. Esmon CT: Protein C: Biochemistry, physiology, and clinical implications. Blood $62: 1155,1983$ 
148. Esmon NL, Owen WG, Esmon CT: Isolation of a membrane-bound cofactor for thrombin-catalyzed activation of protein C. J Biol Chem 257, 859, 1982

149. Esmon $N$, DeBault $L$, Esmon $C$. Proteolytic formation and properties of -carboxyglutamic acid-domainless protein C.J Biol Chem 258:5548, 1983

150. Salem $\mathbf{H H}$, Broze $G J$, Miletich $\mathbb{P}_{\text {, }}$ Majerus $P W$ : Human coagulation factor $\mathrm{V}_{\mathrm{a}}$ is a cofactor for the activation of Protein C. Proc Natl Acad Sci USA 80:1584, 1983

151. Salem $\mathbf{H H}$, Broze GJ, Miletich JP, Majerus PW: The light chain of factor $\mathrm{V}_{\mathrm{a}}$ contains the activity of factor $\mathrm{V}_{\mathrm{a}}$ that accelerates protein $\mathrm{C}$ activation by thrombin. $\mathrm{J}$ Biol Chem 258:8531, 1983

152. Walker F: Regulation of activated protein $\mathrm{C}$ by a new protein: $\mathrm{A}$ possible function for protein S. J Biol Chem 255:5521, 1980

153. Marlar RA, Griffin JH: Deficiency of protein $C$ inhibitor in combined factor V/VIII deficiency disease. J Clin Invest 66:1186, 1980

154. Suzuki $\mathrm{K}$, Nishioka J, Hashimoto S: Protein C inhibitor. Purification from human plasma and characterization. J Biol Chem 258:163, 1983 .

155. Bertina RM, Broekmans AW, van der Linden IK, Mertens $\mathrm{K}$ : Protein C deficiency in a Dutch family with thrombotic disease. Thromb Haemost $48: 1,1982$

156. Reutelingsperger CPM: Vascular anticoagulant, a new physiological anticoagulant mechanism. Thesis, University of Limburg, Maastricht, the Netherlands, 1987

157. Verhey HM, Boffa M-C, Rothen $C_{n}$ Brycaert $M-L_{4}$, Verger $R_{n}$ de Haas GH: Correlation of enzymatic activity and anticoagulant properties of phospholipase A2. Eur J Biochem 112:25, 1980

158. Thiagarajan P, Shapire SS, De Marco L: Monoclonal Immunoglobulin Mll coagulation inhibitor with phospholipid specificity. J Clin Invest 66:397, 1980

159. Feinstein Prog Hemostasis Thromb 1:75, 1972

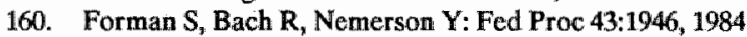

161. Nawroth PP, Kisiel W, Stern DM: Anticoagulant and antithrombotic properties of a carboxyglutamic acid-rich peptide derived from the light chaim of blood coagulation factor X. Thromb Res 44::625, 1986

162. Reutelingsperger $\mathrm{CPM}$, Hornstra $\mathrm{G}$, Hemker $\mathrm{HC}$. Isolation and partial purification of a novel anticoagulant from arteries of human urmbilical cord. Eur J Biochem 151:625, 1985

163. Sanders NL, Bajaj SP, Zivelin A, Rapapont SI: Inhibition of tissue factor/factor VIIa activity in plasma requires factor $X$ and an additional plasma component. Blood 66:204, 1985

164. Carrel RW, Christey PB, Boswell DR: Serpins" antithrombin and other inhibitors of coagulation and fibrinolysis. Evidence from amino acid sequences. In Verstraete $M$, Vermylen J, Lijnen R, Arnout J (eds): Thrombosos and Haemostasis 1987, Leuven University Press, Leuven, pp 1

165. Barrowcliffe TW, Thomas DP: Antithrombin III and heparin, in Bloom AL, Thomas DP (eds): Haemostasis and Thrombosis, Second edition, Churchill Livingstone, 1987, pp 849

166. Abildgaard $U$ : Highly purified antithrombin III with heparin colactor activity prepared by disc electrophoresis. Scand J Clin Lab Invest 21:89, 1968

167. Kurachi $K_{n}$ Schmer $G$, Hermodson MA, Teller DC, Davic EW: Characterization of human, bovine, and horse antithrombin III. Biochemistry 15:368, 1976

168. Murano G, Williams L, Miller-Andersson M, Aronson DL, King C: Some properties of antithrombin III and its concentration in human plasma. Thromb Res 18:259, 1980

169. Conard $J_{p}$ Brosstad $F$, Lie Larsen $M_{4}$ Samama $M$, Abildgaard $U_{*}$ : Molar antithrombin concentration in normal human plasma. Haemostasis $13: 363,1983$

170. Peterson CB, Blackburn MN: Isolation and characterization of an antithrombin III variant with reduced carbohydrate content and enhanced heparin binding. $J$ Biol Chem 260:610, 1985 
171. Milner AE, Burnett $D$, Rutter $J$, Bradwell $A R$ : Detection of antithrombin III microheterogeneity. Thromb Res 37:127, 1985

172. Abildgaard U: Binding of thrombin to antithrombin III. Scand J Clin Lab Inwest 24:23, 1969

173. Binder B: On the complex formatio of antithrombin III with thrombin. Gel filtration studies on human plasma and serum. Thromb Diath Haemorrh $30 ; 280,1973$

174. Pepper DS, Bănhegyi D, Cash JD: The different forms of AT III in serum. Thromb Haemost 38:494, 1977

175. Marciniac E, Gora-Maslak G: High molecular weight forms of antithrombin III complexes in blood. Thromb Haemost 49:32, 1983

176. Jesty I: Dissociation of complexes and their derivates formed during inhibition of bovine thrombin and activated factor $X$ by antithrombin III. J Biol Chem 254:1044, 1979

177. Danielsson $A_{n}$ Bjork 1: Slow, spontaneous dissociation of the antithrombin thrombin complex produces a proteolytically modified form of the inhibitor. FEBS Letters 119:241, 1980

178. Björk 1, Fish WW: Production in vitro and properties of a modified form of antithrombin, cleaved at the active site by thrombin. J Biol Chem 257:9487, 1982

179. Marciniac E, Tsukamura $\mathrm{S}$ : Two progressive inhibitors of factor $\mathrm{X}_{\mathrm{a}}$ in blood. Br $\mathrm{J}$ Haematol 22:341, 1972

180. Lindhout $T$, Baruch $D_{*}$ Schoen $P$, Franssen J, Hemker HC: Thrombin gneration and inactivation in the presence of antithrombin III and heparin. Biochemistry 25:5962, 1986

181. Rosenberg RD: Heparin antithrombin III system. In: Colman RW (ed): Hemostasis and thrombosis. Philadelphia JB Lippincott, 1982, pp 962

182. Björk $I$, Lindahl U: Mechanism of the anticoagulant action of heparin. Molecular and Cellular Biochemistry 48:161, 1982

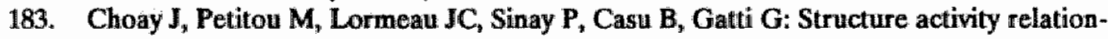
ship in heparin: A synthetic pentasaccharide with high affinity for antithrombin III and eliciting high anti-factor $X_{a}$ activity. Biochem Biophys Res Comm 116: 492, 1983

184. Esquivell CO, Bergqvist D, Blörck C-G, Nilson B: Comparisiom between comercial heparin, low molecular weight heparin and pentosan polysulfate on hemostasis and platelets in vivo. Thromb Res $28: 389,1982$

185. Ellison $N_{\text {, }}$ Edmunds LH, Colman RW: Platelet aggregation following heparin and protamine administration. Anesthesio logy 48:65, 1978

186. Casu B: Structure of heparins and their fragments. Nouvelle Revue Française d'Hematologie 26:211, 1984

187. Lam LH, Silbert JE, Rosenberg RD: The separation of active and inactive forms of heparin. Biochim Biophys Res Comm 69:570, 1976

188. Rosenberg RD, Jordan RE, Favreau LV, Lam LH: Highly active heparin species with multiple binding sites for antithrombin. Biochim Biophys Res Comm 86:1319, 1979

189. Holmer $\mathbf{E}, \mathrm{Kurachi} \mathrm{K}$, Söderström $\mathrm{G}$ : The molecular weight dependence of the rate enhancing effect of heparin on the inhibition of thrombin, factor $\mathbf{X}_{\mathrm{a}}$, factor $\mathbf{I X}_{\mathrm{a}}$, factor $\mathrm{XI}_{\mathrm{a}}$, factor $\mathrm{XII}_{\mathrm{a}}$ and kallikrein by antithrombin. Biochem J 193:295, 1981

190. Griffith MJ: Kinetics of the heparin-enhanced antithrombin III thrombin reaction. Evidence for a template model for the mechanism of action of heparin. $J$ Biol Chem $157: 7360,1982$

191. Lane DA, MacGregor IR, Michalski R, Kakkar VV: Anticoagulant activities of four unfractionated and fractionated heparins. Thromb Res 12:257, 1978

192. Petitou $M$; synthetic heparin fragments: new and efficient tools for the studie of heparin and its interactions. Nouv Rev Franç d'Hematol 26:221; 1984

193. Oosta GM, Gardner WT, Beeler DL, Rosenberg RD: Multiple functional domains of the heparim molecule. Proc Natl Acad Sci USA 78:829, 1981 
194. Lame DA, Denton J, Flymn AM, Thunberg $L_{n}$ Lindahl U: Anticoagulant activities of heparin oligosaccharides and their neutralization by platelet factor 4 . Biochem $\mathbb{J} 218.725$, 1984

195. Ireland $H$, Lane $D A$, Curtis $J R$ : Objective assesment of heparin requirements for haemodialysis in humans. J Lab Clin Med 103:643, 1984

196. Salzman EW: Low-molecular-weight heparin. Is small beautiful? New Eng J Med $315: 957,1986$

197. Carter CJ, Kelton JG, Hirsh J, Cerskus A, Santos AV, Gent M: The relationship between the hemorrhagic and antithrombotic properties of low molecular weight heparin in rabbits. Blood 59:1239, 1982

198. Holmer E, Mattson C, Nilsson S: Anticoagulant and antithrombotic effects of heparim and low molecular weight heparin fragments in rabbits. Thromb Res 25:475, 1982

199. Barrowrliffe TW, Johnson EA, Eggletion CA, Kemball-Cook G, Thomas DP: Anticoagulant activities of high and low molecular weight heparin fractions. Br J Haematol 41:573, 1979

200. Andersson L-O: Anticoagulant properties of heparin fractionated by affinity chromatography on matrix-bound antithrombin III and by gel filtration. Thromb Res $9: 575,1976$

201. Thomas DP: Current status of low molecular weight heparin. Thromb Hacmost $56(3): 241,1986$

202. Thomas DP: Heparin in prophylaxis and treatment of venous thromboembolism. Sem Haematol 15:1, 1978

203. Ofosu FA, Blajchman MA, Modi GJ, Smith LM, Buchanan MR, Hirsh J: The importance of thrombin inhibition for the expression of the anticoagulant activities of heparin, dermatan s ulphate, low molecular weight heparin and pentosan polysul phate. Br J Haematol 60:695, 1985

204. Berquist D, Burmark US, Frisell J: Low molecullar weight heparin once daily compared with conventional low dose heparin twice daily. A prospecticve donble blind multicentre trial on prevention of postoperative thrombosis. Br J Surg 73:204, 1986

205. Hemker HC: The mode of action of heparin in plasma, in Verstraete $M$, Vermylen $J$, Lijnen R, Arnout J (eds): Thrombosis and Haemostasis 1987. Leuven University Press, Leuven 


\title{
Chapter II
}

\section{Neutralization of Heparin by Prothrombin Activation Products ${ }^{\circ}$}

\begin{abstract}
The neutralization of heparin by active site blocked meizothrombin and thrombin, prothrombin fragment 1.2, fragment 1 and fragment 2 was probed by the heparin-dependent factor $X_{\mathrm{a}}$ inactivation by antithrombin III (AT III). Meizothrombin had no effect on the inactivation of factor $X_{a}$, whereas thrombin had an inhibitory effect (IC50 $=700 \mathrm{nM})$. After factor Xa catalyzed cleavage of meizothrombin, the resulting products, prothrombin fragment 1.2 plus thrombin, did not show any heparin neutralizing properties. However, after isolation of the reaction products, both thrombin and prothrombin fragment 1.2 exhibited heparin neutralizing properties in the factor $X_{a}$ inactivation reaction. The IC50values were $700 \mathrm{nM}$ and $100 \mathrm{nM}$, respectively. Prothrombin fragment 1 , when present at $125 \mathrm{nM}$, caused a $50 \%$ reduction of the heparin-dependent rate of inactivation of factor $X_{\mathrm{a}}$ and prothrombin fragment 2 had no effect at all. From this we conclude that, in addition to the thrombin part of the prothrombin molecule, the fragment 1 region also exhibits a rather high affinity for heparin.
\end{abstract}

o $\quad$ Based on: Pieters J, Franssen J, Visch C, Lindhout T: Thromb Res 45:573, 1987 


\section{Introduction}

During the activation of prothrombin by factor $\mathrm{X}_{\mathrm{a}}$ various activation products are formed. Dependent on the order of cleavage, prethrombin 2 or meizothrombin occur as intermediates, which finally give rise to formation of thrombin and the activation peptides fragment 1.2, fragment 1 and fragment $2(1,2)$. As the activation peptide of prothrombin that is released during activation is almost half the prothrombin molecule, it may be related to important biological functions, as suggested by Walker and Esmon (3). Especially, the activation peptides could play a regulatory role in the formation of thrombin at the site of its generation. The persistence of thrombin away from the site of its generation is prevented by several natural inhibitors of serine proteases, of which AT III is the main one $(4,5)$.

Heparin, a highly sulfated mucopolysaccharide, has been shown to greatly enhance the inhibition of thrombin and other serine proteases by AT III. The mechanism is thought to be by binding to AT III and inducing a conformational change which facilitates AT III binding to activated serine proteases $(6,7)$ and/or by direct interaction with these plasma proteins rendering them more susceptible to neutralization by AT III $(8,9)$. The smallest saccharide with an intact AT III binding domain is a pentasaccharide (10).

Recently, Rosing et al. (2) showed the formation of considerable amounts of meizothrombin during prothrombin activation. Their evidence was partly based on the different reactivities of meizothrombin and thrombin towards the heparin-enhanced inactivation by AT III. In fact, heparin appeared to be devoid of any catalytic activity in the meizothrombin/AT III reaction (11). A possible explanation for the latter phenomenon could be the absence of heparin binding sites on the meizothrombin molecule. By making use of the heparin-dependent inactivation of factor $\mathrm{X}_{\mathrm{a}}$ by AT III, we were able to show that meizothrombin does not neutralize heparin, whereas thrombin does. Furthermore, this report demonstrates that the prothrombin activation products fragment 1.2 and fragment 1 are inhibitors of the heparin-enhanced factor $\mathrm{X}_{\mathrm{x}}$ inactivation by AT III, and that this effect is due to their heparin neutralizing properties. 


\section{Materials and Methods}

Materials- Bz-Ile-Glu-(Piperidyl)-Gly-Arg-p-nitro-anilide (S-2337) and DPhe-(Pipecolyl)-Arg-p-nitro-anilide (S-2238) were purchased from AB Kabi Diagnostica, Stockholm. Phe-Pro-Arg-chloromethylketone (PPACK) was obtained from Calbiochem, La Jolla, USA. Human serum albumin, fatty free (HSA), soybean trypsin inhibitor (STI) and Echis carinatus venom were obtained from Sigma. Antithrombin III high affinity heparin (HA-heparin) was obtained by chromatography on an AT III affinity column and was a kind gift from Pharmuka Laboratories, France. The synthetic pentasaccharide (IC 831423) was a product of Laboratoire Choay, France. All reagents used were of the highest grade commercially available.

Proteins- Bovine factor $X_{a}$, factor $V_{a}$, prothrombin, thrombin, prothrombin fragment 1 and prothrombin fragment 2 were purified as described before (1214). Bovine AT III was purified according to Thaler and Schmer (15). The AT III was subsequently freed of heparin contamination by ionic exchange chromatography (16). Prothrombin fragment 1.2 was prepared as an activation product of PPACK-meizothrombin by incubation of PPACK-meizothrombin with factor $X_{a}$ $(10 \mathrm{nM})$, factor $\mathrm{V}_{\mathrm{a}}(50 \mathrm{nM})$, phospholipids $(0.1 \mathrm{mM})$ and $\mathrm{CaCl}_{2}(10 \mathrm{mM})$ in 20 $\mathrm{mM}$ Tris- $\mathrm{HCl}, 100 \mathrm{mM} \mathrm{NaCl}(\mathrm{pH} 7.5)$ at $37^{\circ} \mathrm{C}$. After 30 minutes the reaction was stopped by the addition of EDTA to a final concentration of $20 \mathrm{mM}$ and the reaction mixture was chromatographed on a soybean trypsin inhibitor-Sepharose column (bed volume $2 \mathrm{~mL}$ ) directly followed by a QAE-Sephadex A-50 column (bed volume $94 \mathrm{~mL}$ ) at $4^{\circ} \mathrm{C}$ with a flow rate of $15 \mathrm{~mL} / \mathrm{h}$. The column was eluted with a linear gradient $(2 \times 250 \mathrm{~mL})$ of 0.10 to $0.60 \mathrm{M} \mathrm{NaCl}$ in $20 \mathrm{mM}$ Tris- $\mathrm{HCl}$ (pH 7.5).

Protein Concentrations- Concentrations of thrombin, factor $\mathrm{X}_{\mathrm{a}}$, factor $\mathrm{V}_{\mathrm{a}}$ and prothrombin were determined as reported earlier $(12,17)$. The molar concentrations of bovine AT III, prothrombin fragment 1.2, fragment 1 and fragment 2 were calculated using $E_{280}$ of $6.0,12.3,10.1,12.5$ and MW of 56,600, 35,000, $22,500,12,500$ respectively $(3,13,15)$.

Preparation of Active Site Blocked-Meizothrombin and Thrombin- Active site blocked meizothrombin was prepared by activation of purified prothrombin (10 $\mu \mathrm{M})$ by Echis carinatus venom $(5 \mu \mathrm{g} / \mathrm{mL})$ in the presence of $60 \mu \mathrm{M}$ PPACK at $37^{\circ} \mathrm{C}$ in $50 \mathrm{mM}$ Tris- $\mathrm{HCl}, 175 \mathrm{mM} \mathrm{NaCl}(\mathrm{pH} 7.9)$. The solution was extensively dialyzed against the aforementioned buffer. PPACK-thrombin was prepared by incubating purified thrombin $(11.5 \mu \mathrm{M})$ with PPACK $(60 \mu \mathrm{M})$ at $37^{\circ} \mathrm{C}$ in the same buffer until virtually no amidolytic activity could be detected and finally dialyzed against the same buffer. 
Neutralization of Factor $X_{a}$ activity- Purified factor $\mathrm{X}_{\mathrm{a}}(10 \mathrm{nM})$ was added to AT III $(200 \mathrm{nM})$ and HA-heparin $(30 \mathrm{ng} / \mathrm{mL})$, in the presence of warious concentrations of PPACK-thrombin, PPACK-meizothrombin, prothrombin fragment 1.2 , fragment 1 or fragment 2 at $37^{\circ} \mathrm{C}$ in $50 \mathrm{mM}$ Tris- $\mathrm{HCl}, 175 \mathrm{mM} \mathrm{NaCl}$ and 0.5 mg HSA/mL (pH 7.9). At timed intervals after the addition of factor $\mathrm{Xa}_{\mathrm{a}}, 20 \mu \mathrm{L}$ aliquots were transferred into $330 \mu \mathrm{L}$ of substrate solution [containing $50 \mathrm{mM}$ Tris-HCl, $175 \mathrm{mM} \mathrm{NaCl}, 20 \mathrm{mM}$ EDTA, $0.5 \mathrm{mg} \mathrm{HSA} / \mathrm{mL}$ and $0.22 \mathrm{mM}$ S2337 (pH 7.9)] at $37^{\circ} \mathrm{C}$. After 6 minutes, $150 \mu \mathrm{L}$ of $50 \%$ acetic acid (v/v) was added and the absorbance of the mixture was measured at $405 \mathrm{~nm}$ using an Aminco DW-2 spectrophotometer. Pseudo-first-order rate constants of inhibition of factor $\mathrm{X}_{\mathrm{a}}$ were calculated from a plot of the logarithm of residual factor $\mathrm{X}_{\mathrm{a}}$ concentrations versus time.

\section{Results}

Effects of PPACK-Thrombin and PPACK-Meizothrombin on the Heparin-Catalyzed AT III/Factor $X_{a}$ Reaction-Figure $1 \mathrm{~A}$ depicts the pseudo-first-order plots of inhibition of Factor $X_{a}$ by AT III at varying $H A$-heparin concentrations. It is shown that under these conditions the pseudo-first-order rate constant increased

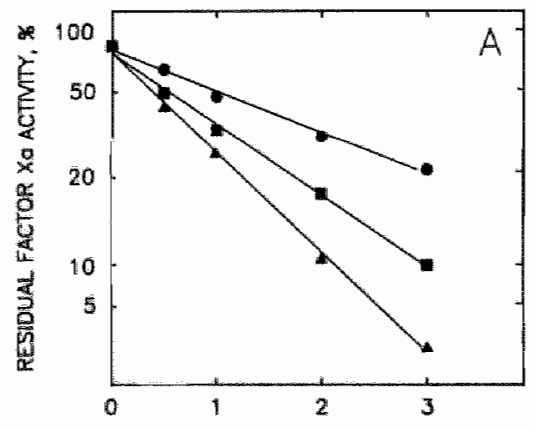

TINE, min

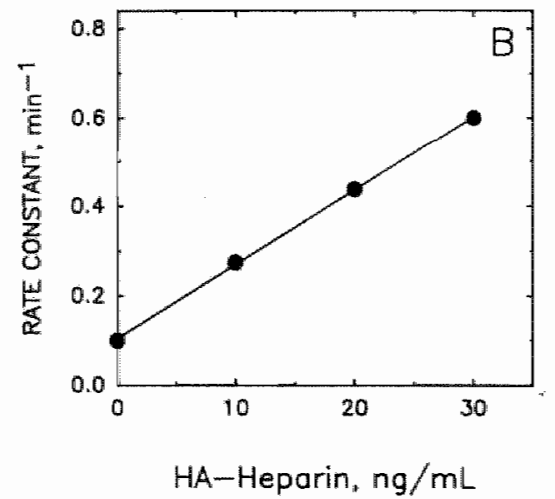

Figure 1: Pseudo-first-orderplots of inhibition of factor $X_{a}(10 \mathrm{nM})$ by AT III (200 $n M$ ) in the presence of $10 \mathrm{ng} / \mathrm{mL}(\bullet), 20 \mathrm{ng} / \mathrm{mL}(\boldsymbol{Q})$ or $30 \mathrm{ng} / \mathrm{mL}(\Delta)$ HA-heparin (panel A), and replot of pseudo-first-order rate constant versus the HA-heparin concentration (panel B). 
proportionally with the HA-heparin concentration (Figure 1B). Thus, the addition of a compound which neutralizes heparin will decrease the apparent pseudo-first-order rate constant as a result of competition of the added compound with AT III for the heparin.

We next examined the effects of thrombin and meizothrombin on the heparincatalyzed AT III/factor $X_{a}$ reaction. In order to avoid depletion of AT III we utilized active site blocked proteases (PPACK-thrombin and PPACKmeizothrombin). It has been reported that PPACK-thrombin has the same affinity for heparin when compared to thrombin, but does not react with AT III (18). Thus a decrease of the pseudo-first-order rate constant will be the result of the neutralization of heparin to the added compound which removes it from the AT III/factor $\mathrm{X}_{\mathrm{a}}$ reaction.

Figure 2 depicts the apparent pseudo-first-order rate constants of inhibition of factor $\mathrm{X}_{\mathrm{a}}$, as a function of the PPACK-thrombin and PPACK-meizothrombin concentration. It is clearly demonstrated that PPACK-meizothrombin does not influence the inhibition of factor $X_{a}$, whereas the addition of PPACK-thrombin reduces the rate constant in a dose-dependent manner. The rate constants are corrected for the heparin-independent reaction $\left(k=0.1 \mathrm{~min}^{-1}\right)$. The concentration of PPACK-thrombin required to obtain half the maximal rate constant of the heparin-dependent factor $X_{a}$ inhibition was $700 \mathrm{nM}$. In order to establish that solely the heparin neutralizing capacity of PPACK-thrombin caused the lower rate constant, we utilized the synthetic pentasaccharide IC 831423. Our results demonstrate that the pentasaccharide $(15 \mathrm{ng} / \mathrm{mL})$ is a highly effective catalyst of the AT II/factor $X_{a}$ reaction, but its action is not influenced by the addition of PPACK-thrombin (Figure 2). This result can readily be explained by the

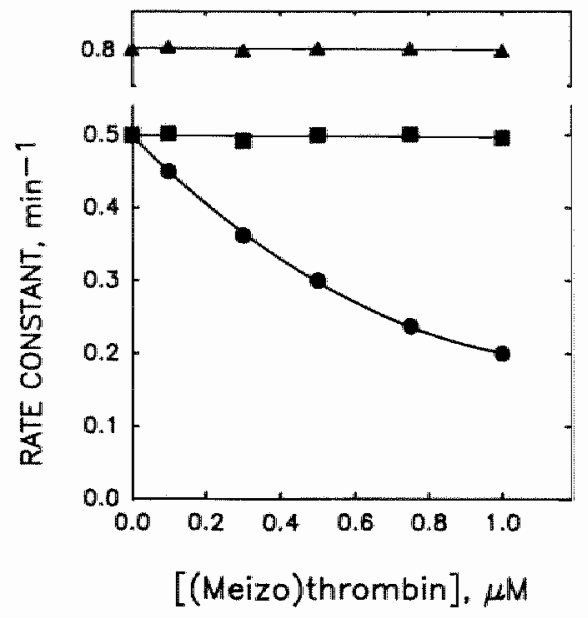

Figure 2: Effect of PPACKthrombin $(\bullet)$ and $P P A C K$. meizothrombin ( $)$ on the apparent pseudo first order rate constant of the HA-heparindependent inhibition of factor $X_{a}$. The effect of PPACK. thrombin on the pseudo first order rate constant of the pentasaccharide-dependent inhibition of factor $X_{a}(\Delta)$. 
absence of any anti-thrombin activity and thus thrombin-binding capacity of this compound (10). Taking these results together, it is our conclusion that PPACKmeizothrombin is unable to interact with heparin. This observation, therefore, might explain our previously lylylyreported finding that the AT III/meizothrombin reaction is not catalyzed by heparin (11).

Conversion of PPACK-Meizothrombin into Prothrombin Fragment 1.2 and PPACK-Thrombin and the Neutralization of Heparin by the Reaction ProductsWe initially assumed that the presence of covalently-bound prothrombin fragment 1.2 in the meizothrombin molecule caused the difference between thrombin and meizothrombin in their heparin-neutralizing properties. Thus, we set out to demonstrate that after cleavage of the PPACK-meizothrombin molecule the obtained prothrombin fragment 1.2 and PPACK-thrombin would show the same properties as the purified proteins. To this end, PPACK-meizothrombin (4 $\mu \mathrm{M})$ was incubated with factor $\mathrm{X}_{\mathrm{a}}(6 \mathrm{nM})$, factor $\mathrm{V}_{\mathrm{a}}(30 \mathrm{nM})$, phospholipid composed of $20 \%$ phosphatidylserine/80\% phosphatidylcholine $(60 \mu \mathrm{M})$ and $\mathrm{CaCl}_{2}(6 \mathrm{mM})$ in $50 \mathrm{mM} \mathrm{Tris}-\mathrm{HCl}, 175 \mathrm{mM} \mathrm{NaCl}(\mathrm{pH} 7.9)$ at $37^{\circ} \mathrm{C}$. The reaction, when monitored by SDS-PAGE, was completed after 30 minutes and gave rise to prothrombin fragment 1.2 and PPACK-thrombin (data not shown). Increasing amounts of this reaction mixture, up to $2 \mu \mathrm{M}$ of converted PPACK-meizothrombin, were unable to slow down the HA-heparin-catalyzed AT III/factor $\mathrm{X}_{\mathrm{a}}$ reaction, indicating that cleaved meizothrombin is unable to neutralize heparin. It is important to note that under these conditions non-covalent association of prothrombin fragment 1.2 and (PPACK-)thrombin might be occurring (19) which can form a product with properties indistinguishable from meizothrombin.

To further investigate the heparin neutralizing properties of prothrombin fragment 1.2 and PPACK-thrombin, we analyzed the reaction mixture by FPLC on a mono-Q column equilibrated with $50 \mathrm{mM}$ Tris, $175 \mathrm{mM} \mathrm{NaCl}$ (pH 7.5), de-

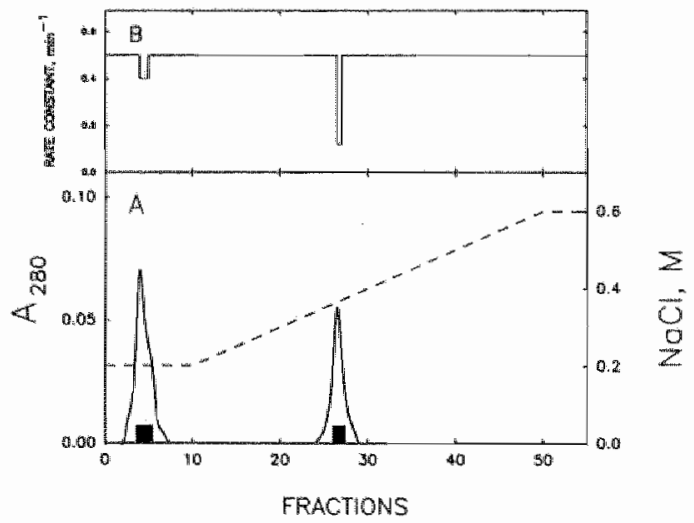

Figure 3: FPLC-analysis of factor $X_{a}$ cleaved PPACK-meizothrombin on $a$ mono-Q column. 
veloped with a linear gradient of 175 to $600 \mathrm{mM} \mathrm{NaCl}$ at room temperature and with a flow rate of $1 \mathrm{~mL} / \mathrm{min}$. PPACK-thrombin eluted with the equilibration buffer containing $175 \mathrm{mM} \mathrm{NaCl}$ and prothrombin fragment 1.2 eluted at $350 \mathrm{mM}$ $\mathrm{NaCl}$ (Figure 3A). The protein peaks, indicated by the solid bars, were dialyzed against $50 \mathrm{mM}$ Tris-HCl, $175 \mathrm{mM} \mathrm{NaCl}(\mathrm{pH} \mathrm{7.9)}$ and then added to the HA-heparin containing AT III-factor $\mathrm{X}_{\mathrm{a}}$ reaction mixture to a final concentration of 100 $\mathrm{nM}$ of PPACK-thrombin and prothrombin fragment 1.2 , respectively. Both PPACK-thrombin and prothrombin fragment 1.2 decreased the pseudo-firstorder rate constant of factor $\mathrm{X}_{\mathrm{a}}$ inhibition from $0.5 \mathrm{~min}^{-1}$ to 0.4 and $0.1 \mathrm{~min}^{-1}$, respectively (Figure 3B). Whereas the effect of PPACK-thrombin was expected, fragment 1.2 was to our surse even more effective in neutralizing heparin.

Effect of Prothrombin Fragment 1.2 on the Heparin-Catalyzed ATIII/Factor Xa Reaction- - Figure 4 depicts the effect of various concentrations of prothrombin fragment 1.2 on the pseudo-first-order rate constant of the HA-heparin-dependent inhibition of factor $\mathrm{X}_{\mathrm{a}}$ by AT III. An IC50 value of $100 \mathrm{nM}$ was found.

We next examined which region of the prothrombin fragment 1.2 molecule contains the site of interaction with heparin. To this end, prothrombin fragment

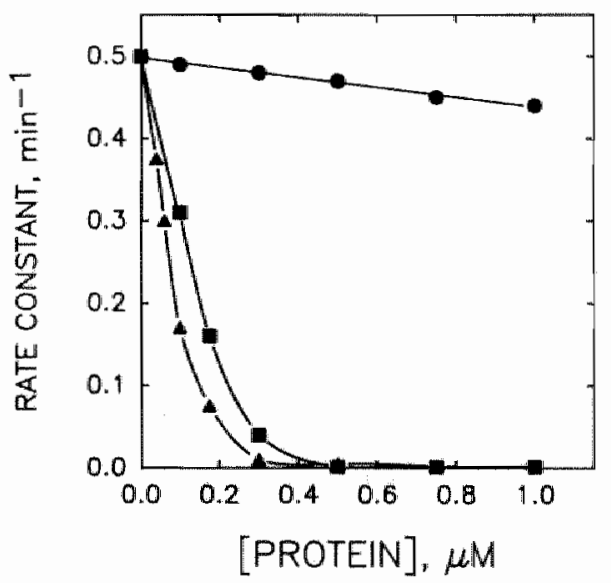

Figure 4: Effect of prothrombin fragment 1.2(४), fragment $1(\square)$ and fragment 2 (•) on the apparent pseudo first orderrate constant of the HA-heparin dependent factor $X_{a}$ inhibition by AT III. 
1.2 ( $5 \mu \mathrm{M})$ was converted into fragment 1 and fragment 2 by incubation with thrombin ( $50 \mathrm{nM}$ ). Analysis by SDS-PAGE revealed that the reaction was completed after $30 \mathrm{~min}$. When samples were taken during the reaction and tested at $100 \mathrm{nM}$ concentrations for their heparin-neutralizing effect, a 50\% inhibition of the factor $X_{a}$ inactivation reaction was observed, independent on the extend of the prothrombin fragment 1.2 cleavage reaction. It was tested that the amount of thrombin carried-over did not interfere with the assay.

Purified fragment 1 and fragment 2 at various concentrations were then added to factor $\mathrm{X}_{\mathrm{a}}$ inactivation mixtures. Their effects on the pseudo-first-order rate constants are shown in Figure 4. Fragment 1 showed the highest affinity for heparin with an IC50-value of $125 \mathrm{nM}$ which is somewhat higher than that for prothrombin fragment $1.2(\mathrm{IC} 50=100 \mathrm{nM})$. However, fragment 2 had an IC 50 value far above $1500 \mathrm{nM}$. Our results indicate that also prothrombin fragment 1 contains a domain which interacts with heparin and at even a higher affinity when compared to the one present in the thrombin region of the prothrombin molecule.

\section{Discussion}

Using the heparin-dependent factor $\mathrm{X}_{\mathrm{a}}$ inactivation by AT III, we were able to show that meizothrombin, an intermediate in prothrombin activation (2) is not able to neutralize heparin, whereas thrombin does. When active site blocked meizothrombin (PPACK-meizothrombin) was titrated into a factor $\mathrm{X}_{\mathrm{a}}$ inactivation mixture, containing $10 \mathrm{nM}$ factor $X_{\mathrm{a}}, 200 \mathrm{nM}$ AT III and $30 \mathrm{ng} / \mathrm{mL}$ HA-heparin, there was no effect at all on the pseudo-first-order rate constant of the heparin-dependent factor $X_{a}$ inactivation reaction. Performing the same experiment with active site blocked thrombin (PPACK-thrombin) we obtained a $50 \%$ inhibition of the inactivation reaction at a concentration of $700 \mathrm{nM}$ PPACK-thrombin. Although our method measures the neutralization of heparin, it seems reasonable to explain this phenomenon in terms of binding affinity between negatively charged heparin and basic amino acids in the neutralizing proteins. Thus, our observations show that PPACK-meizothrombin is not able to bind to heparin, while PPACK-thrombin does contain heparin-binding sites and therefore explains the absence of a stimulatory effect of heparin on the AT III/meizothrombin reaction (11). As meizothrombin is formed by cleavage of the Arg and the Ile in the prothrombin molecule, it still contains the intact fragment 1.2 region. The intriguing question, therefore, is whether covalently-bound fragment 1.2 prevents the exposure of the heparin-binding site(s) present at the thrombin part of the molecule. 
After cleavage of PPACK-meizothrombin by factor $X_{a}$, however, the converted PPACK-meizothrombin was not able to inhibit the HA-heparin-catalyzed AT III-factor $\mathrm{X}_{\mathrm{a}}$ reaction up to a concentration of $2 \mu \mathrm{M}$, although electrophoretic analysis (SDS-PAGE) revealed that after $30 \mathrm{~min}$ PPACKmeizothrombin was completely converted to prothrombin fragment 1.2 and PPACK-thrombin. However, after separating the reaction products by FPLC, PPACK-thrombin and, quite suprisingly, prothrombin fragment 1.2 were able to decrease the pseudo-first-order rate constant of factor $X_{a}$ inhibition. These results suggest that after cleavage of PPACK-meizothrombin, prothrombin fragment 1.2 and PPACK-thrombin remain non-covalently associated and thus exhibit, like the PPACK-meizothrombin molecule, no heparin-binding properties.

To investigate the binding properties of the separate prothrombin fragment region, we purified fragment 1 and fragment 2 . Our data show that the sites responsible for the heparin affinity are located on fragment 1. Fragment 2 hardly shows any affinity for heparin. Aronson et al. (20) demonstrated that during the clotting of blood and plasma in systems in which thrombin is rapidly inactivated, fragment 1.2 can account for at least $90 \%$ of the prothrombin originally present. Together with our results, that indicate strong binding properties of fragment 1.2 towards heparin, one could assume that fragment 1.2 formation indeed plays an important role in the regulation of blood coagulation by competing with AT III for the available heparin.

\section{References}

1. Suttie JW, Jackson CM: Prothrombin structure, activation and biosynthesis. Physiol Rev 57:1, 1977

2. Rosing $\mathrm{J}_{\mathrm{g}}$ Zwaal RFA, Tans $\mathrm{G}$ : Formation of meizothrombin as intermediate in factor $\mathrm{X}_{\mathrm{a}}$-catalyzed prothrombin activation. J Biol Chem 261:4224, 1986

3. Walker FJ, Esmon CT: The effect of prothrombin fragment 2 on the inhibition of thrombin by antithrombin III. J Biol Chem 254:5618, 1979

4. Rosenberg RD, Damus PS: The purification and mechanism of action of human antithrombin-heparin cofactior. J Biol Chem 248:6490, 1973

5. Hemker HC, Willems G, Beguin S: A computer assisted method to obtain the prothrombin activation velocity in whole plasma independent of thrombin decay processes. Thrombos Haemostas $56.9,1986$

6. Einarson R, Andersson LO: Binding of heparin to human antithrombin III as studied by measurements of tryptophan fluoresence. Biochim Biophys Acta 490:104, 1977

7. Villanueva $\mathrm{GB}_{4}$ Danishefsky I: Evidence for a heparin-induced conformational change of AT III. Biochem Biophys Res Comm 79:803, 1977

8. Smith GF: The heparin-thrombin complex in the mechanism of thrombin inactivation by heparin. Biochem Biophys Res Comm 77:111, 1977 
9. Machovich $R$, Staub $M$, Pattby $L:$ Decreased heparin sensitivity of cyclohexanedionemodified thrombin. Eur J Biochem 83:473, 1978

10. Choay J, Petitou $M_{n}$ Lormean JC, Sinay $P$, Casu $P$, Gatti $G_{*}^{*}$ Structure activity relationships in heparin: a synthetic pentasaccharide with bigh affinity for antithrombin III and eliciting bight anti-factor $X_{\text {w }}$ activity. Biochem Biophys Res Comm 116:492, 1983

11. Lindhout $T$, Baruch $D$, Schoen $P$, Franssen $J$, Hemker $\mathbb{H C}$ : Thrombin generation and inactivation in the presence of antithrombin III and heparin. Biochemistry 25:5962, 1986

12. Lindhout T, Govers-Riemslag JWP, van de Waard $P_{x}$ Hemker HC Rosing J: Factor $V_{\mathrm{a}^{-}}$ Factor $X_{a}$ interaction. Effect of phospholipid wesicles of varying composition. Biochemstry $21: 5494,1982$

13. Owen WG, Esmon CT, Jackson CM: The conversion of prothrombin to thrombin. I. Characterization of the reaction products formed during the activation of bovine prothrombin. J Biol Chem 249:594, 1974

14. Govers-Riemslag JWP, Speijer H, Zwaal RFA, Rosing J: The effects of bowine prothrombin fragment 1 and fragment 1.2 on prothrombin activation. Thromb Res $38: 375$, 1985

15. Thaler EJ, Schmer G: A simple two-step isolation procedure for human and bovine antithrombin II/III (heparin cofactor): A comparison of two methodls. $\mathrm{Br} \mathrm{J}$ Haematol 31:233, 1975

16. Miller-Andersson $M$, Borg $\mathbb{H}$, Andersson LO: Purification of antithrombin III by affinity chromatography. Thromb Res 5:439, 1977

17. van Dieijen $G$, Tans $G$, Rosing $J$, Hemker $\mathrm{HC}$. The role of phospholipid and factor VIII $I_{a}$ in the activation of bovine factor X.J Biol Chem 256:3433, 1981.

18. Griffith HJ, Kingdon HS, Lundblad RL: Inhibition of the heparin-antithrombin III/thrombin reaction by active site blocked thrombin. Biochem Biophys Res Comm 87:686, 1979

19. Nesheim ME: The correlation between the thrombin-catalyzed cleavage of prothrombin fragment 1.2 and release of thrombin from prothrombinase. Thrombos Haemostas $54: 148,1985$

20. Aronson DL, Stevan L, Ball AB, Franca BR jr, Finlayson JS: Generation of the combined prothrombin activation peptide (F 1.2) during the clotting of blood and plasma. J Clin Invest 60:1410, 1977 


\title{
Chapter III
}

\section{Inhibition of Factor $\mathrm{IX}_{\mathrm{a}}$ and Factor $\mathrm{X}_{\mathrm{a}}$ by Antithrombin III/Heparin During Factor $X$ Activation $^{\circ}$}

\begin{abstract}
We investigated the kinetics of the inhibitory action of antithrombin III and antithrombin III plus heparin during the activation of factor $\mathrm{X}$ by factor $\mathrm{IX}_{\mathrm{a}}$. Generation and inactivation curves were fitted to a 3-parameter 2-exponentional model to determine the pseudo first order rate constants of inhibition of factor IX $X_{\mathrm{a}}$ and factor $\mathrm{X}_{\mathrm{a}}$ by antithrombin III/heparin. In the absence of heparin, the second order rate constant of inhibition of factor $X_{a}$ generated by factor $I_{X_{a}}$ was 2.5 -fold lower than the rate constant of inhibition of exogenous factor $X_{a}$. It appeared that phospholipid-bound factor $\mathrm{X}$ protected factor $\mathrm{X}_{\mathrm{a}}$ from inactivation by antithrombin III. It is, as yet, unclear whether an active-site or a nonactive-site interaction between factor $X_{a}$ and factor $X$ at the phospholipid surface is involved. The inactivation of factor IX $\mathrm{X}_{\mathrm{a}}$ by antithrombin III was found to be very slow and was not affected by phospholipid, calcium and/or factor X. With unfractionated heparin (UFH) above $40 \mathrm{ng} / \mathrm{mL}$ and antithrombin III at $200 \mathrm{nM}$, the apparent second order rate constant of inhibition of exogenous and generated fac-
\end{abstract}

Based on: Pieters J, Willems $G_{7}$ Hemker HC, Lindhout T: J Biol Chem 263 (30): 1.5313, 1988 
tor $\mathrm{X}_{\mathrm{a}}$ were the same. Thus, in this case phospholipid-bound factor $\mathrm{X}$ did not protect factor $X_{a}$ from inhibition. In the presence of the synthetic pentasaccharide heparin, however, phospholipid-bound factor $\mathrm{X}$ reduced the rate constant about 5 -fold. Pentasaccharide had no effect on the factor $\mathrm{IX}_{\mathrm{a}} /$ antithrombin III reaction. UFH $(1 \mu \mathrm{g} / \mathrm{mL})$ stimulated the antithrombin III-dependent inhibition of factor $\mathrm{IX}_{\mathrm{a}}$ during factor $\mathrm{X}$ activation 400 -fold. In the absence of reaction components this stimulation was 65 -fold. We established that calcium stimulated the heparin-dependent inhibition of factor IX

\section{Introduction}

Antithrombin III (AT III) is a plasma protein that plays an important role in the regulation of a series of activation reactions leading to clot formation (1). From studies with purified serine proteases and inhibitor, it is well known that the main target of AT III is thrombin whereas the activity towards activated factor $\mathrm{X}$ and activated factor IX is less pronounced $(2,3)$.

Heparin accelerates the rate at which AT III inactivates the serine proteases of the blood coagulation system. Dependent on the molecular weight of the heparin preparation used, the rate enhancing effect of heparin on the inhibition of factor $I_{\mathrm{a}}$ and factor $\mathrm{X}_{\mathrm{a}}$ seems to be different (4). Inactivation of factor $\mathrm{IX}_{\mathrm{a}}$ was found to decrease when heparins were used with decreasing molecular weight, whereas the inhibition of factor $\mathrm{X}_{\mathrm{a}}$ was potentiated by low molecular weight heparin fractions who have virtually no effect on the inactivation of factor $\mathbb{I} \mathbf{X}_{\mathrm{a}}$.

As factor $\mathrm{X}_{\mathrm{a}}$ is the only known physiological activator of prothrombin, it plays a key role in the process of coagulation. Its formation has been postulated to be an important target for the control mechanism of thrombin formation $(5,6)$. Furthermore, factor $X_{a}$ may play a role in the activation of factors V, VIII and VII (7-9).

Among the control mechanism which regulate the generation of factor $X_{a}$, the inhibition by antithrombin III is one of the most important ones, especially when heparin is present. Therefore the effect of antithrombin III and antithrombin III plus heparin on isolated factor $\mathbf{X}_{\mathrm{a}}$ and factor $\mathbf{I} \mathrm{X}_{\mathrm{a}}$ has been studied (10-13). However, little is known about the kinetics of inactivation of factor IX $\mathrm{X}_{\mathrm{a}}$ and factor $\mathrm{X}_{\mathrm{a}}$ during factor $\mathrm{X}$ activation, which presents a more physiological situation. Previous studies reported the effect of $\mathrm{AT}$ III on factor $\mathrm{X}_{\mathrm{a}}$ generated by simple activators of factor $\mathrm{X}$, such as the factor $\mathrm{X}_{\mathrm{a}}$ ctivating protein from Russell's Viper venom (14). Recently, Jesty (15) described the inhibition of in situ generated 
factor $X_{a}$ by AT III. When using factor $\mathrm{XX}_{\mathrm{a}}$ as an activator of factor $\mathrm{X}$, he could not accurately analyze the overall factor $X_{a}$ generation and inactivation, however. Also, this author did not present kinetic parameters on the inactivation of factor $\mathrm{X}_{\mathrm{a}}$, generated by factor $\mathrm{IX}_{\mathrm{a}}$.

In this paper we present a method which allows the simultaneous analysis of the kinetics of both factor IX $\mathrm{X}_{\mathrm{a}}$ and factor $\mathrm{X}_{\mathrm{a}}$ inactivation by AT III or AT III plus heparin during factor $\mathrm{X}$ activation. By this approach we were able to assess the relative importance of factor $\mathbb{I X}_{\mathrm{a}}$ inhibition and factor $\mathrm{X}_{\mathrm{a}}$ inhibition to the overall effect of unfractionated heparin (UFH) and a synthetic pentasaccharide heparin on factor $\mathrm{X}_{\mathrm{a}}$ generation. We report some marked differences between the kinetics of the inhibition reactions during factor $\mathrm{X}$ activation and those observed in the absence of factor $\mathrm{X}$, phospholipid and/or calcium.

\section{Materials and Methods}

Materials- The synthetic peptide substrates Bz-Ile-Glu-(Piperidyl)-Gly-Arg-pnitro-anilide hydrochloride (S-2337) and H-D-Phenylalanyl-L-pipecolyl-L-arginine-p-nitro-anilide dihydrochloride ( $\mathrm{S}-2238$ ) were purchased from $\mathrm{AB}$ Kabi Diagnostica, Stockholm. Fatty acid-free ovalbumin was a product of Sigma Chemical Co., St. Louis. All reagents used were of the highest grade commercially available.

Unfractionated heparin (168 units/mg) was from Pharmuka Laboratories, France, and the synthetic pentasaccharide heparin ( 800 anti-factor $X_{a}$ units $/ \mathrm{mg}$ and no anti-thrombin activity) was a kind gift from Institut Choay, France.

Proteins-Bovine ATIII was purified by the method of Thaler and Schmer (16). The AT III was subsequently freed of heparin contamination by ion-exchange chromatography (17). All other bovine clotting factors were prepared and quantitated as previously described (18-20).

Phospholipid Vesicles- Phospholipid vesicles were made from a mixture of phosphatidylserine (PS) and phosphatidylcholine (PC) as previously described (20). Vesicles composed of 25 mole\% PS and 75 mole\% PC were used throug. hout the experiments unless stated otherwise.

Determination of Inhibition Rare of Purified Protease- The inactivation of factor $\mathrm{X}_{\mathrm{a}}$ by AT III was investigated under pseudo-first order conditions essentially as previously described (3). The inactivation of factor $\mathrm{IX}_{\mathrm{a}}$ was followed by incuba- 
tions of factor IX $\mathrm{X}_{\mathrm{a}}$ with $\mathrm{AT} \mathrm{II} / \mathrm{h}$ eparin in the presence or absence of accessory components and at several time points residual factor $\mathbf{L X}_{\mathrm{a}}$ activity was assayed as described previouslly (21) with the following modifications. Factor $\mathrm{IX}_{\mathrm{a}}$ containing samples were diluted $1: 1000$ into buffer containing $50 \mathrm{mM}$ Tris- $\mathrm{HCl}(\mathrm{pH}$ 7.9), $175 \mathrm{mM} \mathrm{NaCl}, 0.5 \mathrm{mg}$ ovalbumin/mL, $5 \mathrm{mM} \mathrm{CaCl} 2,20 \mu \mathrm{M}$ phospholipid and $100 \mathrm{nM}$ thrombin, prewarmed at $37^{\circ} \mathrm{C}$ for $4 \mathrm{~min}$. Factor VIII:C (10 U/mL) was added and allowed to be activated for 15 seconds, after which the reaction was started by the addition of factor $X(0.5 \mu \mathrm{M})$. The rate of factor $X$ activation was determined by measuring the amount of factor $X_{a}$ formed after 30 and 90 seconds using the chromogenic substrate S-2337 as described earlier (3). Factor $\mathrm{X}_{\mathrm{a}}$ formation was linear in time for at least 2 minutes. From the observed rate of factor $\mathrm{X}$ activation the amount of factor $\mathrm{IX}_{\mathrm{a}}$ present in the sample was calculated using a calibration curve made with known amounts of active site titrated factor IX.

Inactivation of Factor $I X_{a}$ and Factor $X_{a}$ by $A T$ III/Heparin During Factor $X$ Activation- Factor $\mathrm{X}(1 \mu \mathrm{M})$ was activated by $80 \mathrm{nM}$ factor $\mathrm{IX}_{\mathrm{a}}$, in the presence of $100 \mu \mathrm{M}$ phospholipid, $10 \mathrm{mM} \mathrm{CaCl}$ and heparin when indicated in $50 \mathrm{mM}$ Tris$\mathrm{HCL}, 175 \mathrm{mM} \mathrm{NaCl}$ and $0.5 \mathrm{mg} / \mathrm{mL}$ ovalbumin, $\mathrm{pH} 7.9$ at $37^{\circ} \mathrm{C}$. At timed intervals after the addition of factor $\mathrm{IX}_{\mathrm{a}}$, aliquots $(7 \mu \mathrm{L})$ were removed and assayed for factor $X_{a}$ activity. Factor $X_{a}$ formation was linear in time for at least 30 min. After $10 \mathrm{~min}$ an aliquot $(200 \mu \mathrm{L})$ was taken from the reaction mixture and added to a solution $(14 \mu \mathrm{L})$ containing AT III and rabbit anti-factor IX IgG. At the same time another aliquot $\left(20{ }_{\mu} \mathrm{L}\right.$ ) was taken from the reaction mixture and added to a solution $(14 \mu \mathrm{L})$ containing AT III alone. Addition of anti-factor IX resulted in instantaneous and complete inhibition of factor $X_{\mathrm{a}}$ formation, but had no effect on factor $\mathbf{X}_{\mathbf{a}}$ activity or on the AT III/factor $\mathbf{X}_{\mathrm{a}}$ reaction. After the addition of AT III or AT III plus anti-factor IX, timed samples $(7 \mu \mathrm{L})$ were taken and assayed for factor $\mathrm{X}_{\mathrm{a}}$ activity.

Because the rabbit anti-factor IX IgG neutralized the unfractionated heparin, anti-factor IX IgG could not be used to block further factor $\mathrm{X}_{\mathrm{a}}$ formation to measure the effects of UFH on factor $X_{a}$ inhibition. Therefore, we modified the experimental set-up for the determination of the effect of UFH on the inactivation of factor $\mathbf{I} \mathrm{X}_{\mathrm{a}}$ and factor $\mathrm{X}_{\mathrm{a}}$ during factor $\mathrm{X}$ activation. Factor $\mathrm{X}$ was activated in the presence of UFH under the same conditions as described before. Factor $X_{\mathrm{a}}$ formation was monitored by removing aliquots $(7 \mu \mathrm{L})$ and assayed for factor $\mathrm{X}_{\mathrm{a}}$ activity. After 10 minutes, $200 \mu \mathrm{L}$ was removed and added to a solution of AT III $(14 \mu \mathrm{L})$. From this reaction mixture, timed samples $(10 \mu \mathrm{L})$ were taken, and assayed for factor $\mathrm{IX}_{\mathrm{a}}$ activity as already described. From the same mixture, aliquots $(7 \mu \mathrm{L})$ were taken and assayed for factor $\mathrm{X}_{\mathrm{a}}$ activity. The pseudo first order rate constants of inhibition of factor $\mathrm{X}_{\mathrm{a}}$ and factor $\mathrm{IX}_{\mathrm{a}}$ were calculated as described in the following section. 
Kinetic Analysis of the Inhibition of Factor $X_{a}$ and Factor $X_{a}$ During Factor $X$ Activation- Under the experimental conditions of our studies the factor $\mathrm{X}_{\mathrm{a}}$ formation was linear during the time-period of the experiment when AT III was absent. This was obtained by using factor $\mathrm{X}$ concentrations well above the $\mathrm{K}_{\mathrm{m}}$ for factor $X$ and less then $20 \%$ of factor $X$ consumed during the experiment. Secondly, the AT III concentrations were in excess over the factor $X_{a}$ and factor IX concentrations, resulting in pseudo-first order kinetics of inhibition. When AT III or AT III plus heparin was present during the activation of factor $\mathrm{X}$ by factor $\mathrm{IX}_{\mathrm{a}}$ we assumed that the amount of amidolytic active factor $\mathrm{X}_{\mathrm{a}}$ present at time $t$ is a function of the rate of inactivation of factor $\mathrm{IX}_{\mathrm{a}}$ and the rate of inactivation of factor $\mathrm{X}_{\mathrm{a}}$. In formula this reads:

$$
d / d t\left[\mathrm{X}_{\mathrm{a}}\right]=v e^{-k_{\mathrm{IX}} t}-k \mathrm{Xa}_{\mathrm{a}}\left[\mathrm{X}_{\mathrm{a}}\right]
$$

where $v$ is the rate of factor $X_{\mathrm{a}}$ formation in the absence of AT III or AT III plus heparin, $k \mathrm{IXa}$ and $k \mathrm{Xa}_{\mathrm{a}}$ are the pseudo first order rate constants of inhibition of factor $I_{\mathrm{a}}$ and factor $\mathrm{X}_{\mathrm{a}}$, respectively.

Integration of Equation 1 by Laplace transformation gives the following equation for the generation of factor $\mathrm{X}_{\mathrm{a}}$ concomitant with its decay.

$$
\left[\mathrm{X}_{\mathrm{a}}\right]_{t}=\left(v /\left(k_{\mathrm{Xa}}-k_{\mathrm{IX}}\right)\right)\left(e^{-k_{\mathrm{IXa}} t}-e^{-k_{\mathrm{Xa}} t}\right)
$$

the parameters, $v, k \mathrm{XXa}$ and $k \mathrm{Xa}_{\mathrm{a}}$ could be determined by fitting equation 2 to the experimental data points. However, we preferred an analysis of our data which also allows independent determinations of the parameters $v$ and $k$ x. To this end, the activation of factor $\mathrm{X}$ in the absence of AT III was performed for $t_{0}$ min, followed by the addition of AT III or AT III plus anti-factor IX IgG.

When AT III is added at time to, the factor $\mathrm{X}_{\mathrm{a}}$ concentration then obtained 


$$
\left[\mathrm{X}_{\mathrm{a}}\right]_{t=t o}=v t_{o}
$$

has to be included into Equation 2:

$$
\left[\mathrm{X}_{\mathrm{a}}\right]_{t}=\left(w /\left(k \mathrm{Xa}_{\mathrm{a}}-k_{\mathrm{IXa}}\right)\right)\left(e^{-k_{\mathrm{IXa}}\left(t-t_{0}\right)}-e^{-k_{\mathrm{Xa}_{\mathrm{a}}}\left(t-t_{0}\right)}\right)+\left[\mathrm{X}_{\mathrm{a}}\right]_{t=t_{0}} e^{-k_{\mathrm{Xa}_{\mathrm{a}}}\left(t-t_{0}\right)}
$$

When AT III plus anti-factor IX IgG are added at time $t_{0}$, factor $\mathrm{X}_{\mathrm{a}}$ formation is completely blocked but not the decay of factor $X_{a}$ and reduces Equation 4 to

$$
\left[\mathrm{X}_{\mathrm{a}}\right]_{t}=\left[\mathrm{X}_{\mathrm{a}}\right]_{t=\mathrm{r}_{\mathrm{D}}} e^{\left.-k_{\mathrm{Xa}_{\mathrm{a}}\left(t-t_{\mathrm{o}}\right)}\right)}
$$

If $t \leq t_{o}$ then

$$
\left[\mathrm{X}_{\mathrm{a}}\right]_{t}=v t
$$

Equations 4-6 were simultaneously fitted to experimental data points, obtained in the absence or presence of AT III/heparin or in the presence of AT III/heparin plus anti-factor IX IgG. The fit procedure, based upon a nonlinear least squares regression method which uses a re-iterative Gauss-Newton algorithm (22), produced $v, k_{\mathrm{IXa}}$ and $k_{\mathrm{Xa}} \cdot$ In addition, $k_{\mathrm{Xa}}$ and $v$ were separately cal- 
culated using Equations 5 and 6, respectively, to estimate the validity of the parameter values as calculated by the fit procedure. The reported errors represent the $95 \%$ confidence interval, about twice the S.D. of the estimate.

\section{Results}

Determination of Factor $I X_{a}$ and Factor $X_{a}$ Inactivation by Antithrombin III During Factor $X$ Activation-Factor $\mathrm{X}$ was activated by factor $\mathrm{IX}_{\mathrm{a}}$ in the presence of phospholipid and calcium. After $10 \mathrm{~min}$ to a part of the reaction mixture a solution of AT III and rabbit anti-factor IX IgG was added, and at the same time AT III alone was added to another part of the reaction mixture. The result of

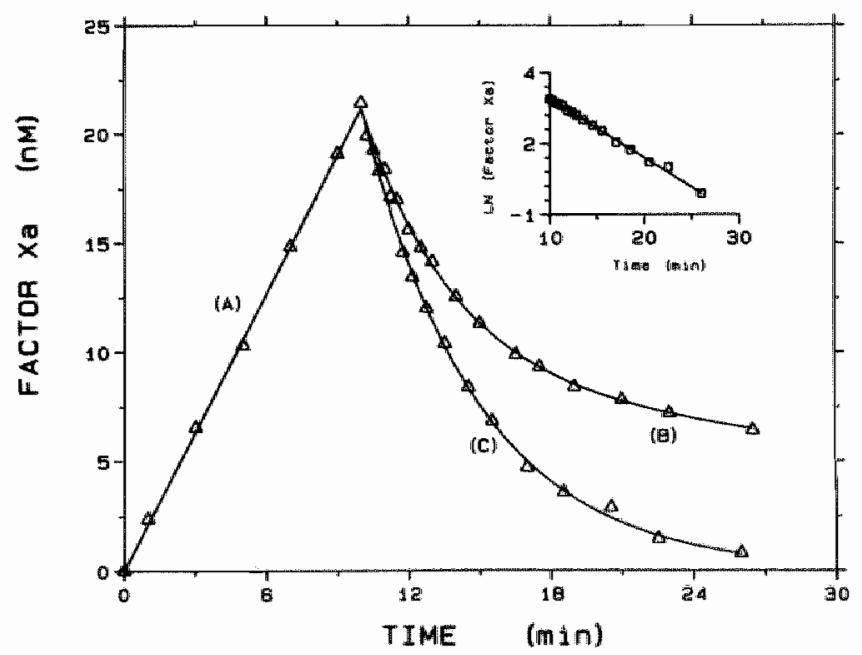

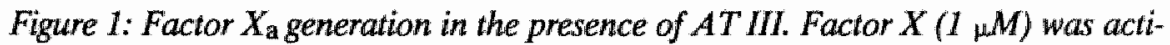
vated by $80 \mathrm{nM}$ factor $I X_{\mathrm{a}}$ in the presence of $100{ }_{\mu} \mathrm{M}$ phospholipid and $10 \mathrm{mM} \mathrm{cal}$ cium (curve A). At 10 minutes to $200 \mu L$ of the reaction mixture, $1 \mu M$ AT III was added (curve B). At the same time, to another $200 \mu L$ of the reaction mixture $1 \mu M$ $A T I I I$ and anti-factor IX Ig $G$ was added (curve C). Factor $X_{\mathrm{a}}$ activity was assayed as described under Materials and Methods. The solid lines represent the factor $X_{a}$ generation and inactivation as calculated by the fit procedure.

Inset: semi-logarithmic replot of curve $C$. 
such a typical experiment is shown in Figure 1. Curve $A$ shows a linear factor $\mathrm{X}_{\mathrm{a}}$ generation and addition of both anti-factor IX IgG and AT III at $t=10 \mathrm{~min}$ resulted in the exponential decay of the formed factor $\mathrm{X}_{\mathrm{a}}$ (curve $\mathrm{C}$ ), whereas addition of AT III alone resulted in significant higher residual factor $X_{\mathrm{a}}$ activities because of ongoing factor $\mathrm{X}_{\mathrm{a}}$ generation (curve $\mathrm{B}$ ).

Equations 4-6 (see Materials and Methods) were fitted to the experimental data and the factor $X_{a}$ generation and inactivation curves, indicated by the solid lines, are the results of the best fit to the data points. The pseudo first order rate constants of inactivation of factor $\mathrm{X}_{\mathrm{a}}$ and factor $\mathrm{LX}_{\mathrm{a}}$ by AT III as well as the velocity of factor $\mathrm{X}_{\mathrm{a}}$ formation in the absence of AT III were obtained by the computer fit-procedure. In this typical experiment the velocity of factor $X_{a}$ formation (v) was found to be $2.1 \pm 0.1 \mathrm{nM}^{-1} \mathrm{~min}^{-1}$, whereas the pseudo first order rate constants $(k)$ of inactivation of factor $\mathrm{X}_{\mathrm{a}}$ by AT III $(1 \mu \mathrm{M})$ was $0.21 \pm 0.01 \mathrm{~min}^{-1}$. However, the pseudo first order rate constant of inactivation of factor IX by AT III was too small to measure accurately $\left(\leq 0.01 \mathrm{~min}^{-1}\right)$.

The calculated parameters $v$ and $k$ can also be determined directly from part A and part $\mathrm{C}$ of the curves, respectively. The rate of factor $\mathrm{X}_{\mathrm{a}}$ formation was 2.1 $\mathrm{nM} /$ min (part A). The pseudo first order rate constant of inactivation of factor $\mathrm{X}_{\mathrm{a}}$ by AT III was determined from the semilogarithmic plot of part $\mathrm{C}$ of the curve versus time, $k \mathrm{Xa}_{\mathrm{a}}=0.21 \mathrm{~min}^{-1}$ (Figure 1, inset). Thus, the independently determined values for the rate of factor $\mathrm{X}$ activation and the rate constant of factor $\mathrm{X}_{\mathrm{a}}$ inactivation were the very same as the values from the fit-procedure, indicating the validity of our mathematical model.

This procedure was repeated in the presence of various AT III concentrations $(0-1.5 \mu \mathrm{M})$. A linear relationship between the pseudo first order rate constants of inhibition of factor $X_{a}$ and the AT III concentration was found. The second order rate constant was $2.1 \pm 0.1 \times 10^{5} \mathrm{M}^{-1} \mathrm{~min}^{-1}$. The inactivation of factor $\mathrm{IX}_{\mathrm{a}}$ during factor $\mathrm{X}$ activation at the AT III concentrations used was too small ( $k \mathrm{TXa}$ $\leq 0.010 \mathrm{~min}^{-1}$ ) to be measured accurately. Higher AT III concentrations, however, could not be used in this experimental setup, because then the factor $X_{a}$ generated by factor $\mathrm{IX}_{\mathrm{a}}$ was too fast inactivated and resulted in very low residual factor $\mathrm{X}_{\mathrm{a}}$ activities.

In order to determine the inactivation of factor IX $\mathrm{X}_{\mathrm{a}}$ at higher AT III concentrations, we made use of a factor $\mathrm{IX}_{\mathrm{a}}$-assay in which functional factor $\mathrm{IX}_{\mathrm{a}}$ activity was determined via the factor VIII: $\mathrm{C}_{\mathrm{a}}$ enhanced activation of factor $\mathrm{X}$ (see Materials and Methods). The pseudo first order rate constants of factor $\mathrm{IX}_{\mathrm{a}}$ inactivation by $A T$ III in the presence of factor $X$, phospholipid and calcium were plotted versus the AT III concentration $(0-10 \mu \mathrm{M})$. A second order rate constant of $8.2 \times 10^{3} \mathrm{M}^{-1} \mathrm{~min}^{-1}$ was calculated. In the absence of the reaction components 
(factor X, phospholipid and $\mathrm{Ca}^{2+}$ ) the second order rate constant of factor $\mathrm{IX}_{4}$ inactivation was found to be the very same as in their presence $\left(k_{2}=8.2 \times 10^{3}\right.$ $\left.\mathrm{M}^{-1} \min ^{-1}\right)$.

Effect of Accesory Components on Factor $X_{a}$ Inactivation by Antithrombin IIIAs several investigators reported contradictory effects of phospholipid or calcium (23-27) on the inactivation of factor $\mathrm{X}_{\mathrm{a}}$ by AT III, we examined whether our decay constants, determined by the fit-procedure during factor $\mathrm{X}$ activation, differed from the decay constants of factor $X_{a}$ in free solution.

To this end, we incubated purified factor $\mathrm{X}_{\mathrm{a}}(10 \mathrm{nM})$ with AT III $(0-1.5 \mu \mathrm{M})$, either in the absence or presence of phospholipid $(100 \mu \mathrm{M})$, calcium $(10 \mathrm{mM})$ or both. Figure 2 shows the results, revealing a second order rate constant of inhibition of factor $X_{a}$ by AT III in free solution was $5.0 \times 10^{5} \mathrm{M}^{-1} \mathrm{~min}^{-1}$. It is clear that neither the addition of phospholipid or calcium or phospholipid plus calcium protected factor $\mathrm{X}_{\mathrm{a}}$ from being inactivated by AT III. Under all conditions the rate constants were $5.0 \pm 0.1 \times 10^{5} \mathrm{M}^{-1} \mathrm{~min}^{-1}$. However, these rates of inactivation of factor $\mathrm{X}_{\mathrm{a}}$ appeared to be still about 2.5 -fold faster when compared to the rates of inactivation under the conditions of factor $\mathrm{X}$ activation (see previous section). In order to find an explanation for this discrepancy we added besides

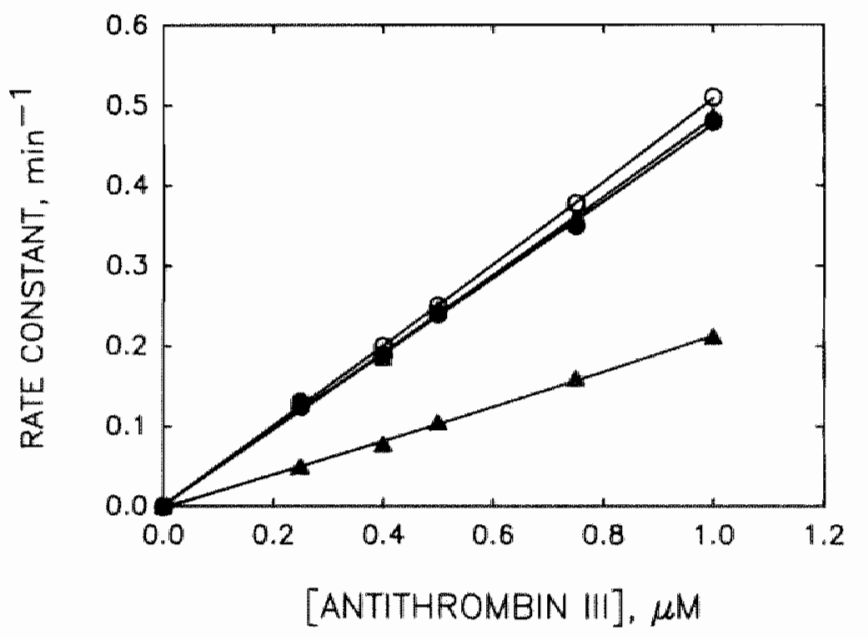

Figure 2: Pseudo first order rate constant of inactivation of factor $X_{\mathrm{a}}(10 n M)$ as a function of the antithrombin III concentration in the presence of phospholipid (100 $\mu M$ ) and $10 \mathrm{mM}$ calcium ( $\bullet$ ); Factor $X(1 \mu M)$ and $10 \mathrm{mM}$ calcium ( $\Delta)$; Factor $X(1 \mu M)$, phospholipid $(100 \mu M)$ and $10 \mathrm{mM}$ calcium (4); or alone (0). 
phospholipid and calcium, also factor $\mathrm{X}(1 \mu \mathrm{M})$ to the inactivation mixture. The second order rate constant of $2.1 \times 10^{5} \mathrm{M}^{-1} \mathrm{~min}^{-1}$ for factor $\mathrm{X}_{\mathrm{a}}$ inactivation by $\mathrm{AT}$ III thus obtained, was the very same as determined during factor $\mathrm{X}$ activation (Figure 2; closed triangles).

These results suggest that the decrease of the second order rate constant of the factor $\mathrm{X}_{\mathrm{a}}$ - AT III reaction during factor $\mathrm{X}$ activation is due to the presence ofphospholipid-bound factor $X$. Indeed, the pseudo first order rate constant of inhibition of factor $\mathrm{X}_{\mathrm{a}}$ in the presence of a fixed phospholipid concentration decreased with increasing factor $X$ concentration (Figure 3A). Also an increase of the phospholipid concentration at a fixed factor $\mathrm{X}$ concentration resulted in a decrease of the rate constant (Figure 3B). In both cases the rate constant progressively decreased to an apparent end value of $0.2 \mathrm{~min}^{-1}$.

One of the explanations for this phenomenon could be the autocatalytical activation of factor $X$ by factor $X_{a}$. Indeed, it has been reported that bovine factor $X$ can be converted by factor $X_{a}$ into $\beta$-factor $X$, factor $X_{a}$ and/or $\beta$-factor $X_{a}(28$ 30).
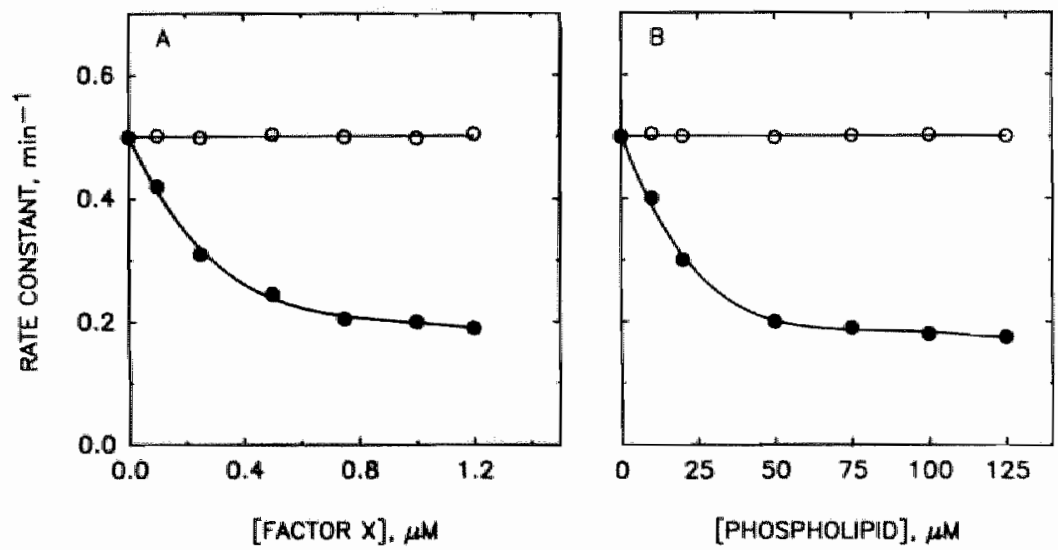

Figure 3: Effect of factor $X$ and phospholipid on the inactivation of factor $X_{\mathrm{a}}$ by $A T$ III. Panel $A$, factor $X_{\mathrm{a}}(10 \mathrm{nM})$ was incubated with $A T I I I(I \mu M)$ in the presence of varying amounts of factor $X, \mathrm{Ca}^{2+}(10 \mathrm{mM})$ and $100 \mu M$ phospholipid (•) or in the absence of phospholipid ( 0$)$. Panel $B$, the same incubation but in the presence of vaying amounts of phospholipid, $\mathrm{Ca}^{2+}(10 \mathrm{mM})$ and $1 \mu M$ factor $X(\bullet)$ or in the absence of factor $X(0)$. The pseudo first order rate constants of inactivation of factor Xa by AT III were determined as described under Materials and Methods. 
In the presence of phospholipid the major reaction product appeared to be $\beta$ factor $X(30)$. An exponentional increase in factor $X_{\text {a }}$ generation as a result of the autocatalytic activation of factor $\mathrm{X}$ by factor $\mathrm{X}_{\mathrm{a}}$ might explain the apparent lower pseudo first order rate constant of inactivation of factor $\mathrm{X}_{\mathrm{a}}$ in the presence of phospholipid-bound factor X. However, under none of our experimental conditions, an increase in amidolytic factor $\mathrm{X}_{\mathrm{a}}$ activity could be detected. In addition, sodium dodecylsulfate polyacrylamide gel electrophoresis of samples taken from a mixture containing $10 \mathrm{nM}$ factor $\mathrm{X}_{\mathrm{a}}, 200 \mu \mathrm{M}$ phospholipid, $10 \mathrm{mM}$ $\mathrm{Ca}^{2+}$ and $5 \mu \mathrm{M}$ of factor $\mathrm{X}$ revealed the formation of $\beta$-factor $\mathrm{X}$ at a very slow rate.

Under the same conditions but in the absence of phospholipid, no cleavage of factor $\mathrm{X}$ was observed over an 1-hour period.

In order to explore the effect of phospholipid-bound factor $\mathrm{X}$ in more detail, the following experiment was performed. Pseudo first order rate constants of inactivation of factor $X_{\mathrm{a}}(10 \mathrm{nM})$ by AT III $(1 \mu \mathrm{M})$ were determined in the presence of factor $\mathrm{X}(10 \mu \mathrm{M}), \mathrm{Ca}^{2+}(10 \mathrm{mM})$ and varying concentrations of

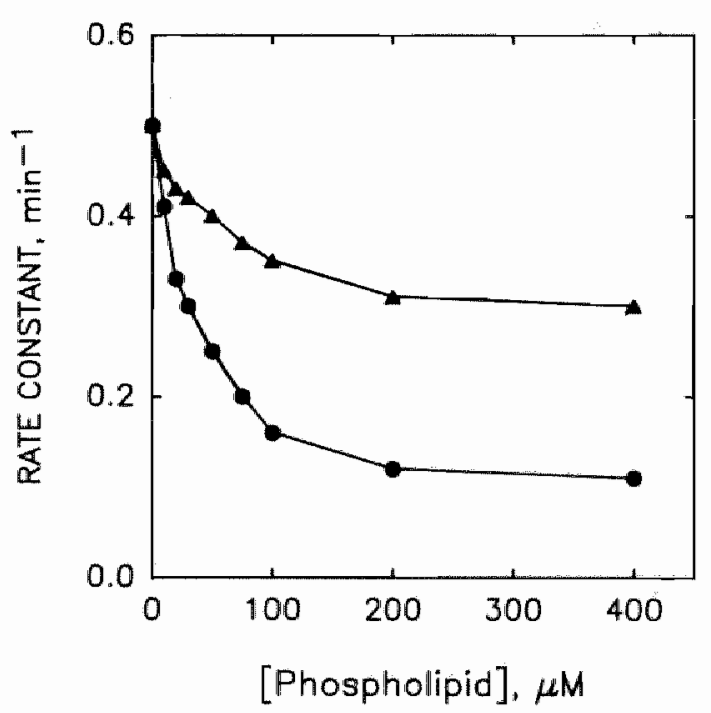

Figure 4: Effect of factor $X$ and phospholipids of different compositions on the inactivation of factor $X_{\mathrm{a}}$ by antithrombin III. Factor $X_{\mathrm{a}}(10 \mathrm{nM})$ was incubated with antithrombin $I I I(I \mu M)$ in the presence of factor $X(10 \mu \mathrm{M})$, calcium $(10 \mathrm{mM})$ and varying concentrations of phospholipid vesicles composed of 10 mol\% PS/90 mol\% $P C$ (^), or 25 mol\% PS/75 mol\% PC (•). 
phospholipid composed of $10 \mathrm{~mol} \%$ PS $/ 90 \mathrm{~mol} \%$ PC or $25 \mathrm{~mol} \%$ PS $/ 75 \mathrm{~mol} \%$ PC. The rate constants progressively decreased until apparent end levels of 0.1 $\mathrm{min}^{-1}$ and $0.3 \mathrm{~min}^{-1}$ in the presence of vesicles containing 25 mole \%PS or 10 mole \% PS, respectively (Figure 4). From reported factor X-phospholipid binding parameters $(31,32)$ it was calculated that at each phospholipid concentration used, virtually all available phospholipid binding sites were saturated with factor $X$ i.e. $12.3 \mu \mathrm{mol}$ of factor $X$ bound $/ \mathrm{mmol}$ of $25 \%$ PS - 75\% PC and $6.7 \mu \mathrm{mol}$ factor X bound/mmol of $10 \%$ PS - $90 \%$ PC. Thus, the fraction of factor $\mathrm{X}$ bound to phospholipid linearly increased with the phospholipid concentration. Although factor $\mathrm{X}$ and factor $\mathrm{X}_{\mathrm{a}}$ interact competitively with the same phospholipid binding sites, factor $\mathrm{X}$, by virtue of its affinity for phospholipid and factor $X_{\mathrm{a},}$, promotes the binding of factor $X_{a}$ at the surface. Hence, an apparent inhibition of the inactivation reaction might be a consequence of a decreased fluid phase factor $X_{a}$ concentration concomitant with an increase in the concentration of phospholipid-bound factor X.

Additional support for our notion that the factor $\mathrm{X}_{\mathrm{a}}$-factor $\mathrm{X}$ association rate at the surface might be the controlling element was obtained from an identical set of experiments but using a non-saturating factor $X$ concentration $(0.2 \mu \mathrm{M})$. The observed rate constant of the inactivation reaction went through a minimum of $0.4 \mathrm{~min}^{-1}$ at $60 \mu \mathrm{M}$ phospholipid (25\% PS - 75\% PC) and then increased with further increase in the concentration of the phospholipid until an almost non-inhibited value $\left(0.55 \mathrm{~min}^{-1}\right)$ at $400 \mu \mathrm{M}$ of phospholipid.

Effect of Unfractionated Heparin and Pentasaccharide on Factor $X_{a}$ and Factor $X_{a}$ Inactivation by Antithrombin III during Factor $X$ Activation- For the determination of the pseudo first order reaction rate constants of factor $\mathbf{I X}_{\mathrm{a}}$ and factor $X_{a}$ inactivation during factor $X$ activation by AT III $(200 \mathrm{nM})$ in the presence of UFH (0-120 $\mathrm{ng} / \mathrm{mL})$ or pentasaccharide $(0-12 \mathrm{ng} / \mathrm{mL})$, the same fit-procedure as already described was used. However, as the rabbit antifactor IX IgG neutralized the UFH, but not pentasaccharide, we modified the experimental set-up for the investigation of the effect of UFH. Instead of blocking the factor $\mathrm{IX}_{\mathrm{a}}$ activity by the addition of anti-factor IX IgG, only AT III was added and factor IX $\mathrm{X}_{\mathrm{a}}$ inactivation was determined separately as described under Materials and Methods. In order to obtain the decay constant of factor $\mathrm{X}_{\mathrm{a}}$ generated by factor $\mathrm{IX}_{\mathrm{a}}$, the Equations $\mathbb{1 - 4}$ were fitted to the experimental data with the parameters $V \mathrm{Xa}_{\mathrm{a}}$ and $k$ IXa set at values calculated from the direct measurements according to Equation 6 and to $\left[\mathrm{IX}_{\mathrm{a}}\right]_{\ell}=\left[\mathrm{IX}_{\mathrm{a}}\right]_{0} \exp \left(-k \mathrm{XXa}_{\mathrm{a}} t\right)$, respectively. Our mathematical model for analysis of the data depends on heparin-dependent factor $\mathrm{X}_{\mathrm{a}}$ and factor $\mathrm{IX}_{\mathrm{a}}$ inactivation being a pseudo first order reaction. This approach will only work if the protease concentrations remain far below saturation levels (1). Therefore, pseudo first order rate constants had to be determined as a function of the protease concentration under the same experimental conditions. To this end, factor IX $_{\mathrm{a}}$ at different concentrations ( 40 and $80 \mathrm{nM}$ ) was incubated with AT III (200 $\mathrm{nM})$ and heparin $(300 \mathrm{ng} / \mathrm{mL})$ in $50 \mathrm{mM}$ Tris-HCl (pH 7.9), $175 \mathrm{mM} \mathrm{NaCl}, 5$ 

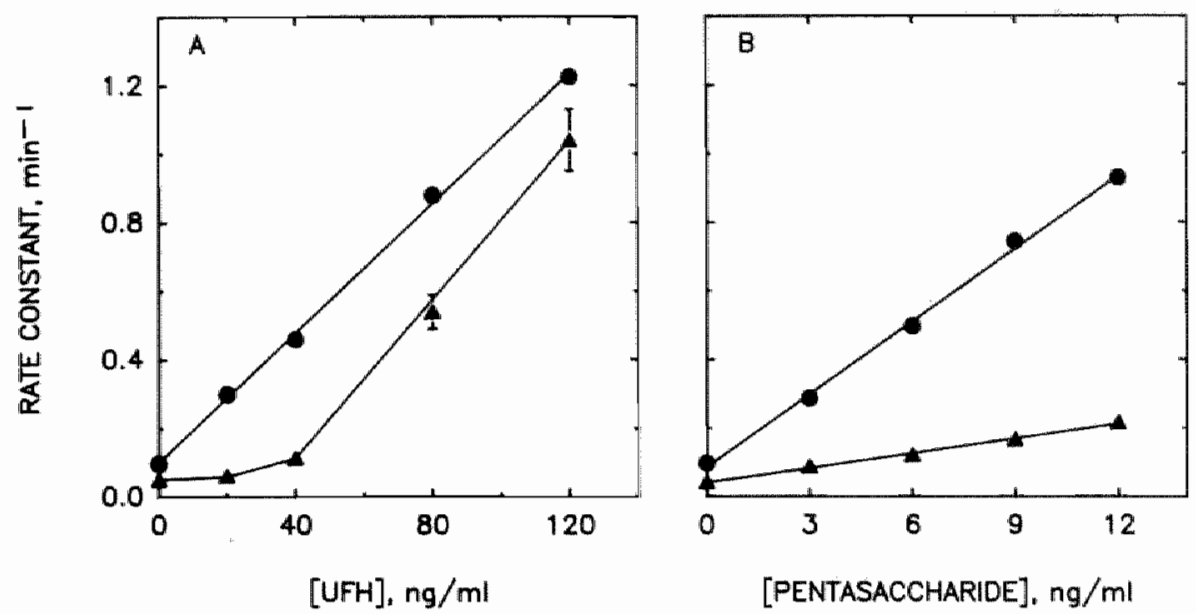

Figure 5: Pseudo first order rate constants of inactivation of factor $X_{\mathrm{a}}$ by AT III as a function of the UFH (panel $A$ ) and the pentasaccharide (panel B) concentration. (•), factor $X_{\mathrm{a}}(10 \mathrm{nM})$ plus $A$ T III $(200 \mathrm{nM})$ and $(\Delta)$, factor $X_{\mathrm{a}}$ during factor $X$ activation by [factor $I X_{\mathrm{a}}$-phospholipid-Ca ${ }^{2+}$ ] in the presence of $A T$ III (200 nM).

$\mathrm{mM} \mathrm{CaCl} 2$ and $0.5 \mathrm{mg}$ ovalbumin/mL. Linear first order rate plots were obtained for at least $70 \%$ of the reaction. Rate constants SE were calculated from a linear least-squares fit using 6 time points in triplicate to be $0.203 \pm 0.017 \mathrm{~min}^{-1}$ (40 $\mathrm{nM}$ factor $\mathrm{IX}_{\mathrm{a}}$ ) and $0.213 \pm 0.011 \mathrm{~min}^{-1}\left(80 \mathrm{nM}\right.$ factor $\left.\mathrm{IX}_{\mathrm{a}}\right)$. We concluded that the apparent pseudo first order rate constant of inhibition of factor IX $\mathbf{X}_{\mathbf{a}}$ under our conditions and within the range used, was independent of the factor $\mathrm{IX}_{\mathrm{a}}$ concentration. This finding also holds for the inactivation of factor $\mathrm{X}_{\mathrm{a}}$ by AT III $(200 \mathrm{nM})$ in the presence of heparin $(80 \mathrm{ng} / \mathrm{mL})$. The rate constants were 0.756 土 $0.033 \mathrm{~min}^{-1}\left(10 \mathrm{nM}\right.$ factor $\left.\mathrm{X}_{\mathrm{a}}\right)$ and $0.759 \pm 0.039 \mathrm{~min}^{-1}\left(20 \mathrm{nM}\right.$ factor $\left.\mathrm{X}_{\mathrm{a}}\right)$.

Figure 5 shows the effect of UFH and pentasaccharide on the inactivation of factor $\mathrm{X}_{\mathrm{a}}$ by AT III, both for free solution and for factor $\mathrm{X}_{\mathrm{a}}$ during factor $\mathrm{X}$ activation. The stimulating effect of UFH on the inactivation of purified factor $X_{a}$ by AT III (Figure 5A) was the same either in the presence or in the absence of phospholipids and/or calcium, with a rate constant of $0.012 \mathrm{~min}^{-1}(\mathrm{ng} / \mathrm{mL})^{-1}$. However, during factor $\mathrm{X}$ activation the inhibition of factor $\mathrm{X}_{\mathrm{a}}$ generated by factor $\mathrm{IX}_{\mathrm{a}}$ was markedly reduced at heparin concentrations up to $40 \mathrm{ng} / \mathrm{mL}$. At higher UFH concentrations the stimulating effect was the same as observed with purified factor $\mathrm{X}_{\mathrm{a}}$ in free solution. Because this phenomenon was also observed 


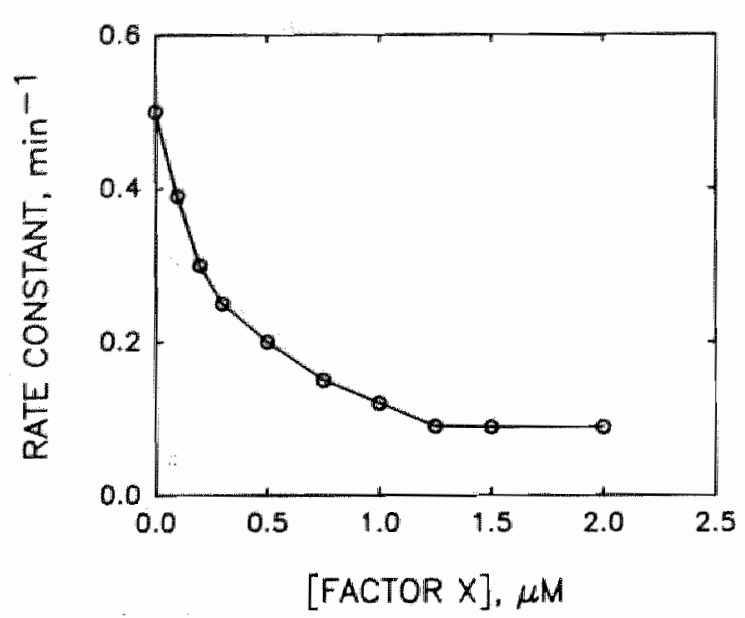

Figure 6: Pseudo first order rate constants of inactivation of factor $X_{\mathrm{a}}(10 \mathrm{nM})$ as a function of the factor $X$ concentration in the presence of $100 \mu \mathrm{M}$ phospholipid, $10 \mathrm{mM}$ calcium, $200 \mathrm{nM}$ antithrombin III and 40 $n g / m L U F H$.

in the presence of factor $X$ alone, it might indicate that factor $X$ and AT III compete with each other for UFH. Indeed, in Figure 6 it is shown that when increasing amounts of factor $X$ were added to a mixture containing factor $X_{a}(10 \mathrm{nM})$, AT III ( $200 \mathrm{nM})$ and $40 \mathrm{ng} / \mathrm{mL}$ UFH, the rate constant of the inactivation reaction progressively decreased with increasing factor $X$ until the value of the beparin-independent AT III-Xa reaction. The factor $X$ concentration that neutralized half the amount of available UFH was $0.2 \mu \mathrm{M}$.

The stimulating effect of pentasaccharide on the inactivation of factor $X_{a}$ by AT III was 5-fold lower during factor $\mathrm{X}$ activation as compared to factor $\mathrm{X}_{\mathrm{a}}$ inactivation in free solution (Figure 5B). The rate constants were $0.014 \mathrm{~min}^{-1}$ $(\mathrm{ng} / \mathrm{mL})^{-1}$ and $0.071 \mathrm{~min}^{-1}(\mathrm{ng} / \mathrm{mL})^{-1}$, respectively. Factor $\mathrm{X}$ alone did not have an effect on the pentasaccharide-dependent inactivation of factor $X_{\mathfrak{a} .}$. Thus, the lower rate constant during factor $X$ activation was again the result of the protective effect of phospholipid-bound factor $\mathrm{X}$ on the inactivation of factor $\mathrm{X}_{\mathrm{a}}$.

Pentasaccharide was unable to enhance the inactivation of factor $\mathbf{I X}_{a}$, either in the absence or presence of calcium, phospholipid and/or factor X. Figure 7 shows that UFH had a very small effect on the inactivation of factor $\mathbf{I X}_{\mathrm{a}}$ in free solution, $k=0.11 \mathrm{~min}^{-1}(\mu \mathrm{g} / \mathrm{mL})^{-1}$. However, during factor $\mathrm{X}$ activation a 6-fold higher rate constant of inactivation of factor $\mathrm{IX}_{\mathrm{a}}$ was found, a $k=0.68 \mathrm{~min}^{-1}$ $(\mu \mathrm{g} / \mathrm{mL})^{-1}$. In order to establish the cause of this discrepancy, we examined the 


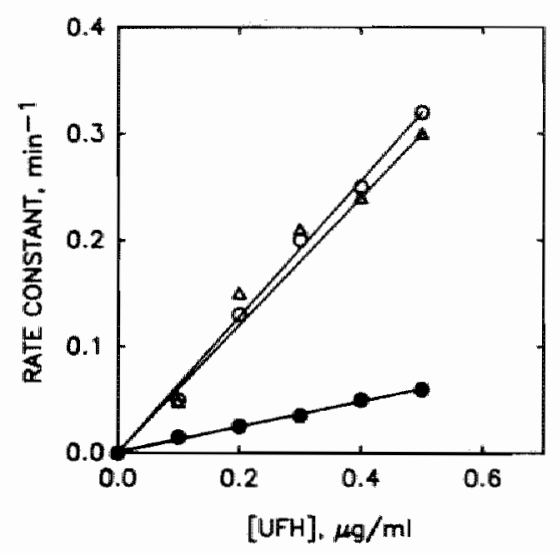

Figure 7: Pseudo first order rate constants of inactivation of factor $I X_{\mathrm{a}}(80 \mathrm{nM})$ by AT III (200 nM) as a function of the UFH concentration. ( $\bullet$ factor $L X_{\mathrm{a}}$ alone, $(0)$ factor $I X_{\mathrm{a}}$ during factor $X$ activation and $(\Delta)$ factor $I X_{\mathrm{a}}$ in the presence of calcium $(10 \mathrm{mM})$.

effect of UFH on factor $\mathrm{IX}_{\mathrm{a}}$ inactivation in the presence of the individual components present in the factor $\mathrm{X}$ activation mixture. From Figure 7 it is clear that the enhanced inactivation rate of factor $\mathrm{IX}_{\mathrm{a}}$ by antithrombin III and heparin is solely due to the presence of calcium.

\section{Discussion}

Several investigators have studied the inactivation of activated coagulation factors IX and X by AT III (10-13). However, the majority of these studies dealed with the effect of AT III on purified factor $\mathrm{IX}_{\mathrm{a}}$ and factor $\mathrm{X}_{\mathrm{a}}$ in free solution.

In the present paper, we describe a method for the determination of decay constants under more physiological conditions by modelling the inactivation of factor $\mathrm{IX}_{\mathrm{a}}$ and factor $\mathrm{X}_{\mathrm{a}}$ during factor $\mathrm{X}$ activation. The validity of this model was confirmed by the close resemblance between the data computed by the fitprocedure and the experimentally obtained data points (Figure 1). Furthermore, our experimental approach provided independent control of the velocity of fac- 
tor $X_{a}$ formation and rate of inactivation of generated factor $X_{\mathrm{a}}$. These values were in good agreement with the values as determined by the fit-procedure. The second order rate constant for factor $X_{a}$ inactivation by AT III thus obtained was $2.1 \times 10^{5} \mathrm{M}^{-1} \mathrm{~min}^{-1}$. Because of the much lower rate of inhibition of factor $\mathbb{I X}_{\mathrm{a}}$ under these conditions when compared with factor $X_{a}$, we were unable to calculate the rate constant of inhibition of factor IX $\mathrm{X}_{\mathrm{a}}$ by AT III. However, by making use of a factor IX assay and high AT III concentrations, we found that the reaction of factor $\mathrm{XX}_{\mathrm{a}}$ and AT III proceeded with a second order rate constant of 8.2 $\times 10^{3} \mathrm{M}^{-1} \mathrm{~min}^{-1}$, thus about 25 -fold slower when compared with the factor $\mathrm{X}_{\mathrm{a}} / \mathrm{AT}$ III reaction.

As several authors reported that human factor $X_{\mathrm{a}}(25)$ and bovine factor $\mathrm{X}_{\mathrm{a}}$ (26) are protected from inactivation by AT III in the presence of phospholipids, we compared the decay constant of factor $X_{a}$ determined during factor $X$ activation with the decay constant of free factor $X_{a}$. Indeed, we found that the second order rate constant of factor $X_{a}$ inactivation by AT III was $5.0 \times 10^{5} \mathrm{M}^{-1} \mathrm{~min}^{-1}$, compared to a second order rate constant of $2.1 \times 10^{5} \mathrm{M}^{-1} \mathrm{~min}^{-1}$ during factor $\mathrm{X}$ activation. However, in contrast to Ellis et al. (24) and Walker and Esmon (26), but in accordance with Marciniak (27) and Jesty (15), we did not observe that factor $X_{a}$ was protected from inhibition by phospholipids. Using previously reported binding data of the factor $X(a)$-phospholipid interaction $(31,32)$, it can be calculated that in the presence of $100 \mu \mathrm{M}$ of phospholipid $(25$ mole\% phosphatidylserine 75 mole\% phosphatidylcholine) $90 \%$ of total factor $X_{\mathrm{a}}(10 \mathrm{nM})$ is bound to the phospholipid surface and yet, the pseudo first order rate constant of inhibition of factor $X_{a}$ is the very same as that in the absence of phospholipid (Figures 2 and 3 ). Therefore, the presence of phospholipid do not explain the lower decay constant of factor $X_{a}$ during factor $X$ activation. Surprisingly, factor $X$ appeared to reduce the rate of the factor $X_{a} / A T$ III reaction. This phenomenon was only observed when both calcium and phospholipid were present. The similar effects of either increasing amounts of phospholipid at a fixed factor $X$ concentration or increasing factor $X$ at a fixed phospholipid concentration on the decay constant of factor $X_{a}$ strongly suggest that phospholipid-bound factor $X$ protected factor $X_{a}$ from inhibition (Figure 3 ).

In view of a factor $X_{a}$-catalyzed conversion of phospholipid-bound factor $X$ to $\beta$-factor $X(28-30)$ it seems reasonable to rationalize the observed inhibition of the inactivation reaction in terms of a competitive enzyme-substrate interaction. Thus, the rate constant of the $A T$ III-factor $X_{\text {a }}$ reaction will be attenuated by a factor of $1 /\left(1+[S] / K_{\mathrm{m}}\right)$ and should approach zero at saturating substrate levels (33). However, a substantial increase in surface-bound factor $\mathrm{X}$ did not result in a further decrease of the apparent rate constant when factor $\mathrm{X}_{\mathrm{a}}$ was quantitatively bound to the surface (Figure 4). Moreover, the level to which the inactivation reaction could be inhibited appeared to be a function of the phosphatidyl- 
serine content of the phospholipid vesicle. Because the binding capacity of vesicles increases with increasing phosphatidylserine content (31) it seems that the local factor $X$ concentration at the surface, rather than the bulk phospholipid-bound factor $X$ concentration, is the effective substrate concentration for the competitive reaction.

At present, an alternative mechanism, in which the active site of factor $X_{a}$ is not involved in the factor $X_{a}$-factor $X$ interaction at the surface, can not be rulled out. That is, the decrease in the rate of inactivation of factor $\mathbf{X}_{\mathbf{a}}$ could also reflect a reduced reactivity of factor $X_{a}$ in the ternary complex of factor $X$-phospholipid-factor $\mathrm{X}_{\mathrm{a}}$ towards AT III.

The inactivation of factor $\mathrm{IX}_{\mathrm{a}}$ was not affected by the accessory components (phospholipid, calcium) and factor X. Regardless of the presence of factor $\mathrm{X}$, phospholipids and/or calcium, the second order rate constant for factor $\mathbf{I X}_{\mathrm{a}}$ inactivation by AT III was $8.2 \times 10^{3} \mathrm{M}^{-1} \mathrm{~min}^{-1}$. In view of the protection of factor $\mathrm{X}_{\mathrm{a}}$ by phospholipid-bound factor $X$, it is quite striking that the interaction between factor $\mathrm{IX}_{\mathrm{a}}$ and factor $\mathrm{X}$ at the surface does not compete with the AT III-factor IX $_{\mathrm{a}}$ reaction. However, because the phospholipid-factor $\mathrm{IX}_{\mathrm{a}}$ interaction would be one of the affecting elements, it is interesting to note that the binding constant of this interaction is substantially larger than the one reported for the factor

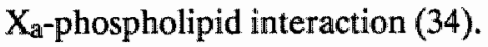

We next examined the effects of two types of heparin, unfractionated heparin (UFH) and synthetic pentasaccharide heparin, on the inhibition of factor LXa $_{\mathbf{a}}$ and factor $\mathrm{X}_{\mathrm{a}}$ during factor $\mathrm{X}$ activation. Pentasaccharide was included in our study because of reported effects of the non-AT III binding region of heparin molecules on factor $\mathrm{X}_{\mathrm{a}}(25)$ and factor $\mathrm{IX}_{\mathrm{a}}$ inhibition (13). Comparing the inhibition of factor $X_{a}$ during factor $X$ activation in the presence of UFH and pentasaccharide, it is evident that a polysaccharide sequence in addition to the AT III binding sequence alters the kinetics of factor $X_{a}$ inhibition in such a way that it diminishes the protection of factor $\mathbf{X}_{\mathrm{a}}$ by phospholipid-bound factor $\mathbf{X}$. It is feasible that the competitive interaction between factor $X_{\mathrm{a}}$ and phospholipid-bound factor $\mathrm{X}$ is counterbalanced more strongly by the interaction between factor $\mathbf{X}_{\mathrm{a}}$ and UFH-AT III because of the higher affinity of factor $\mathrm{X}_{\mathrm{a}}$ for UFH-AT III than for pentasaccharide-AT III.

Pentasaccharide could not enhance the inhibition of factor IX $\mathrm{X}_{\mathfrak{a}}$ by AT III. Apparently, factor $\mathrm{IX}_{\mathrm{a}}$ binding regions on the heparin molecule are absolutely required for its catalytic function. The decay constant of factor $\mathbf{I X} \mathbf{X}_{\mathbf{a}}$ increased linear with the concentration of UFH, $k=0.65 \mathrm{~min}^{-1} \mathrm{per} \mu \mathrm{g}$ UFH $/ \mathrm{mL}$. To our surprise, the stimulatory effect of UFH on the inactivation of factor IX was about 6-fold higher during factor $\mathrm{X}$ activation as in free solution. It appeared that this stimu- 
lation was due to the presence of calcium (Figure 7). The same phenomenon has been reported for human factor $X_{a}(25)$. Calcium, because of its ability to induce structural changes in factor $\mathrm{IX}_{\mathrm{a}}(35,36)$ may affect the heparin-catalyzed reaction either by enhancing ternary complex formation or by increasing the intrinsic rate constant of the AT III-factor $\mathrm{IX}_{\mathrm{a}}$ reaction at the heparin surface.

Acknowledgment. We wish to thank Dr. Hans Soons for valuable discussions.

\section{References}

1. Griffith MJ:in Zwaal RFA, Hemker HC (eds): Blood Coagulation. Elsevier, Amsterdam. 1986, pp 239- 283

2. Jordan RE, Oosta GM, Garder WT, Rosenberg RD: The kinetics of bemostatic enzyme-antithrombin III interactions in the presence of low molecular weight heparin. J Biol Chem 255:10081, 1980

3. Lindhout $T$, Baruch D, Schoen $P$, Franssen J, Hemker HC: Thrombin generation and inactivation in the presence of antithrombin III and heparin. Biochemistry 25:5962, 1986

4. Holmer $\mathrm{E}$, Kurachi $\mathrm{K}$, Soderstrom $\mathrm{G}$ : The mollecular weight dependence of heparin on the rate-enhancing effect of heparin on the inhibition of thrombin, factor $\mathrm{X}_{\mathbf{a}}$, factor $\mathrm{IX}_{\mathrm{a}}$, factor $\mathrm{XI}_{\mathrm{a}}$ factor $\mathrm{XII}_{\mathrm{a}}$ and kallikrein by antithrombin III. Biochem $\mathrm{J}$ 193:395, 1981

5. Gitel SN, Stephenson RC, Wessler S: In vitro and in vivo correlation of clotting protease activity: Effect of heparin. Proc Natl Acad Sci USA 74:3028, 1977

6. McNeely TB, Griffith MJ: The anticoagulant mechanism of action of heparin in contact-activated plasma: Inbibition of factor X activation. Blood 65:1226, 1985

7. Foster WB, Nesheim ME, Mann KG: The factor $X_{\mathbf{a}}$-catalyzed activation of factor $\mathrm{V} . \mathrm{J}$ Biol Chem 258:13970, 1983

8. Mertens $\mathrm{K}$, Bertina RM: Activation of human coagulation factor VIII by activated factor $\mathrm{X}$, the common product of the intrinsic and the extrinsic pathway of blood coagulation Thromb Haemostas 47:96, 1982

9. Rao LVM, Rapaport SI, Bajaj SP: Activation of human factor VII in the initiation of tissue factor-dependent coagulation. Blood 68:685, 1986

10. Osterud $\mathrm{B}_{4}$ Miller-Andersson $\mathrm{M}$, Abildgaard U, Prydz $\mathrm{H}$ : The effect of antithrombin III on the activity of the coagulation factors VII, IX and X. Thromb Haemostas 35:295, 1976

11. Jesty $\mathrm{J}$ : The intibition of activated bovine coagulation factors $\mathrm{X}$ and VII by antithrombin III. Arch Eiochem Biophys 185;165, 1978

12. Jesty J: Dissociation of complexes and their derivatives formed during inhibition of bovine thrombin and activated factor X by antithrombin III. J Biol Chem 254:1044, 1979

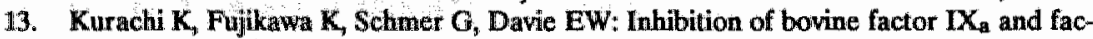
tor $X_{\text {a }}$ by antithrombin III. Biochemistry 15:373, 1976

14. Jesty J, Morrison SA, Harpel PC. Measurement of human activated factor $\mathrm{X}_{\mathrm{antithrom}}$ bin III complex by an onzyme-linked differential-antibody immunosorbent assay. Anal Biochem 139:158 1984

15. Jesty $J$ : analysis of the generation and inhibition of activated coagulation factor $\mathbf{X}$ in pure systems and in human plasma. J Biol Chem 261:8695, 1986 
16. Thaler $\mathrm{E}_{\mathrm{x}} \mathrm{Schmer} \mathrm{G}$ : A simple two-step isolation procedure for human and bowine antithrombin II/antithrombin III (heparin cofactor): a comparision of two methods. Br J Haematol 31:233, 1975

17. Miller-Andersson $M_{w}$ Borg $H_{*}$, Andersson L-O: Purification of antithrombin III by af finity chromatography. Thromb Res 5:439, 1974

18. Van Dieijen $G_{3}$, Tans $G$, Rosing $J$, Hemker $H_{C}$ : Role of phospholipid and factor $V_{I I}$ in the activation of bovine factor X. J Biol Chem 256:3433, 1981

19. Rosing $J_{n}$ van Rijn JLML, wan Dieijen $G$, Comfurius $P$, Zwaal RFA: The role of actiwated human platelets in prothrombin and factor X activation. Blood 65:319, 1980

20. Lindhout $T$, Govers-Riemslag JWP, wan de Waart P, Hemker HC Rosing J: Factor $V_{a-}$ factor $\mathrm{X}_{\mathrm{a}}$ interaction. Effects of phospholipid vesicles of varying composition. Biochemistry $21: 5494,1982$

21. Soons H, Janssen-Claessen T, Hemker HC, Tans G: The effect of platelets in the actiwation of human blood coagulation factior IX by factor XIa. Blood 68:140, 1986

22. Gill PE, Murray W:Siam J Num Anal 15:977, 1978

23. Ellis $V$, Scully $M$, Kakkar V: The effect of divalent metal cations on the inhuibition of human coagulation factor $X_{\mathrm{a}}$ by plasma proteinase inhibitors. Biochim Biophys Acta $747: 123,1983$

24. Ellis V, Scully MF, Kakkar V: Inhibition of prothrombinase complex by plasma proteinase inhibitors. Biochemistry 23:5882, 1984

25. Barrowcliffe TW, Havercroft SI, Kemball-Cook G, Lindahl U: The effect of $\mathrm{Ca}^{+{ }^{+}}$, phospholipid and factor $V$ on the anti-(factor $\left.X_{a}\right)$ activity of heparin and its high-affinity oligosaccharides. Biochem J 243:31

26. Walker FJ, Esmon CT: The effects of phospholipids and factor Va on the inhibition of factor $X_{a}$ by antithrombin III. Biochem Biophys. Res Comm 90:641, 1979

27. Marciniak $E$ : Factor $X_{a}$ inactivation by antithrombin III: evidence for biological stabilization of factor $X_{a}$ by factor $V$-phospholipid complex. Br $\mathbb{J}$ Haematol 24:391, 1973

28. Jesty $\mathbf{J}$, Spencer AK, Nemerson Y: The mechanism of activation of factor X. Kinetic control of alternative pathways leading to the formation of activated factor $\mathrm{X}$. J Biol Chem 249:5614, 1974

29. Jesty J, Spencer AK, Nakashima $Y$, Nemerson $Y$, Konigsberg W: The activation of coagulation factor $X$. Identity of cleavage sites in the alternative activation pathways and characterization of the COOK-terminal peptide. J Biol Chem 250:4497, 1975

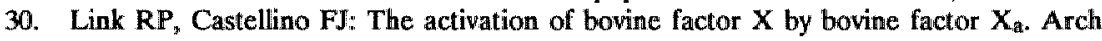
Biochem Biophys 215:215, 1982

31. Nelsestue GL, Broderius M: Interaction of prothrombin and blood-clotting factor $X$ with membranes of varying composition. Büochemistry 16:4172, 1977

32. van de Waart $\mathbf{P}$, Bruls $\mathbf{H}$, Hemker HC, Lindhout T: Interaction of bovine blood clotting factor $V_{\mathrm{a}}$ and its subunits with phospholipid vesiclles. Biochemistry 22:2427, 1983

33. Griffith MJ: Measurement of the heparin enhanced antithrombin III thrombin reaction rate in the presence of synthetic substrate. Thromb Res $25: 245,1982$

34. Beals JM, Castellino FJ: The interaction of bovine factor IX, its activation intermediate, factor IX, and its activation products, factor $\mathrm{IX}_{\mathrm{a}}$ nd factor $\mathbb{I X} \mathrm{X}_{\mathrm{a}}$, with acidlic phospholipid vesicles of various compositions. Biochem $\mathrm{J} 2368811,1986$

35. Chuang TF, Sargeant $R B$, Hougie $C$ : The effect of calcium ions on the properties of factor IX and its activated form. Br J Haematol 27:281, 1974

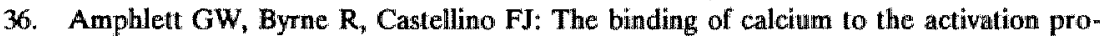
ducts of bovine factor IX. J Biol Chem 254:6333, 1979 


\title{
Chapter IV
}

\section{The Limited Importance of Factor $\mathbf{X}_{\mathbf{a}}$ Inhibition to the Anticoagulant Property of Heparin in Thromboplastin-Activated Plasma ${ }^{0}$}

\begin{abstract}
The anti-factor $\mathrm{X}_{\mathrm{a}}$ activities of heparin fractions are widely used as an ex vivo index of their antithrombotic efficacy. Its clinical meaning, however, remains speculative. In this study we measured the effects of standard heparin, a synthetic pentasaccharide heparin (anti-factor $\mathrm{X}_{\mathrm{a}}$ activity only), and a low molecular weight heparin (LMWH) on factor $X_{a}$, factor $V_{a}$ and thrombin generation in thromboplastin-activated plasma. We clearly demonstrated that the anti-factor $X_{a}$ activity of heparin contributed little to its anticoagulant activity. The inhibition of factor $\mathrm{V}_{\mathrm{a}}$ generation, dependent of the heparin anti-thrombin activity only, is of prime importance to the inhibition of thrombin generation in plasma. The inhibition of thrombin generation by LMWH was comparable with that of standard heparin on basis of their respective anti-thrombin specific activities but not on basis of their anti-factor $\mathrm{X}_{\mathrm{a}}$ activities.
\end{abstract}

- Based on: Pieters J, Lindhout T: Blood, in press 


\section{Introduction}

Until now, the antithrombotic activity of heparin is very poorly correlated with any laboratory parameter. Especially the recently developed low molecular weight heparins have made this problem quite clear. To reduce the bleeding risk associated with classical unfractionated heparin, a lot of clinical trials have been necessary to find an acceptable dosage scheme that optimizes the antithrombotic properties of heparin and minimizes its bleeding risk. For the recently developed low molecular weight heparins (LMWH) the approach was not to perform so many clinical trials until the right dosage was found, but rather to use laboratory tests to compare the new heparin types with the classical heparins. However, the main problem that arose with this approach was that it was not very clear what laboratory properties of heparin indicated its antithrombotic or hemorrhagic activities. Thus, the search for the proper laboratory correlate to in vivo antithrombotic action has become a central theme in heparin research.

Experiments in animal models suggested that these low molecular weight heparins might be as good an antithrombotic agent as unfractionated heparin, while at the same time reducing the bleeding risk (1-4). Then, one started to look for a property that was different in both types of heparin, and which was found in the relative anti-factor $X_{a}$ potency. Low molecular weight heparins namely, which have a molecular weight between 4,000 and 9,000 daltons, loose their anti-thrombin action but retain their anti-factor $X_{a}$ activity (5). It was therefore thought that the anti-factor $X_{a}$ activity correlated with the antithrombotic properties, and the anti-thrombin action of heparin with its bleeding risk (6-8). Consequently, the anti-factor $\mathrm{X}_{\mathrm{a}}$ specific activity became the in vitro index of the in vivo antithrombotic properties of heparin.

However, it is becoming increasingly apparent that the anti- $\mathrm{X}_{\mathrm{a}}$ activity of heparin is not closely correlated with its clinical antithrombotic potency (9). Buchanan et al (10) reported that better antithrombotic effects were achieved by heparin or heparinoid capable of influencing the inactivation and/or the generation of thrombin. Hemker et al (11) developed a method which allowed the determination of the prothrombinase activity in the absence and presence of heparin, and they thus found that inhibition of thrombin is of major importance for the anticoagulant activity of heparin in plasma. The low molecular weight heparins they studied using this approach, could be divided into two classes: heparins that only inhibited thrombin (S-type heparins, after the similarity of these heparins with standard heparin), and heparins that do not act on thrombin but do inhibit prothrombinase $(11,12)$. 
In the present study, we studied the effect of heparin in a situation very close to the physiological one, namely in plasma that is activated with thromboplastin. To this end, we first had to develop very sensitive assays that were able to measure picomolar amounts of activated coagulation factors. The measurement of these activated factors directly with the available chromogenic substrates is not possible in plasma, because of the interference of various other plasma proteins, e.g. thrombin, antithrombin III, etc.. Therefore, we made use of the ability of factor $\mathrm{X}_{\mathrm{a}}$ to activate (bovine) prothrombin in the presence of (bovine) factor $V_{a}$, phospholipids and calcium ions. In a similar way the plasma factor $V_{a}$ concentration was determined, namely by the ability of factor $V_{a}$ to accelerate prothrombin activation by factor $\mathrm{X}_{\mathrm{a}}$, phospholipids and calcium ions. In that way, we could very specifically determine the concentrations of factor $X_{a}$ and factor $V_{a}$. Because of the large amounts that are usually generated, thrombin activity could be measured straightforward using a chromogenic substrate.

Using these assays, we investigated the effect of heparin and heparin analogues on the generation of thrombin, factor $\mathrm{X}_{\mathrm{a}}$ and factor $\mathrm{V}_{\mathrm{a}}$ in thromboplastinactivated plasma. For these studies we made use of three different heparin preparations; first of all we used the 4th international standard heparin, which possesses both high anti-thrombin and anti-factor $X_{a}$ activity, second we made use of the synthetic pentasaccharide which possesses only anti-factor $X_{a}$ activity, and as a third heparin preparation we used the low molecular weight heparin CY 216 which exerts a high anti-factor $\mathrm{X}_{\mathrm{a}}$ activity and a low anti-thrombin activity. Our results indicate that factor $V_{a}$ generation is the rate limiting step in the formation of the prothrombin converting complex, that consists of factor $\mathbf{X}_{\mathbf{a}}$, factor $\mathrm{V}_{\mathrm{a}}$ and phospholipid. We hypothesized that the effect of heparin on thrombin generation is related mainly to its ability to influence factor $V_{a}$ formation and thus to its anti-thrombin activity rather than to its anti-factor $\mathrm{X}_{\mathrm{a}}$ activity.

\section{Materials and Methods}

Materials- The synthetic peptide substrates Bz-Ile-Glu-(Piperidyl)-Gly-Arg-pnitro-anilide hydrochloride (S-2337) and H-D-Phenylalanyl-L-pipecolyl-L-arginine-p-nitro-anilide dihydrochloride ( $\mathrm{S}-2238$ ) were purchased from AB Kabi Diagnostica, Stockholm. Fatty acid-free ovalbumin was a product of Sigma Chemical Co., St. Louis. All reagents used were of the highest grade commercially available.

The 4th International Standard for Heparin (195 U/mg) was supplied by the National Institute for Biological Standards and Control (NIBSC). A synthetic pentasaccharide heparin (manufacturers specific activity of $0 \mathrm{USP} U / \mathrm{mg}$ and 
4,000 anti-factor $\mathrm{X}_{\mathrm{a} \mathrm{U}} \mathrm{U} / \mathrm{mg}$ ) and a low molecular weight heparin CY 216 (manufacturers specific activity of 10-20 anti-thrombin $\mathrm{U} / \mathrm{mg}$ and 200 anti-factor $\mathrm{X}_{\mathrm{a}}$ $\mathrm{U} / \mathrm{mg}$ ) were a kind gift from Choay Institute (Paris).

Human brain thromboplastin was prepared by the method of Owren and Aas (13). It was homogenated in a Potter Elvehjem homogenizer for 3 minutes, centrifugated at $2,000 \times \mathrm{g}$ for 15 minutes and stored at $-80^{\circ} \mathrm{C}$. Its concentration was adjusted with Tris-saline to give a prothrombin time of $13 \mathrm{~s}$.

Proteins- All bovine clotting factors were prepared and quantitated as previously described (14-16).

Phospholipid Vesicles- Phospholipid vesicles were made from a mixture of phosphatidylserine (PS) and phosphatidylcholine (PC) as previously described (16). Vesicles composed of 25 mole\% PS and 75 mole\% PC were used throughout the experiments.

Preparation of Human Normal Plasma- Blood from healthy donors was collected on $0.13 \mathrm{M}$ trisodium citrate; nine parts blood to one part of citrate solution. The blood was then centrifugated twice at room temperature for 15 minutes at $3,000 \mathrm{xg}$. A third centrifugation was done at $4^{\circ} \mathrm{C}$ for one our at $23,000 \mathrm{xg}$. The obtained platelet free plasma was stored at $-80^{\circ} \mathrm{C}$.

Thromboplastin-Induced Factor $X_{a}$, Factor $V_{a}$ and Thrombin Generation in Platelet Free Plasma- To $0.13 \mathrm{~mL}$ of citrated human plasma, $9 \mu \mathrm{L}$ of a Tris-buffer ( 50 $\mathrm{mM}$ Tris, $180 \mathrm{mM} \mathrm{NaCl}, 0.5 \mathrm{mg}$ ovalbumin/mL, $\mathrm{pH} 7.9$ ) with or without heparin(fraction) was added and incubated for $4 \mathrm{~min}$ in a flat-bottom plastic tube while stirring. Clotting was initiated by the addition of $11 \mu \mathrm{L}$ of the Tris-buffer containing $0.27 \mathrm{~mol} / \mathrm{L} \mathrm{CaCl} 2$ and human brain thromboplastin. Timed samples $(10 \mu \mathrm{L})$ were removed from incubations and assayed for either factor $\mathrm{V}_{\mathrm{a}}$, factor $\mathrm{X}_{\mathrm{a}}$ or thrombin activity.

Factor $V_{a}$ Assay- Factor $V_{a}$ was assayed in plasma samples, diluted 1:200 in Tris-buffer containing $5 \mathrm{mM} \mathrm{CaCl}$ and $0.5 \mu \mathrm{g} \mathrm{UFH} / \mathrm{mL}$. Ten $\mu \mathrm{L}$ of the diluted sample was added to a cuvette containing $13 \mathrm{pmol} / \mathrm{L}$ factor $\mathrm{X}_{\mathrm{a}}, 5 \mathrm{mM} \mathrm{CaCl} 2$ and $0.05 \mathrm{mM}$ phospholipid $(25 \mathrm{~mol} \%$ phosphatidylserine and $75 \mathrm{~mol} \%$ phosphatidylcholine) in Tris-buffer. After 4 min thrombin generation was initiated by the addition of prothrombin $(0.2 \mu \mathrm{M}$ final concentration in $125 \mu \mathrm{L})$. The reaction was stopped after $2 \mathrm{~min}$ by the addition of $325 \mu \mathrm{L}$ Tris-buffer containing $20 \mathrm{mM}$ EDTA. The amount of thrombin was measured in a dual-wavelength spectrophotometer using S-2238 as described previously (15). 
Factor $X_{a}$ Assay- Factor $X_{\mathrm{a}}$ was assayed in plasma samples diluted 1:200 in Tris-buffer. Ten $\mu \mathrm{L}$ of the diluted sample was added to a cuvette containing 0.6 nmol/L factor $\mathrm{V}_{\mathrm{a}}, 0.05 \mathrm{mM}$ phospholipid and $5 \mathrm{mM} \mathrm{CaCl} 2$ in Tris-buffer. After 4 min prothrombin $(1.5 \mu \mathrm{M}$ final concentration in $50 \mu \mathrm{L})$ was added and the assay was proceeded as described for factor $V_{a}$.

Thrombin Assay- Undiluted plasma samples $(5 \mu \mathrm{L})$ were added to a cuvette containing $495 \mu \mathrm{L}$ Tris-buffer, $20 \mathrm{mM}$ EDTA and $0.25 \mathrm{mM} \mathrm{S-2238.} \mathrm{The} \mathrm{throm-}$ bin activity was calculated from the change in absorbance as described previously (17).

\section{Results}

Measurement of Activated Coagulation Factors in Plasma- In order to be able to measure very specific the generation of factor $X_{a}$ and factor $V_{a}$ in plasma, we developed extremely sensitive assays. These determinations are based on the activity of these factors on their natural substrates.

Plasma factor $\mathrm{X}_{\mathrm{a}}$ was assayed by its ability to activate (bovine) prothrombin in the presence of calcium, phospholipids and (bovine) factor $V_{a}$; the sample taken from activated plasma was diluted a thousand-fold into the factor $X_{a}$ assay mixture, and the assay was performed as described under Materials and Methods. Figure $1 \mathrm{~A}$ shows a calibration curve made with a human factor $\mathrm{X}_{\mathrm{a}}$ preparation of a known concentration. Factor $X_{a}$ concentrations down to $0.1 \mathrm{pM}$ could be detected, corresponding to an amount of $0.1 \mathrm{nM}$ in plasma. Thrombin was determined by diluting the plasma directly a hundred-fold in EDTA-buffer containing the chromogenic substrate for thrombin.

The determination of activated factor $\mathrm{V}$ proceeded in a similar way. We made use of the ability of human factor $\mathrm{V}_{\mathrm{a}}$ to accelerate prothrombin activation by factor $X_{a}$, phospholipid and calcium tremendously. An over thousand-fold diluted plasma sample was added to the factor $\mathrm{V}_{\mathrm{a}}$ assay mixture, and the factor $\mathrm{V}_{\mathrm{a}}$ present in the sample was measured via the prothrombin activation (see Materials and Methods). Factor V did not show any activity in this assay. However, one problem aroused with this factor $V_{a}$ determination, which was the carry-over of factor $X_{a}$ in this assay. This factor $X_{a}$ present in the diluted sample, also accelerated the prothrombin activation. By adding heparin to the first dilution buffer in a concentration of $0.5 \mu \mathrm{g} / \mathrm{mL}$, the present antithrombin III inactivated this factor $\mathrm{X}_{\mathrm{a}}$ within 15 minutes. 

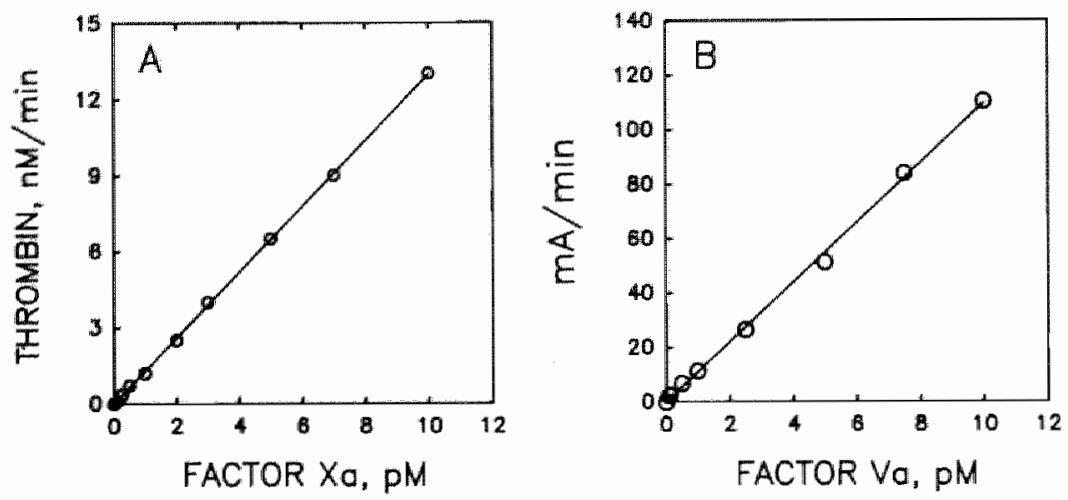

Figure 1. Calibration curve for the factor $X_{\mathrm{a}}$ and factor $V_{\mathrm{a}}$ assays. The rate of (bovine) prothrombin activation was determined in the presence of $A$ : Phospholipid, calcium and (bovine) factor $V_{a}$ and B: Phospholipid, calcium and (bovine) factor $X_{\mathrm{a}}$.

Figure 1B shows the calibration curve made with known amounts of (bovine) factor $V_{a}$ (control experiments revealed that bovine and human factor $X_{a}$ were comparable with respect to their activity in the prothrombinase complex).

Generation of Activated Coagulation Factors in Thromboplastin-Activated Human Plasma- To study the activation of prothrombin, factor $\mathrm{X}_{\mathrm{a}}$ and factor $\mathrm{V}_{\mathrm{a}}$ generation in normal human plasma, citrated human plasma was activated as described under Materials and Methods, using a thromboplastin concentration of $1 / 30(\mathrm{vol} / \mathrm{vol})$. With such a high thromboplastin concentration, the activation of factor $\mathrm{X}_{\mathrm{a}}$ generation in normal plasma is similar to factor $\mathrm{X}_{\mathrm{a}}$ generation in factor IX deficient plasma, indicating that in this case intrinsic factor $X$ activation is not relevant (data not shown).

Figure 2A shows the obtained thrombin generation curve. After a very short lag-phase, explosive thrombin formation is followed by a very rapid decay of the formed thrombin. A maximum of about $350 \mathrm{nM}$ of thrombin was formed. The inactivation, which occurs after the peak at 1 minute, is mainly due to the action of antithrombin III and $\alpha 2$-macroglobulin (19). The complex of thrombin and $\alpha_{2}-$ macroglobulin still has amidolytic activity towards the chromogenic substrate S2238 , thus resulting in an apparent end level of thrombin activity (11). 


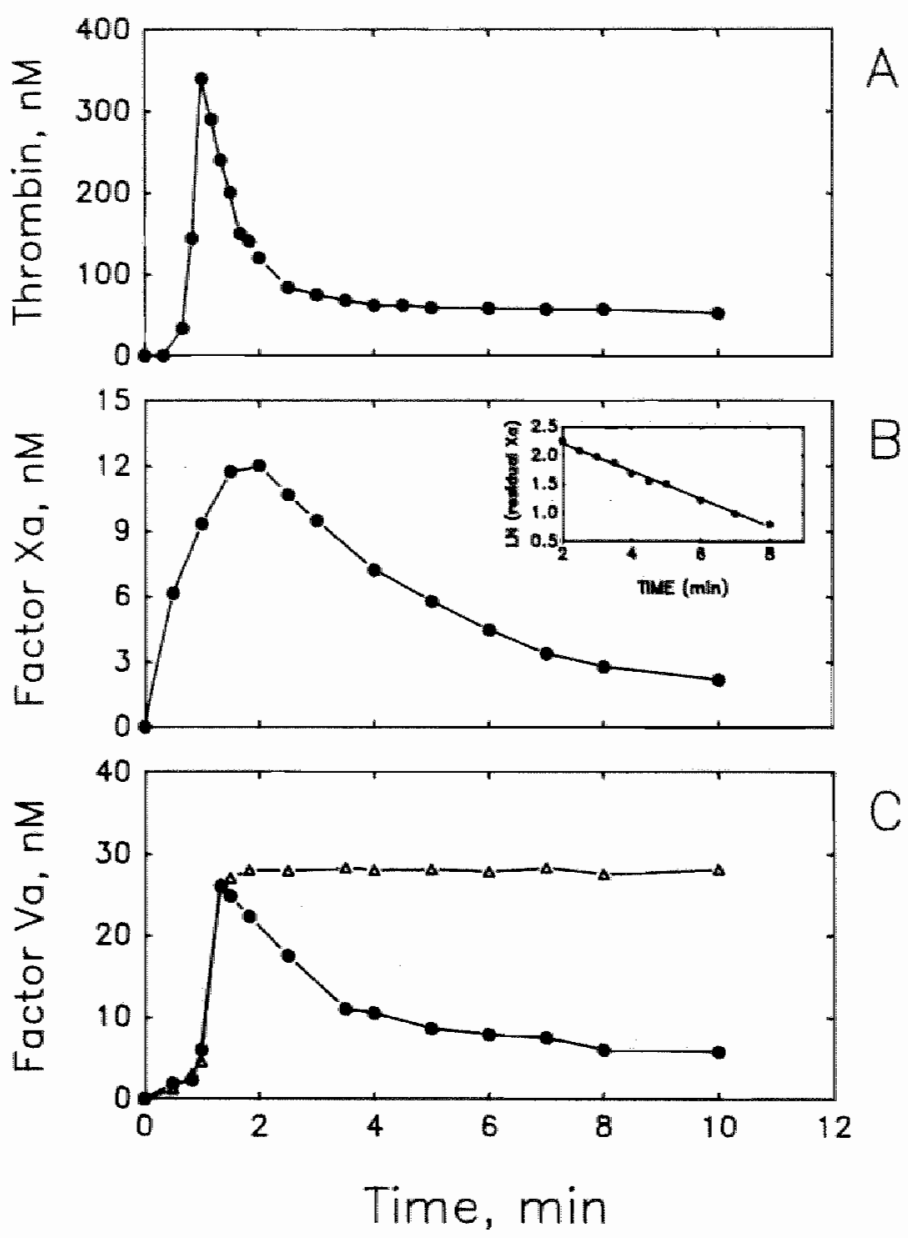

Figure 2. Generation of activated coagulation factors in plasma. Plasma was activated with 1/30 (vol//vol.) thromboplastin and the generation of thrombin (panel A), factor $X_{\mathrm{a}}\left(\right.$ panel $B$ ) and factor $V_{\mathrm{a}}($ panel $C$ ) was determined. Panel B, inset: semilogarithmic plot of the decay part of the factor $X_{\mathrm{a}}$ generation curve in the absence of heparin. Panel $C$ : the generation of factor $V_{\mathrm{a}}$ in protein $C$ depleted plasma is also shown $(\Delta)$.

In Figure $2 \mathrm{~B}$ the factor $\mathrm{X}_{\mathrm{a}}$ generation curve is depicted. No lag phase is present, and the maximal amount of factor $\mathrm{X}_{\mathrm{a}}$ generated is $12 \mathrm{nM}$. This is only about $10 \%$ of the total amount of factor X present in plasma. Surprisingly, as is depicted in the inset, the decay phase, which starts after 2 minutes, can be modelled according to pseudo-first order reaction rate kinetics. This means that after 2 
minutes, no factor $\mathrm{X}$ is further activated, and only factor $\mathrm{X}_{\mathrm{a}}$ inactivation is observed. The calculated pseudo first order rate constant of inhibition of in situ formed factor $X_{\mathrm{a}}$ thus, $0.30 \mathrm{~min}^{-1}$, is in accordance with the value reported by Jesty (18). The fact that factor $X$ activation stops after 2 minutes, might be caused by the extrinsic pathway inhibitor (EPI) in combination with factor $\mathrm{X}_{\mathrm{a}}$ recently described by Rao et al (19, see also scheme $\mathbf{I})$. Indeed, addition of an extra 1/30 ( vol/ $/ \mathrm{vol})$ amount of thromboplastin resulted in a similar factor $\mathrm{X}_{\mathrm{a}}$ generation as depicted in figure $2 \mathrm{~B}$ (results not shown).

The factor $\mathrm{V}$ activation is shown in Figure $2 \mathrm{C}$ by the closed circles. As for thrombin generation, also here a short lag phase is observed, followed by explosive factor $V_{a}$ generation, and a rapid decay. The inhibition of factor $V_{a}$ appeared to be due to activated protein $\mathrm{C}$, as in protein $\mathrm{C}$ deficient plasma (a kind gift of Dr. Bertina), no inactivation of the generated factor $V_{a}$ was observed. Also the addition of EDTA immediately stopped the factor $\mathrm{V}_{\mathrm{a}}$ inactivation reaction. Factor $\mathrm{V}_{\mathrm{a}}$ generation in protein $\mathrm{C}$ depleted plasma is shown in Figure $2 \mathrm{C}$ by the open triangles.

Effect of Standard Heparin on the Generation of Activated Coagulation Factors in Plasma-To asses the effect of standard heparin on the generation of activated coagulation factors in plasma, we added standard heparin in several concentrations to the plasma. The plasma was subsequently activated with $1 / 30(\mathrm{vol} / \mathrm{vol})$ thromboplastin and the generation of thrombin, factor $\mathrm{X}_{\mathrm{a}}$ and factor $\mathrm{V}_{\mathrm{a}}$ was determined. Figure 3 depicts the effect of the addition of standard heparin at a concentration of 1 and $2 \mu \mathrm{g} / \mathrm{mL}$ on the thrombin, factor $X_{a}$ and factor $V_{a}$ generation curves.

From Figure $3 \mathrm{~A}$ it is clear that standard heparin induces a prolonged lag time, and also the total amount of thrombin formed is greatly reduced. The factor $X_{a}$ generation curves, as depicted in Figure 3B, do not show a lag phase, but instead the effect of heparin is to greatly reduce the factor $X_{a}$ yield. Figure $3 \mathrm{C}$ shows the effect of standard heparin on the generation of factor $V_{a}$. As for thrombin generation, also factor $V_{a}$ is generated only after a lag period, which length is dependent on the heparin concentration added to the plasma.

From Figure 3 it is already clear, that the lag-phase observed for thrombin generation is not correlated with the inhibition of factor $X_{a}$ generation, because no lag phase was induced in factor $X_{a}$ generation upon the addition of standard heparin. 


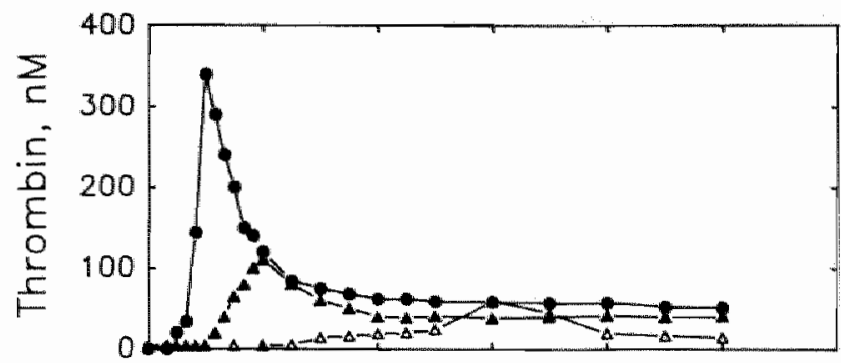

A

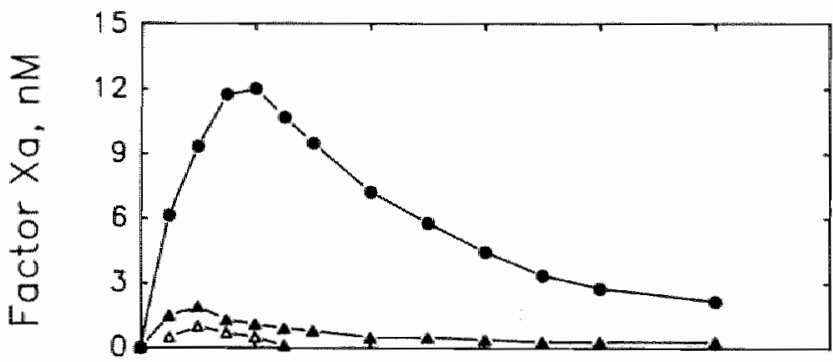

B

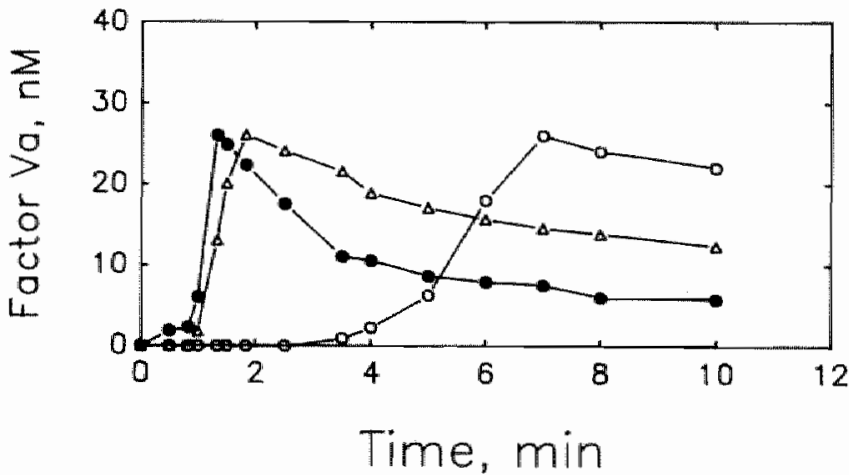

Figure 3. Effect of standard heparin on the generation of thrombin (panel A), factor $X_{\mathrm{a}}$ (panel $B$ ) and factor $V_{\mathrm{a}}$ (panel $C$ ) in thromboplastin activated plasma. Concentrations used are $0_{\mu g} / m L(\bullet), 1 \mu g / m L(\Delta)$ and $2 \mu g / m L(\Delta)$.

Effect of Pentasaccharide on the Generation of Activated Coagulation Factors in Plasma- Next, we investigated the effect of the synthetic pentasaccharide on the generation of thrombin, factor $\mathrm{X}_{\mathrm{a}}$ and factor $\mathrm{V}_{\mathrm{a}}$ in thromboplastin-activated plasma. As pentasaccharide possesses only anti-factor $X_{a}$ activity, the addition of pentasaccharide would show the effect of the anti- $X_{a}$ activity to the inhibition of thrombin generation and thus clotting in plasma. Figure 4 shows the effect of adding the pentasaccharide in a concentration of 0.5 and $1 \mu \mathrm{g} / \mathrm{mL}$ to the plasma. 
From Figure 4A it is clear that pentasaccharide has practically no effect on thrombin generation. The peak amount of formed thrombin remains at 1 minute, and only the total amount of the thrombin formed is reduced. As expected, the generation of factor $\mathrm{X}_{\mathrm{a}}$ was significantly reduced (panel $\mathrm{B}$ ). It is noteworthy that, although factor $X_{a}$ levels in plasma containing $1 \mu \mathrm{g} / \mathrm{mL}$ are very low (panel $B$ ), thrombin generation is only slightly reduced (pańel A). Panel C shows that, as for the generation of thrombin, factor $\mathrm{V}_{\mathrm{a}}$ generation is not significantly influenced.
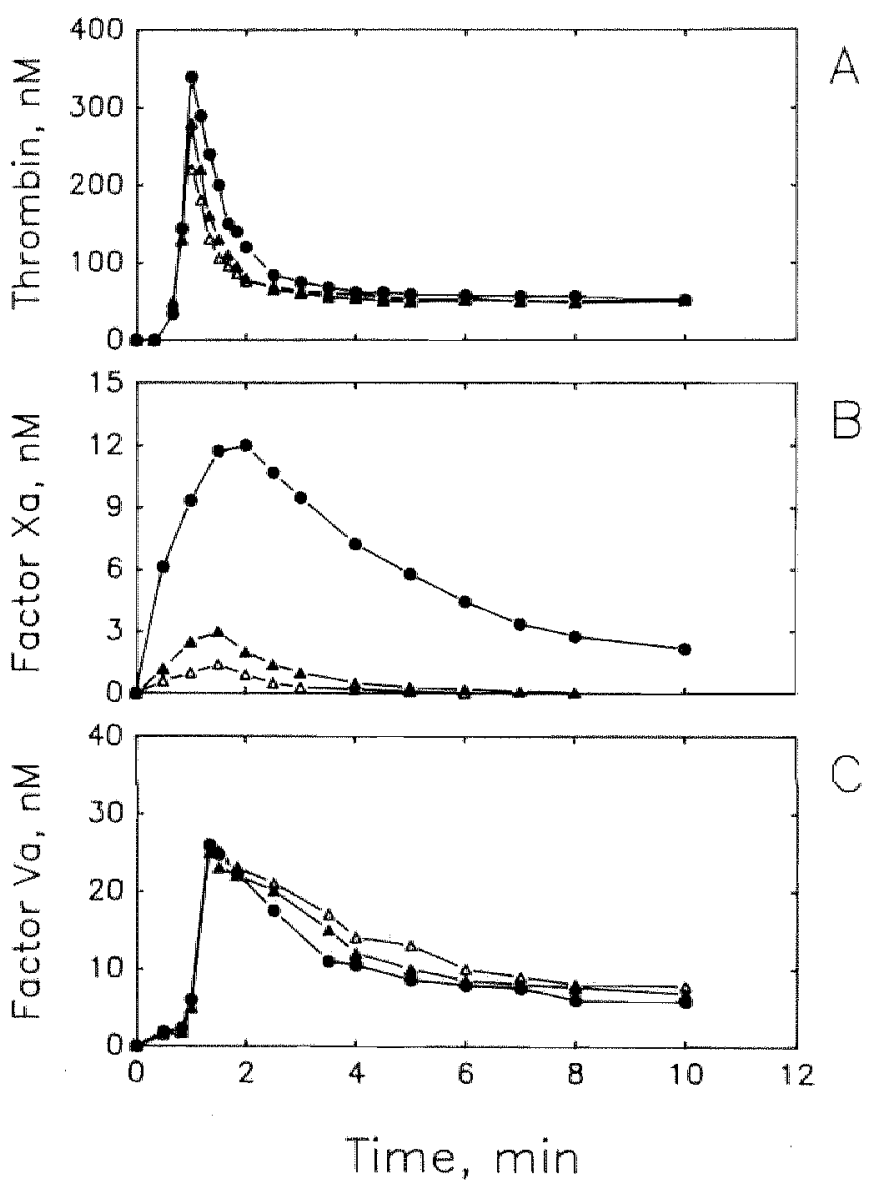

Figure 4. Effect of the synthetic pentasaccharide on the generation of thrombin (panel $A)$, factor $X_{\mathrm{a}}($ panel $B)$ and factor $V_{\mathrm{a}}($ panel $C)$ in thromboplastin activated plasma. Concentrations used are $0 \mu \mathrm{g} / \mathrm{mL}(\bullet), 0.5 \mu \mathrm{g} / \mathrm{mL}(\Delta)$ and $1 \mu \mathrm{g} / \mathrm{mL}(\triangle)$. 


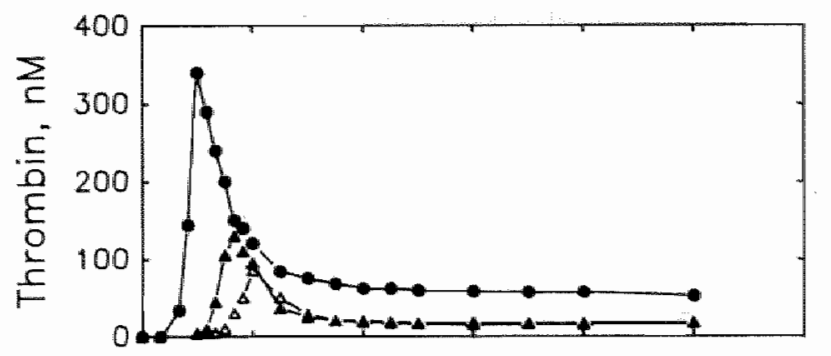

A

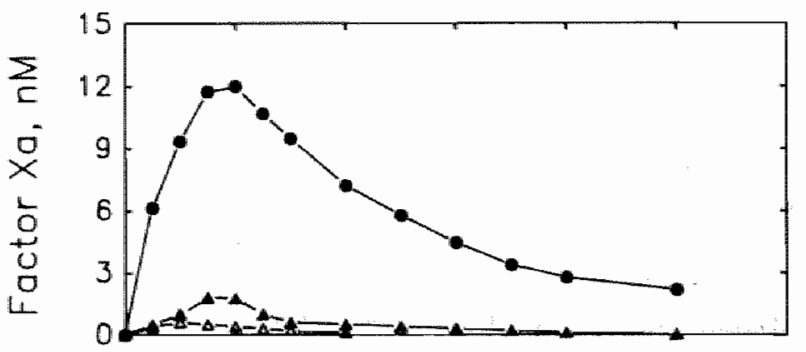

B

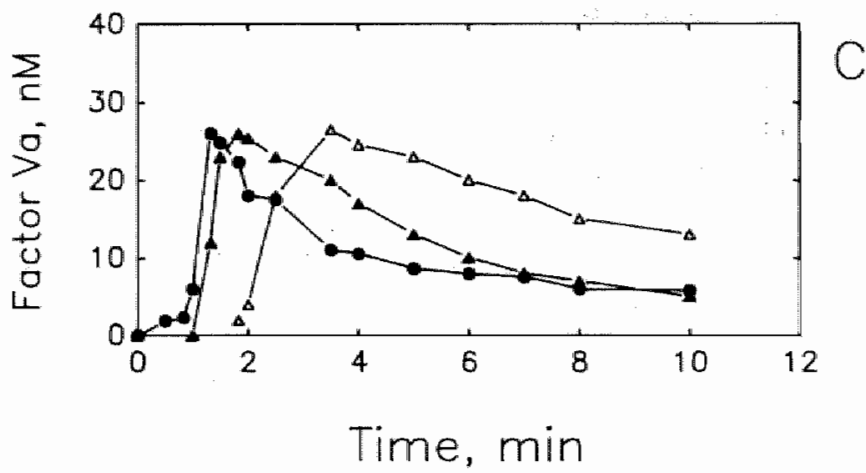

Figure 5. Effect of the low molecular weight heparin $C Y 216$ on the generation of thrombin (panel $A)$, factor $X_{\mathrm{a}}\left(\right.$ panel $B$ ) and factor $V_{\mathrm{a}}$ (panel $C$ ) in thromboplastin activated plasma. Concentrations used are $0 \mu \mathrm{g} / \mathrm{mL}(\bullet), 10 \mu \mathrm{g} / \mathrm{mL}(\Delta)$ and 20 $\mu g / m L(\Delta)$.

Effect of the Low Molecular Weight Heparin CY 216 on the Generation of Activated Coagulation Factors in Plasma- As a third heparin preparation we used CY 216 , a low molecular weight heparin with a high anti- $X_{a}$ over anti-thrombin ratio. The obtained results are depicted in Figure 5. We added CY 216 in a concentration of 10 and $20 \mu \mathrm{g} / \mathrm{mL}$ to the plasma. As can be seen in panel $\mathrm{A}$, the addition of $20 \mu \mathrm{g} / \mathrm{mL} \mathrm{CY} 216$ results in a similar inhibition of the thrombin generation 
curve as was the case with $1 \mu \mathrm{g} / \mathrm{mL}$ standard heparin. Indeed, this parallels their anti-thrombin activities: standard heparin possessing $195 \mathrm{U} / \mathrm{mL}$, and CY 21610 $20 \mathrm{U} / \mathrm{mL}$. In panel $\mathrm{B}$ the effect of CY 216 on the generation of factor $X_{\mathrm{a}}$ is depicted. CY 216 exerts the same concentration dependence as standard heparin for the inhibition of factor $X_{a}$ generation, and indeed, the two heparin preparations posses the same specific anti-factor $X_{a}$ activities. The factor $V_{\text {a }}$ generation curves again parallel the thrombin generation, as already was seen for standard heparin and pentasaccharide (see panel C).

Table I summarizes the effects of the three used heparins and heparin analogues in thromboplastin activated plasma. The effects of these heparins on thrombin generation and factor $X_{a}$ generation is expressed as percentages of the peak values. Also the effect on the clotting time is given. As can be seen in Table I, pentasaccharide and CY 216, when compared with standard heparin are much less effective than was expected from their given specific anti-factor $X_{a}$ activities. Also, Table I shows that reducing the factor $X_{a}$ yield, does not cause a similar reduction in thrombin yield; a reduction of the factor $X_{a}$ yield to $5 \%$ for example, causes a reduction of the thrombin generation peak value of $14 \%$ (standard heparin). $25 \%$ (CY 216) or $71 \%$ (pentasaccharide). This shows that the reduction in thrombin yield parallels rather the anti-thrombin activity of the heparins, than their anti-factor $\mathrm{X}_{\mathrm{a}}$ activity. The prolongation of the clotting time also parallels the anti-thrombin activity, rather than the anti-factor $\mathrm{X}_{\mathrm{a}}$ activity.

Table 1. Thromboplastin-dependent plasma factor $X_{\mathrm{a}}$ and thrombin generation as a function of the heparin concentration.

\begin{tabular}{|c|c|c|c|c|c|c|}
\hline \multirow[b]{2}{*}{ Heparin Type } & \multicolumn{3}{|c|}{ Concentration } & \multicolumn{2}{|c|}{ Peak Values $(0)$} & \multirow{2}{*}{$\begin{array}{l}\text { Clotting Time } \\
\quad(\mathrm{sec})\end{array}$} \\
\hline & $(\mu \mathrm{g} / \mathrm{mL})$ & (a-1Ia U/mL) & (a- $X_{\mathbb{a}} \mathrm{U} / \mathrm{mL}$ ) & Ila & $x_{a}$ & \\
\hline \multirow[t]{4}{*}{4 th ISH } & 0 & 0 & 0 & 100 & 100 & 45 \\
\hline & 0.5 & 0.1 & 0.1 & so & 45 & 60 \\
\hline & 1.0 & 0.2 & 0.2 & 30 & 17 & 85 \\
\hline & 2.5 & 0.5 & 0.5 & 14 & 6 & 510 \\
\hline \multirow[t]{4}{*}{$C \times 216$} & 2.5 & $0.025 \cdot 0.05$ & 0.5 & 60 & 49 & 48 \\
\hline & 10.0 & $0.1 \cdot 0.2$ & 2.0 & 38 & 19 & 70 \\
\hline & 20.0 & $0.2-0.4$ & 4.0 & 25 & 6 & 90 \\
\hline & 50.0 & $0.5-1.0$ & 10.0 & 5 & nd & 630 \\
\hline \multirow[t]{4}{*}{ Pentasaccharide } & 0.5 & 0 & 2.0 & 90 & 29 & so \\
\hline & 2.5 & 0 & 10.0 & 71 & 4 & 62 \\
\hline & 10.0 & 0 & 40.0 & 60 & ind & 75 \\
\hline & 40.0 & 0 & 160 & 35 & ind & 90 \\
\hline
\end{tabular}

Experimental conditions were the same as in Figures 3-5. nd: not detectable 
Effect of the Inhibition of Factor $X_{a}$ on the Anticoagulant Effect of Heparin in Plasma- As already is clear from Figures 3-5 and Table I, the inhibition of the factor $\mathrm{X}_{\mathrm{a}}$ generation did not in all cases reduce the thrombin generation in plasma. Therefore, in order to investigate the contribution of factor $X_{a}$ inhibition to thrombin generation, we used a weight amount of each heparin that caused similar factor $X_{a}$ generation curves in which the factor $X_{a}$ peak values were $5 \%$ of the control, as is depicted in Figure 6, i.e. $2.5 \mu \mathrm{g} / \mathrm{mL}$ of standard heparin (panel B), $20 \mu \mathrm{g} / \mathrm{mL}$ of CY 216 (panel C), and $2.5 \mu \mathrm{g} / \mathrm{mL}$ of pentasaccharide (panel D).
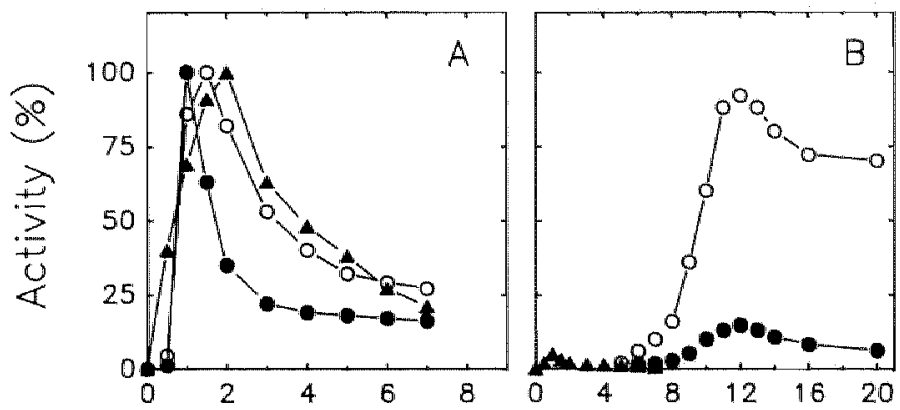

Time (min)

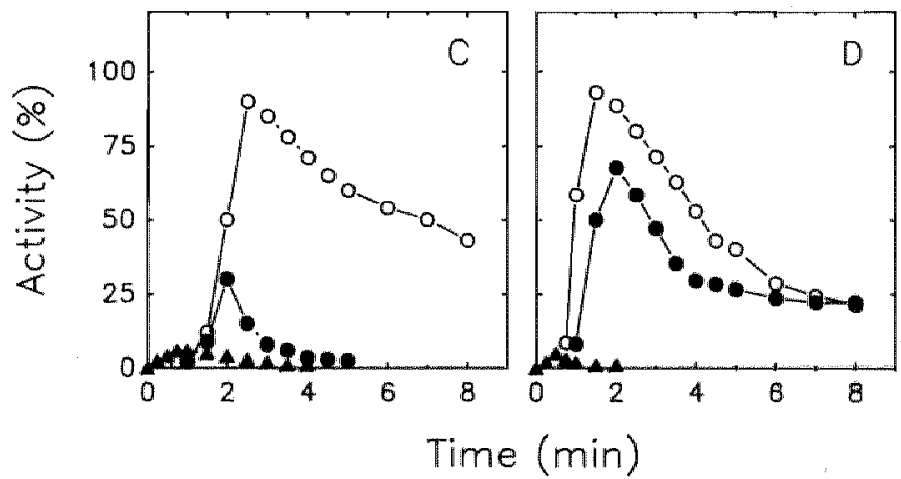

Figure 6. Effects of heparin and heparin fractions on the generation of thrombin (๑), factor $X_{\mathrm{a}}(\Delta)$ and factor $V_{\mathrm{a}}(0)$ in thromboplastin activated plasma. (A) no heparin, (B) 2,5 $\mathrm{gg} / \mathrm{mL}$ of standard heparin, (C) $20 \mu \mathrm{g} / \mathrm{mL}$ of $C Y 216$ and (D) 2.5 ug/ $m L$ of the synthetic pentasaccharide. The amounts are expressed as a percentage of the maximum amounts in the absence of heparin, i.e. $1 \mathrm{U} / \mathrm{mL}(25 \mathrm{nmol} / \mathrm{L})$ of factor $V_{\mathrm{a}}, 320 \mathrm{nmol} / \mathrm{L}$ of thrombin and $12 \mathrm{nmol} / \mathrm{L}$ of factor $X_{\mathrm{a}}$. 
Thus, the only variable in these experiments was the anti-thrombin activity, $0.5 \mathrm{U} / \mathrm{mL}$ (Standard heparin), $0.2-0.4 \mathrm{U} / \mathrm{mL}$ (CY 216) and $0 \mathrm{U} / \mathrm{mL}$ for pentasaccharide, respectively. Figure 6 shows that despite similar factor $\mathrm{X}_{\mathrm{a}}$ generation curves, thrombin generation differed markedly with the heparin used. Our results indicate that indeed thrombin generation is not directly associated with factor $\mathrm{X}_{\mathrm{a}}$ generation. That is, the prolongation of the lag phase observed in thrombin generation in the presence of standard heparin is not solely the result of factor $X_{a}$ inhibition, because the same, quantitative, factor $X_{a}$ inhibition in the presence of pentasaccharide had a minor effect on the lag phase and slightly reduced the thrombin yield. In the presence of standard heparin $(2.5 \mu \mathrm{g} / \mathrm{mL})$ the maximum thrombin activity is about $10 \%$ of the control, but it should be recognized that the virtual thrombin concentration is much higher because of the rapid decay of the thrombin activity once it is formed. Thus, despite a greatly reduced factor $\mathrm{X}_{\mathrm{a}}$ yield, even below our detection limit of $0.1 \mathrm{nmol} / \mathrm{L}$ in plasma, significant amounts of thrombin can be produced (Figure 6B).

The explanation for the relatively weak anticoagulant activities of pentasaccharide and $C Y 216$ can be found in their effects on factor $V_{a}$ generation in plasma. Factor $V_{a}$ is an essential cofactor of factor $X_{a}$ and is generated from the pro-cofactor $\mathrm{V}$ by thrombin. As also shown in Figure 6 , factor $V_{a}$ generation is greatly delayed in plasma containing a relatively high anti-thrombin activity (standard heparin) but hardly in plasma containing pentasaccharide, devoid of anti-thrombin activity. Also, the inhibition of the formed factor $V_{a}$ appeared to be dependent on the amount of thrombin present, probably because protein $\mathrm{C}$ activation is thrombin dependent.

In support of our notion that factor $\mathrm{V}_{\mathrm{a}}$ generation by thrombin is the rate-limiting step in prothrombin activation, the addition of factor $V_{a}$ to heparinized plasma at different time intervals after thromboplastin addition, immediately caused an extremely rapid thrombin generation, followed by a rapid decay as the result of prothrombin depletion and inactivation of thrombin (Figure 7). Clot formations were observed within $10 \mathrm{~s}$ after the additions of factor $\mathrm{V}_{\mathrm{a}}$. The thrombin peak activities thus obtained appeared to parallel the amount of residual factor $X_{\mathrm{a}}$ activity at that time present. Factor $X_{a}$ generation was not influenced by the addition of factor $V_{a}$ and maximum plasma factor $V_{a}$ levels observed were about twice the value found when no factor $V_{a}$ was added. These results indicate that the presence of factor $V_{a}$ makes extremely low levels of factor $X_{a}$ sufficient to produce thrombin at a high rate. 


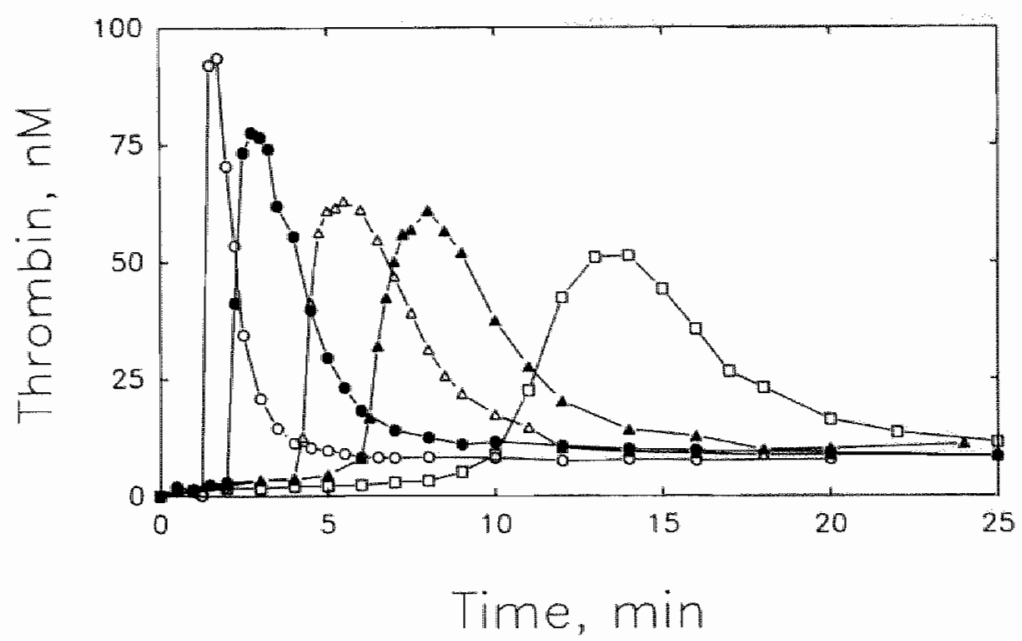

Figure 7. Factor $V_{\mathrm{a}}$ stimulated thrombin generation in heparinized plasma. Thrombin was measured in mixtures containing human plasma, thromboplastin (1/30 of total volume) and $2.5 \mu \mathrm{g} / \mathrm{mL}$ of the standard heparin ( $\square$ ). In separate experiments purified factor $V_{\text {a }}$ (final concentration of $25 \mathrm{nmol} / \mathrm{L}$ ) was added $1 \mathrm{~min}(\mathrm{O}), 2 \mathrm{~min}$ $(\bullet), 4 \min (\Delta)$ or $6 \min (\Delta)$ after the addition of thromboplastin.

\section{Discussion}

The process of blood coagulation comprises a complicated series of protein interactions that functions in a series of interlinked positive and negative feedback loops. It is because of this complexity that at present no definite information is available to assess the relative importance of the anti-thrombin and anti-factor $X_{\mathrm{a}}$ activities of heparin to the overall reaction rate of the coagulation sequence ex vivo. In addition, the activated clotting factors generated in clotting plasma were not directly available for quantitation because of the lack of sensitive and specific bioassays. In the present paper we presented a method by which factor $V_{a}$ and factor $X_{a}$ generation could be monitored in clotting plasma. The essential feature of these assays is that the natural substrate, prothrombin, is used to measure the enzyme and cofactor activities. Because of the fact that for the prothrombin activation only very small amounts of factor $X_{a}$ or factor $V_{a}$ are needed, the plasma could be diluted a thousand-fold before measurement, thus eliminating all factors that could interfere with our factor $\mathrm{X}_{\mathrm{a}}$ or factor $\mathrm{V}_{\mathrm{a}}$ determination. 
The aim of our study was to estimate the relative contributions of the heparindependent inhibition of factor $X_{\text {a }}$ and thrombin to the anticoagulant effect of heparin in plasma. Thereto, the action of heparin on the following processes have to be considered: i) formation of the prothrombinase complex (inhibition of factor $X_{a}$ and factor $V_{a}$ generation), ii) inhibition of prothrombinase activity and iii) inhibition of thrombin.

The generation of both factor $V_{a}$ and factor $X_{\text {a }}$ are controlled by positive feedback reactions. In particular, the so-called intrinsic activation of factor $X$ is a complicated process in which activation of factor VIII:C by thrombin and probably also by factor $X_{a}$ is of crucial importance (20). As a first attempt we, therefore, restricted ourselves to an investigation of the so-called extrinsic pathway of blood coagulation. To this end, human brain thromboplastin was used at a concentration that produced factor $X_{a}$ with a rate indistinguishable from that in factor IX deficient plasma. The activation and inactivation reactions that are then important are depicted in Scheme 1. The TF: factor $\mathrm{VII}_{\mathrm{a}}$ complex activates factor $X$ into factor $X_{a}$, which then converts some prothrombin into thrombin. These first traces of thrombin are sufficient to activate factor $V$ into factor $V_{a}$ to form together with factor $X_{a}$, phospholipids and calcium the so-called prothrombinase complex. Only then sufficient amounts of thrombin are produced to form a fibrin-clot.

The inhibitory pathways are also depicted in Scheme 1. First of all there is the extrinsic pathway inhibitor, inhibiting the activity of tissue factor when factor $X_{a}$ and calcium are present (19). Second, activated protein $C$ inhibits the activated factor $V$, and finally antithrombin III is a very important inhibitor of thrombin and factor $X_{a}$, which inhibition is dramatically accelerated when heparin is present.

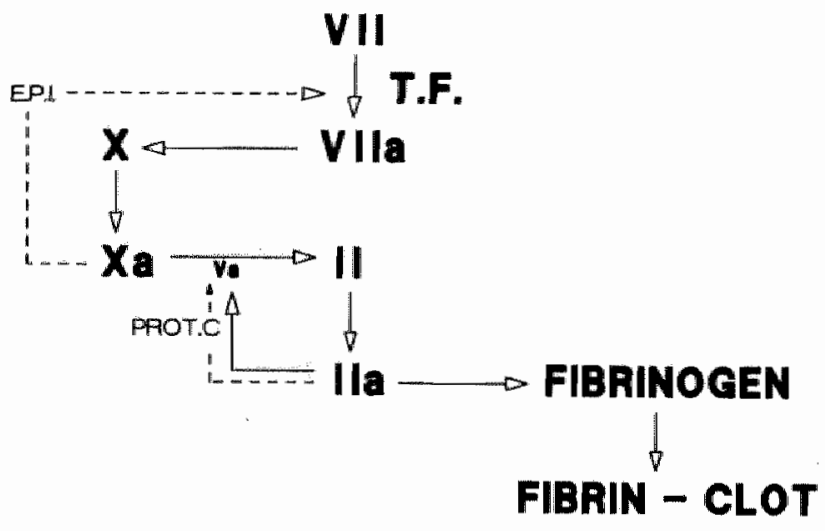

Scheme I. Activation (-) and inactivation (-) reactions upon triggering plasma with a high concentration of thromboplastin. 
First of all we determined how the activated coagulation factors were generated in plasma, when triggered with a high concentration of thromboplastin. The fact that no lag phase was observed in factor $\mathrm{X}_{\mathrm{a}}$ generation, whereas factor $V_{a}$ generation did show a lag phase, already indicates that factor $V_{a}$ formation might be the rate limiting step in the formation of the prothrombinase complex and thus in the generation of sufficient amounts of thrombin (about $10 \mathrm{nM}$ ) to produce the critical fibrin concentration that results in cllot formation.

We determined the effects of three different types of heparin on the generation of thrombin, factor $\mathrm{X}_{\mathrm{a}}$ and factor $\mathrm{V}_{\mathrm{a}}$ in plasma. These three differed from each other in their anti-thrombin and anti-factor $X_{a}$ activities. The most important conclusions from these experiments are that apparently, the generation of factor $\mathrm{X}_{\mathrm{a}}$ does not correlate with the generation of thrombin. Rather the generation of factor $\mathrm{V}_{\mathrm{a}}$ activity is correlated to thrombin generation.

In order to investigate further whether the inhibition of factor $\mathrm{X}_{\mathrm{a}}$ generation is really important for the inhibition of thrombin generation, we added the three heparins in a concentration which caused the factor $X_{a}$ generation to be only $5 \%$ of normal.

When solely the generation of factor $X_{a}$ is inhibited (Figure 6D) the rather low thrombin concentrations required for factor $V_{a}$ formation are readily produced as indicated by a minor increase in the lag phase of factor $V_{a}$ formation. The slight decrease of the maximum thrombin activity suggest a minor reduction of prothrombinase activity, either caused by the lower levels of factor $X_{\mathbf{a}}$ and/or by inhibition of factor $X_{a}$ in the complex. At higher pentasaccharide concentrations, where factor $X_{a}$ generation was diminished below our detection limit, and only sub-nanomolar amounts of prothrombinase might be present, still significant amounts of thrombin were generated. All together, these findings strongly suggest that the anti-factor $\mathrm{X}_{\mathrm{a}}$ activity is of minor importance to the overall anticoagulant activity of heparin. In contrast, the heparin-dependent inhibition of thrombin during the initial stage of thromboplastin-triggered coagulation, when factor $V$ is converted into factor $V_{a}$ by thrombin (Figure 6B), appeared to be of prime importance to the anticoagulant activity of heparin.

Indeed, the anticoagulant effect of heparin could be reversed upon the addition of purified factor $V_{a}$ to thromboplastin-activated heparinized plasma during the period where still no substantial thrombin generation was observed and where factor $\mathrm{X}_{\mathrm{a}}$ activity was already greatly reduced (Figure 7),

Barrowcliffe et al. (21) have demonstrated in a purified system that when molar activities are compared unfractionated heparin is a more efficient inhibitor of the amidolytic factor $\mathrm{X}_{\mathrm{a}}$ activity in the prothrombinase complex than pentasaccharide. In the experiments shown in Figure 6, the molar activities of stand- 
ard heparin (MW $=15.000,40 \%$ of the molecules with high affinity for AT III) and pentasaccharide $(\mathrm{MW}=1714)$ were $0.07 \mu \mathrm{M}$ and $1.5 \mu \mathrm{M}$, respectively. Thus, it is unlikely that the dramatic differences observed in the thrombin generation curves in the presence of heparin and pentasaccharide are the result of a higher anti-prothrombinase activity in case of standard heparin. In addition, it has been pointed out by Béguin et al. (22) that no direct action of heparin on prothrombinase needs to be assumed if one takes into account the effect of thrombin inhibition on thrombin-mediated feedback reactions.

It is tempting to speculate that the rather insignificant contribution of the heparin anti-factor $\mathrm{X}_{\mathrm{a}}$ activity in the anticoagulant activity of heparin, as demonstrated here, might be one of the reasons why the heparin anti-factor $\mathrm{X}_{\mathrm{a}}$ activity does not parallel antithrombotic efficacy. However, we have to emphasize that if factor $X_{\mathrm{a}}$ generation via the intrinsic pathway is more relevant to the in vivo coagulation and if activation of factor VIII: $\mathrm{C}$ by factor $\mathrm{X}_{\mathrm{a}}$ contributes significantly to the positive feedback reaction of factor $\mathrm{X}_{\mathrm{a}}$ generation in plasma, then the anti-factor $X_{\mathrm{a}}$ activity has to be taken into account as well. In a purified system, however, thrombin-catalyzed activation of factor VIII:C appeared to be about 15 -fold more efficient in the factor $\mathrm{IX}_{\mathrm{a}}$-catalyzed factor $\mathrm{X}$ activation than the activation of factor VIII;C by factor $\mathrm{X}_{\mathrm{a}}$ (20). Currently, the initiation of feedback activation of factor VIII:C in plasma is poorly understood and requires further studies.

\section{References}

1. Choay J, Petitou M, Lormeau JC, Sinay P, Casu B, Gatti G: Structure-activity relationship in heparim: asynthetic pentasaccharide with high affinity for antithrombin III and eliciting high anti-factor $X_{\mathrm{a}}$ activity. Biochim Biophys Res Comm 116: 492, 1983

2. Esquivel CO, Bergqist D, Bjork CG, Nilson B: Comparison between commercial heparin, low molecular weight heparin and pemtosan polysulfate on bemostasis and platelets in vivo. Thromb Res $28: 389,1982$

3. Holmer $E_{n}$ Mattson $C$, Nilsson S: Anticoagulant and antithrombotic effects of low molecular weight heparin fragments in rabbits. Thromb Res 25: 475, 1982

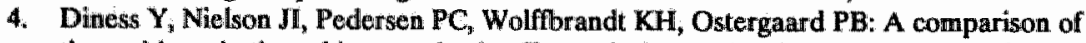
the antithrombotic and haemorrhagic effects of a low molecular weight heparin (LHN1) and conventional heparin. Thromb Haemost 55: 410, 1986

5. Carter CJ, Kelton JG, Hirsh J, Cerskus A, Santos AV, Gent M: The relationship between the hemorrhagic and antithrombotic properties of low molecular weight heparin in rabbits, Blood 59: 1239, 1982

6. Fussi F, Girolami A, Cella G: Low molecular weight heparins and their effect in vitro, in experimental models and in humans, in Lundblat RL, Brown WV, Mann KG. Roberts HR (eds): Chemistry and biology of heparin. Elsevier/North Holland, New York, 1981, p 535 
7. Thomas DP, Merton RE, Lewis WE, Barrowcliffe TW: Studies in man and experimental animals of a low molecullar weight heparin fraction. Thromb Haenost 45:218, 1981

8. Holmer $E$, Mattson C, Nilsson S: Anticoagulant and antithrombotic effects of heparin and low molecular weight heparin fragments in rabbits. Thromb Res $25: 475,1982$

9. Thomas DP: Current status of low molecular weight heparin. Thromb Haemost 56:241, 1986 (Letter)

10. Buchanan MR, Boneu $B$, Ofosu $F$, Hirsh J: The relative importance of thrombin inhibition and factor $X_{\mathrm{a}}$ inhibition to antithrombotic effects of heparin. Blood 65: 198, 1985

11. Hemker HC, Willems GM, Beguin S: A computer assisted method to obtain the prothrombin activation vellocity in whole plasma independent of thrombin decay processes. Thromb Haemost 56(1):9, 1986

12. Hemker $\mathbf{H C}$ : The mode of action of heparin in plasma, in Verstraete $M$, Vermylen $J$, Lijnen HR, Arnout $\mathbf{J}$ (eds): Thrombosis and haemostasis 1987, ISTH, Leuven, 1987, p17

13. Owren PA, Aas K: The control of dicoumarol therapy and the quantitative determination of prothrombin and proconvertin. Scand J Clin Lab lnvest 3:201, 1951

14. Van Dieijen G, Tans $G$, Rosing J, Hemker HC: Role of phospholipid and factor VIII in the activation of bovine factor X. J Biol Chem 256:3433, 1981

15. Rosing J, van Rijn JLML, van Dieijen $G$, Comfurius P, Zwaal RFA: The role of activated human platelets in prothrombin and factor X activation. Blood 65:319, 1980

16. Lindhout T, Govers-Riemslag. JWP, van de Waart $P$, Hemker HC, Rosing J: Factor $V_{a-}$ factor $\mathrm{X}_{\mathrm{a}}$ interaction. Effects of phospholipid vesicles of varying composition. Biochemistry 21:5494, 1982

17. Lindhout $T$, Baruch D, Schoen P, Franssen J, Hemker HC: Thrombin generation and inactivation in the presence of antithrombin III and heparin. Biochemistry 25: 5962, 1986

18. Jesty $\mathrm{J}$ : Analysis of the generation and inhibition of activated coagulation factor $\mathbf{X}$ in pure systems and in human plasma. J Biol Chem 261: 8695, 1986

19. Rao LVM, Rapaport SI: Studies of a mechanism inhibiting the initiation of the extrinsic pathway of coagulation. Blood 69:645, 1987

20. Lollar P, Knutson GJ, Fass DN: Activation of porcine factor VIII:C by thrombin and factor Xa. Biochemistry 24: 8056, 1985

21. Barrowcliffe TW, Havercroft SJ, Kemball-Cook G, Lindlahl U: The effect of $\mathrm{Ca}^{2+}$, phospholipid and factor $V$ on the anti- (factor $X_{a}$ ) activity of heparin and its high-affinity oligosaccharides. Biochem J 243: 31, 1987

22. Béguin $\mathrm{S}$, Lindhout $\mathrm{T}$, Hemker $\mathrm{HC}$ : The mode of action of heparin in plasma. Thromb Haemost (in press) 


\title{
Chapter V
}

\section{Factor $\mathbf{X I}_{\mathbf{a}}$ Catalyzed Generation of Factor $\mathbf{I X}_{\mathbf{a}}$ in Human Plasma.}

\author{
Regulation by Plasma Proteinase Inhibitors and Heparin ${ }^{\circ}$
}

\section{Abstract}

The generation and inhibition of factor $\mathrm{IX}_{\mathrm{a}}$ have been studied in factor $\mathrm{XI}_{\mathrm{a}}$-activated plasma to determine the kinetics of inhibition of factor $\mathbf{X I}_{\mathrm{a}}$ and factor IX $_{\mathrm{a}}$ during factor IX activation. Interference of other (activated) factors with the factor $\mathrm{IX}_{\mathrm{a}}$ activity measurements could be avoided by using a highly specific and sensitive bioassay. Factor IX $\mathrm{X}_{\mathrm{a}}$ generation curves were analyzed according to a 3parameter model to determine the $k_{c a t} / K_{m}$ ratio for factor IX activation by factor $\mathrm{XI}_{\mathrm{a}}$. Simultaneously, apparent first order rate constants of inhibition of factor $\mathrm{XI}_{\mathrm{S}}$ and in situ generated factor $\mathrm{IX}_{\mathrm{a}}$ were determined in plasma containing free $\mathrm{Ca}^{2+}$ levels of $4 \mathrm{mM}$ and phospholipids. The fitted value for the $k_{\mathrm{ca}} / \mathrm{K}_{\mathrm{m}}$ ratio, $320 \mu \mathrm{M}^{-1} \min ^{-1}$ was in good agreement with the reported ratio. In the absence of heparin no decay of factor $\mathrm{IX}_{\mathrm{a}}$ activity was observed. Maximal levels of factor $\mathrm{IX}_{\mathrm{a}}$ varied with the factor $\mathbf{X I}_{\mathrm{a}}$ concentration as a result of inhibition of factor $\mathbf{X I}_{\mathrm{a}}$ by plasma proteinase inhibitors at a rate constant of $0.35 \mathrm{~min}^{-1}$. In the presence of unfractionated heparin the apparent second order rate constant of inhibition of factor $\mathrm{IX}_{\mathrm{a}}$ was $6.16 \mathrm{~min}^{-1} / \mathrm{mg}$ heparin/mL. The rate constant in the presence of

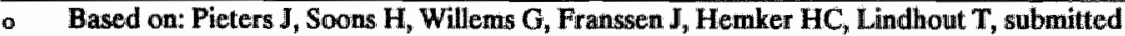


a synthetic pentasaccharide heparin was $0.70 \mathrm{~min}^{-1} / \mu \mathrm{g}$ pentasaccharide/mL. $\mathrm{Ca}^{2+}$ ions (4 mM) were required to obtain heparin-dependent inhibition of factor $\mathrm{IX}_{\mathrm{a}}$. Clot formation but not thrombin formation abolished the heparin stimulated inhibition of factor $\mathrm{IX}_{\mathrm{a}}$. Factor $\mathrm{XI}_{\mathrm{a}}$ inhibition was not affected by heparin in the range studied.

\section{Introduction}

Factor IX can be activated via both the extrinsic and intrinsic coagulation pathway. It thus formes a link between these pathways that is thought to be of crucial importance for the initiation phase of blood coagulation (for recent reviews, see references 1 and 2 )

The majority of studies on the regulation of factor $\mathrm{IX}_{\mathrm{a}}$ by plasma proteinase inhibitors have been done with purified enzyme either in plasma or in buffer (3$5)$. It has been shown that bovine and human factor $I X_{a}$ react slowly with antithrombin III but not with $\alpha_{2}$-macroglobulin and $\alpha_{1}$-proteinase inhibitor $(4,6)$. The reaction with antithrombin III is greatly stimulated by the presence of heparin. Like in case of thrombin, the simultaneous binding of both the inhibitor and enzyme to the same heparin molecule seems to be required for maximal rates of inactivation of factor $\mathrm{IX}_{\mathrm{a}}(7)$. Indeed, for bovine factor $\mathrm{IX}_{\mathrm{a}}$ it was found that pentasaccharide did not stimulate its inactivation by antithrombin III (5). Whereas $\mathrm{Ca}^{2+}$ ions reduce the rate of inactivation of thrombin by antithrombin III/heparin (8), they greatly enhance the reaction between bovine factor IX $\mathrm{X}_{\mathrm{a}}$ and antithrombin III/heparin (5).

In addition to these studies, two groups have reported on the effects of heparin on the progress of activation of radiolabelled factor IX in contact-activated plasma (3) and in thromboplastin-activated plasma (9). In the latter case, 5 $\mathrm{U} / \mathrm{mL}$ of heparin almost completely blocked factor IX activation. During contact activation, heparin did not significantly affect the steps preceding factor $\mathrm{X}$ activation. That is, in the absence or presence of $0.5 \mathrm{U} / \mathrm{mL}$ heparin, the extent of radiolabelled factor IX cleavages at 30 minutes were essential identical. Factor IXa activity levels were reduced in the presence of heparin but still to be found significantly higher than was required for factor $\mathrm{X}$ activation to occur in the absence of heparin.

However, a straightforward analysis of the generation and inhibition of factor IX activity in heparinized plasma on basis of a model that describes the time course of factor IX $\mathrm{X}_{\mathrm{a}}$ generation and decay is currently not available. One of the reasons might be the problem of measuring factor IX $_{\mathbf{a}}$ activity generated in situ without interference by other activated coagulation factors formed. 
The present studies were undertaken to examine the effects of two types of heparin, i.e. unfractionated heparin and ultra low molecular weight heparin, on factor $\mathrm{XI}_{\mathrm{a}}$-catalyzed factor $\mathrm{IX}_{\mathrm{a}}$ generation in plasma and inactivation of in situ generated factor $\mathrm{IX}_{\mathrm{a}}$. It was possible by using a highly specific and sensitive bioassay to monitor the generation and inhibition of factor $\mathbf{I} \mathbf{X}_{\mathbf{a}}$ in factor $\mathbf{X I}_{\mathrm{a}}$-activated plasma. Factor IX $\mathrm{X}_{\mathrm{a}}$ generation curves were fitted to a 3-parameter model to assess quantitatively the effects of unfractionated heparin and a synthetic pentasaccharide heparin on factor $\mathbf{I X}_{\mathrm{a}}$ and factor $\mathbf{X I}_{\mathrm{a}}$ inhibition by antithrombin III.

\section{Materials and Methods}

Materials- The synthetic peptide substrate Bz-Ile-Glu(Piperidyl)-Gly-Arg-pnitro-anilide hydrochloride (S-2337) was purchased from AB Kabi Diagnostica, Stockholm, Sweden.

Factor IX deficient plasma was obtained from congenitally deficient patients and was purchased from DiaMed AG, Switzerland. Ovalbumin was a product of Sigma Chemical Co., St. Louis. All reagents used were of the highest grade commercially available.

The 4th International Standard for Heparin (ISH; 195 units/mg) was obtained from the National Institute for Biological Standards and Control, London. The synthetic pentasaccharide (IC 83.1423; 800 anti-factor $\mathrm{X}_{\mathrm{a}}$ units/mg) was a kind gift from Institut Choay, France.

Proteins- Human factor IX and human factor XI were purified as described earlier (10). All other bovine clotting factors were prepared and quantitated as previously described (11-13).

Phospholipid Vesicles- Phospholipid vesicles were made from a mixture of phosphatidylserine (PS) and phosphatidylcholine (PC) as previously described (13). Vesicles composed of 25 mole \% PS and 75 mole \% PC were used throughout the experiments.

Preparation of Human Normal Plasma- Blood from healthy donors was collected on $0.13 \mathrm{M}$ trisodium citrate; nine parts blood to one part of citrate solution. The blood was then centrifugated twice at room temperature for 15 minutes at $3,000 \times \mathrm{g}$. A third centrifugation was done at $4^{\circ} \mathrm{C}$ for one our at $23,000 \times \mathrm{g}$. The obtained platelet free plasma was stored at $-80^{\circ} \mathrm{C}$. 
Determination of Free $\mathrm{Ca}^{2+}$ Concentration in plasma- For the determination of the amount of free $\mathrm{Ca}^{2+}$ ions in recalcified plasma, a reference curve was made using a calomel electrode from $0-100 \mathrm{mM} \mathrm{Ca}^{2+}$ in buffer containing 50 $\mathrm{mM}$ Tris- $\mathrm{HCl}(\mathrm{pH} \mathrm{7.9)}, 175 \mathrm{mM} \mathrm{NaCl}$. The free calcium ion concentration thus measured in citrated plasma reconstituted with $20 \mathrm{mM} \mathrm{Ca}^{2+}$ was $4 \mathrm{mM}$.

Factor $I X_{a}$ Determination- To follow the activation of factor $\mathrm{IX}$ by factor $\mathrm{XI}_{\mathrm{a}}$ either in plasma or in a purified system, an assay was developed in which factor $\mathrm{IX}_{\mathrm{a}}$ was determined via its ability to activate bovine factor $\mathrm{X}$ in the presence of $\mathrm{CaCl}_{2}$, phospholipid and activated factor VIII:C. Factor IX $\mathrm{X}_{\mathrm{a}}$ containing samples were diluted 1:1000 into buffer containing $50 \mathrm{mM}$ Tris- $\mathrm{HCl}(\mathrm{pH} 7.9), 175 \mathrm{mM}$ $\mathrm{NaCl}, 0.5 \mathrm{mg}$ ovalbumin/mL, $5 \mathrm{mM} \mathrm{CaCl}, 20 \mu \mathrm{M}$ phospholipid $10 \mathrm{U} / \mathrm{mL}$ factor VIII:C and $0.5 \mu \mathrm{M}$ factor $\mathrm{X}$. Factor $\mathrm{X}$ activation was started by the addition of $100 \mathrm{nM}$ thrombin and the reaction was allowed to proceed for 90 seconds, after which $20 \mathrm{mM}$ EDTA was added to stop the reaction. Subsequently, the chromogenic substrate S-2337 was added in order to determine the amount of factor $X_{a}$ formed as described previously (5). From the observed rate of factor $X_{a}$ formation, the amount of factor $\mathrm{IX}_{\mathrm{a}}$ present in the sample was calculated using a calibration curve made with known amounts of human factor $\mathbf{I} \mathrm{X}_{\mathrm{a}}$

Factor $L X_{a}$ Generation in Plasma- To $160 \mu \mathrm{L}$ of citrated human plasma, $23 \mu \mathrm{L}$ of a Tris-buffer $(50 \mathrm{mmol} / \mathrm{L}$ Tris, $180 \mathrm{mmol} / \mathrm{L} \mathrm{NaCl}, 0.5 \mathrm{mg}$ ovalbumin $/ \mathrm{mL}, \mathrm{pH}$ 7.9) with or without heparin(fraction) was added and incubated for $4 \mathrm{~min}$ in a flat-bottom plastic tube while stirring. Phospholipids were also added to yield a final concentration of $20 \mu \mathrm{M}$ The plasma was activated by the addition of factor $\mathbf{X I}_{\mathbf{a}}$ and calcium ions at the concentrations indicated. Timed samples $(5 \mu \mathrm{L})$ were removed from incubations and assayed for factor $\mathrm{IX}_{\mathrm{a}}$ activity.

Analysis- The analysis of the factor $\mathrm{IX}_{\mathrm{a}}$ generation curves in the presence of proteinase inhibitors was based on the following assumptions: 1. Factor IX activation by factor $\mathrm{XI}_{\mathrm{a}}$ followed Michaelis-Menten kinetics; 2 . Inactivation of factor $\mathrm{IX}_{\mathrm{a}}$ generated and factor $\mathrm{XI}_{\mathrm{a}}$ can both be described as simple pseudo first order reactions.

If we assume that the actual concentration of factor IX at time $t$ equals

$$
\left[\mathbf{I X} \mathbf{t}_{t}=[\mathbf{I X}]_{0}-\left[\mathrm{IX}_{\mathrm{a}}\right]-\left[\mathrm{IX}_{\mathrm{a}} \cdot \mathrm{I}\right]\right.
$$


where $[\mathrm{IXX}]_{0}$ is the factor $\mathrm{IX}$ concentration at $t=0,\left[\mathrm{IX}_{\mathrm{a}}\right]$ is the concentration of free factor $\mathrm{IX}_{\mathrm{a}}$ at $t=t$ and $\left[\mathrm{LX}_{\mathrm{a}} \mathrm{I}\right]$ is the concentration of factor $\mathrm{IX}_{\mathrm{a}}$-inhibitor complex at $t=t$, then the factor $\mathrm{IX}_{\mathrm{a}}$ generation curves can be described by the following set of differential equations:

$$
\begin{aligned}
& d / d t\left[\mathrm{XI}_{\mathrm{a}}\right]=-k \mathrm{XIa}_{\mathrm{a}}\left[\mathrm{XI}_{\mathrm{a}}\right] \\
& d / d t\left[\mathrm{IX}_{\mathrm{a} \cdot \mathrm{I}]}=k \mathrm{xX}_{\mathrm{a}}\left[\mathrm{IX}_{\mathrm{a}}\right]\right.
\end{aligned}
$$

and

$$
d / d t\left[\mathrm{IX}_{\mathrm{a}}\right]=\left(\left(k_{\mathrm{cat}} / \mathrm{K}_{\mathrm{m}}\right)\left[\mathrm{XI}_{\mathrm{a}}\right][\mathrm{IXX}]\right)-k_{\mathrm{IX}_{\mathrm{a}}}\left[\mathrm{IX}_{\mathrm{a}}\right]
$$

where $[\mathrm{IX}]=[\mathrm{IX}]_{0}-\left[\mathrm{IX}_{\mathrm{a}}\right]-\left[\mathrm{IX}_{\mathrm{a}} \mathrm{I}\right]$, and $k_{\mathrm{TXa}}$ and $k \mathrm{XIa}$ are the pseudo first order rate constants of inhibition of factor $\mathrm{IX}_{\mathrm{a}}$ and factor $\mathrm{XI}_{\mathrm{a}}$, respectively.

The initial conditions are:

1. $\left[\mathrm{XI}_{\mathrm{a}}\right]$ at $t=0$ is the amount of factor $\mathrm{XI}_{\mathrm{a}}$ added to the plasma;

2. $\left[\mathrm{IX}_{\mathrm{a}}\right]=0$ at $t=0$;

3. $\left[\mathrm{IX}_{\mathrm{a}} \mathrm{I}\right]=0$ at $t=0$. 
The values for $\mathrm{K}_{\mathrm{m}} / k_{\mathrm{cat}}, k_{\mathrm{TX}}$ and $k \mathrm{xal}_{\mathrm{a}}$ were estimated by a least squares fit of the solution $\mathrm{IX}_{\mathrm{a}}(t)$ of Equation 4 to the experimentally determined factor $\mathrm{IX}_{\mathrm{a}}$ generation curves which uses a iterative Gauss-Newton algorithm (14).

The differential equations for [ $\left[\mathrm{X}_{\mathrm{a}}\right]$,

$$
8\left[\mathrm{IX}_{\mathrm{a}}\right] / 8 \mathrm{kTX} \quad \text { and } \quad \delta\left[\mathrm{XI}_{\mathrm{a}}\right] / \delta k \times \mathrm{ara}
$$

were then solved numerically by the fourth order Runge-Kutta method (15) with stepsize $d t=1 \mathrm{~s}$. Accuracy estimated by halving the stepsize was better than $0.1 \%$. The approximate $95 \%$ confidence intervals of the parameters were estimated by linearization of the non-linear equations at the obtained parameter values $(16)$.

\section{Results}

Factor $D X_{a}$ Bioassay- We developed an assay for activated factor IX based on the formation of a highly efficient factor $\mathrm{X}$ converting complex that consists of factor $\mathrm{IX}_{\mathrm{a}}$ phospholipids, $\mathrm{Ca}^{2+}$ and activated factor VIII:C. Under the assay conditions used, the rate of factor $X$ activation is linear in time and factor IX is the only rate limiting factor. Thus, the amount of factor $X_{a}$ generated, measured as amidolytic activity towards $\mathrm{S}-2337$, is proportional with the amount of factor $\mathrm{IX}_{\mathrm{a}}$ present in the assay. A reference curve, made with known amounts of purified, human factor $I X_{a}$ is shown in Figure 1 . Plasma could be highly dilluted because of the high sensitivity of the assay, thus abolishing interference of other activated clotting factors. A 200 -fold dilution of an activated plasma sample was sufficient to stop further factor IIX generation and inhibition. Typical factor IX generation curves are shown in Figure 2. Purified human factor IX $(70 \mathrm{nM})$ was added to congenital factor IX deficient plasma (less then $1 \%$ factor IX) after which the plasma was activated with purified human factor $\mathrm{XI}_{\mathrm{a}}(2.5 \mathrm{nM})$ in the presence of $4 \mathrm{mM}$ free calcium and $20 \mu \mathrm{M}$ phospholipid. Although phospholipids are not required for the factor $\mathrm{XI}_{\mathrm{a}}$ catalyzed factor $\mathrm{IX}$ activation reaction (17), it was included to let the process of blood coagulation to proceed via factor $\mathrm{X}_{\mathrm{a}}$ and thrombin generation into fibrin formation. The plasma clotting time was 2.5 minutes. As shown in Figure 2 virtually all factor IX added to the plasma could be recovered as activated factor IX. Interestingly, inhibition of activated factor IX was not observed. The same experiment but performed with purified factor $\mathbf{X I}_{\mathbf{a}}$ and factor IX in a buffer system revealed the very same factor $\mathbf{I X}_{\mathbf{a}}$ generation curve. As expected, no factor $\mathbf{I X}_{\mathbf{a}}$ activity could be demonstrated in 


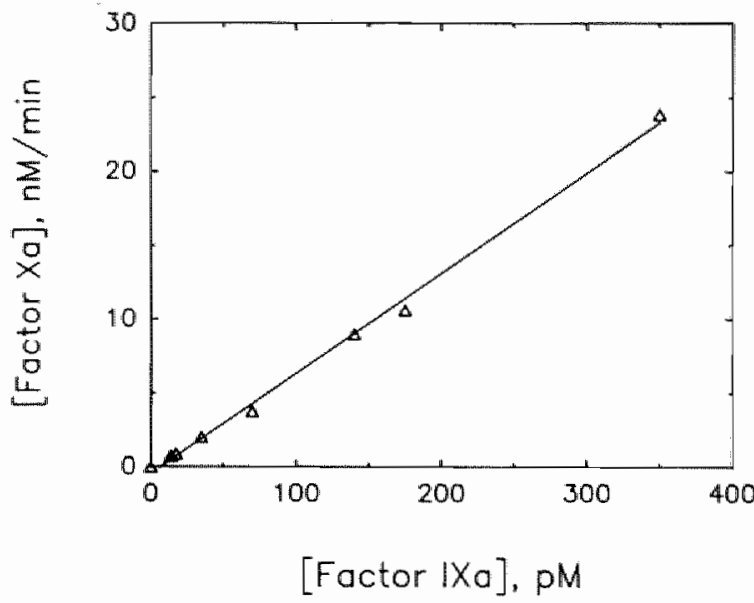

Figure 1: Calibration of the factor $I X_{\mathrm{a}}$ assay

factor IX deficient plasma. To check that our factor $I X_{a}$ assay could not be influenced by the generation of other activated factors, e.g. factor $\mathrm{X}_{\mathrm{a}}$ or thrombin, factor IX deficient plasma was activated with thromboplastin. Although the plasma clotted at 45 seconds and peak values for factor $X_{a}$ and thrombin were 10 $\mathrm{nM}$ and $360 \mathrm{nM}$ respectively, no amidolytic activity could be detected with the actor $\mathrm{IX}_{\mathrm{a}}$ bioassay (data not shown).

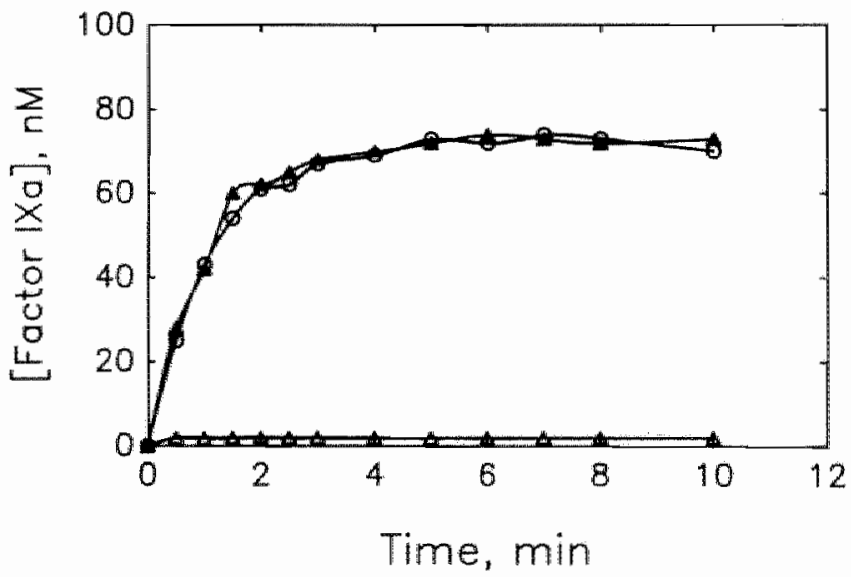

Figure 2: Factor $I X_{\mathrm{a}}$ a generation upon the addition of $70 \mathrm{nM}$ factor $I X_{\mathrm{a}}$ and 2.5 $n M$ factor $X I_{a}$ to factor $I X$ deficient plasma $(\mathbf{\Lambda})$, or buffer $(0) .(\Delta)$ : control, factor $I X$ deficient plasma without factor $I X$ reconstitution. 


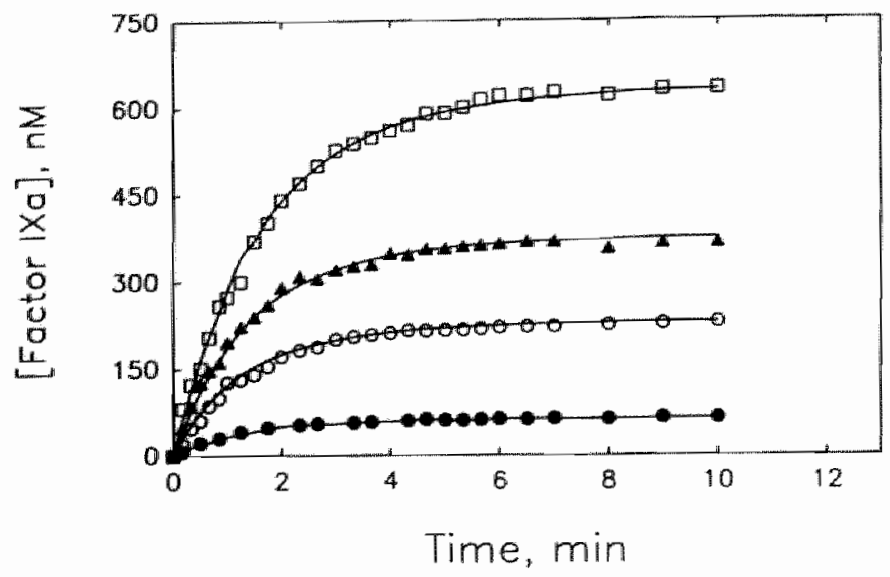

Figure 3: Factor $X_{\mathrm{a}}$ generation curves in plasma by $2.5 \mathrm{nM}$ factor $X I_{\mathrm{a}}$ at a final concentration of $70 \mathrm{nM}$ factor $I X(\bullet), 250 \mathrm{nM}$ factor $I X(\mathrm{o}), 360 \mathrm{nM}$ factor $I X(\star)$ or $650 \mathrm{nM}$ factor $L X(\square)$.

Analysis of Factor $I X_{a}$ Generation Curves in Plasma- In order to be able to evaluate the kinetics of factor $\mathbf{I X}$ and factor $\mathbf{X I}_{\mathbf{a}}$ inhibition in plasma, we first had to determine the $k_{\mathrm{cat}} / \mathrm{K}_{\mathrm{m}}$ value for factor $\mathrm{XI}_{\mathrm{a}}$ catalyzed factor IX activation in plasma. This ratio was determined from a set of factor $I_{\mathrm{a}}$ generation curves as is depicted in Figure 3. Factor IX was added to normal plasma, in order to get a final concentration ranging from $70 \mathrm{nM}$ up to $650 \mathrm{nM}$.

Factor IX activation was started by the addition of $2.5 \mathrm{nM}$ factor $\mathrm{XI}_{\mathrm{a}}, 4 \mathrm{mM}$ free $\mathrm{Ca}^{2+}$ and $20 \mu \mathrm{M}$ phospholipid to the plasma. The lines drawn are the result of the best fit of the mathematical model (described in Materials and Methods) to the data points. The by the fit procedure estimated $k_{\mathrm{ca}} / \mathrm{K}_{\mathrm{m}}$ ratio was $320 \mu \mathrm{M}^{-}$ ${ }^{1}$ min $^{-1}$. The estimated values for the inhibition of factor $\mathrm{XI}_{\mathrm{a}}$ and factor $\mathrm{IX}_{\mathrm{a}}$ was $0.35 \pm 0.05 \mathrm{~min}^{-1}$ and 0 , respectively.

Effect of Heparin on Factor I $X_{a}$ Generation and Inhibition in Plasma- The effects of the 4th International Standard for Heparin (ISH) and the synthetic pentasacellaride heparin on factor $I \mathrm{X}_{\mathrm{a}}$ generation and inhibition were studied in normal plasma using factor $\mathrm{XI}_{\mathrm{a}}(1.25 \mathrm{nM})$, phospholipid $(20 \mu \mathrm{M})$ and $\mathrm{Ca}^{2+}$ (free concentration of $4 \mathrm{mM}$ ) to start coagulation.

Whereas fitting of factor $\mathrm{IX}_{\mathrm{a}}$ activity data from activated plasma in the $\mathrm{ab}$ sence of heparin to our model appears to be excellent, it was not in the presence of heparin. Large deviation between the computed and the experimental gene- 


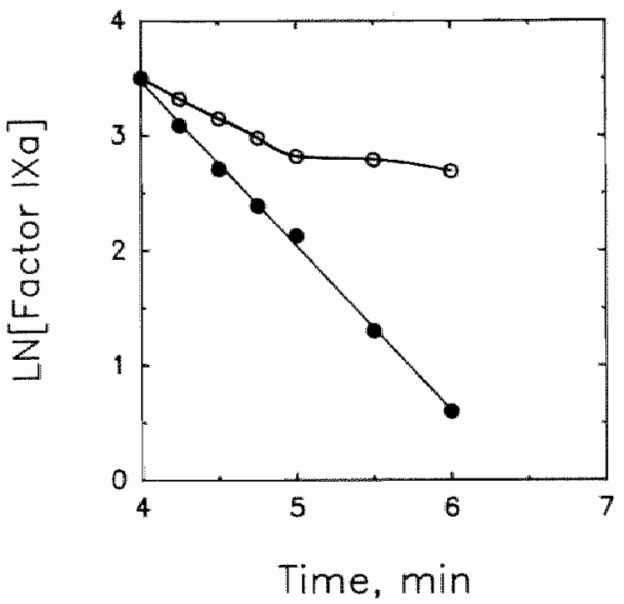

Figure 4: Factor $I X_{\mathrm{a}}$ decay by antithrombin III/heparin in plasma with (-) or without (o) the addition of hirudin. Plasma was activated by factor $X I_{\mathrm{a}}$ as described, and after 4 minutes heparin $(0.175 \mathrm{\mu g} / \mathrm{mL})$ was added and the decay was determined.

ration curves were seen at the decay phase following the plasma clotting time. Obviously, our assumption that the decay of factor $\mathrm{IX}_{\mathrm{a}}$ activity in the presence of heparin could be described as a simple pseudo first order reaction during the entire generation curve was not correct.

In an attempt to examine whether the heparin-dependent inhibition of in situ generated factor $\mathrm{IX}_{\mathrm{a}}$ was different prior to and after fibrin formation the following experiments were performed. Hirudin $(250 \mathrm{nM})$ was added to plasma to prolong the clotting time from 2.5 to over 6 minutes. In order to be able to measure factor $\mathrm{IX}_{\mathrm{a}}$ decay, plasma clotting had to be prolonged, because at the clotting time ( $2.5 \mathrm{~min}$.) factor IX activation was still going on. Standard heparin (0.035 $\mathrm{U} / \mathrm{mL}$ ) was added at 4 minutes to plasma containing hirudin or not. Although in both experiments the very same factor $\mathrm{IX}_{\mathrm{a}}$ levels were obtained, with or without the addition of hirudin, the decay curves, as is shown in Figure 4 were quite different. Whereas heparin-dependent inhibition of in situ generated factor $\mathbf{I X}_{\mathbf{a}}$ followed simple pseudo first order kinetics when the plasma was not clotted (in the case of hirudin addition), it seems that the heparin-dependent factor $\mathbf{I X}_{\mathbf{a}}$ decay once the plasma clots behaves very different (Figure 4).

As yet, we have no explanation for this unexpected phenomenon. The very same observation was made in factor VIII:C deficient plasma prior to and after clotting was initiated by adding factor $\mathrm{X}_{\mathrm{a}}(10 \mathrm{nM})$ to factor $\mathrm{XI}_{\mathrm{a}}$ activated plasma. From this we concluded that protection of factor $\mathbf{I X}_{\mathrm{a}}$ from inhibition by antithrombin III/heparin as a result of complex formation between factor IX phospholipid and factor VIII: $\mathrm{C}_{\mathrm{a}}$ could be ruled out. 
As the factor $\mathrm{IX}_{\mathrm{a}}$ inhibition in heparinized plasma did not follow first order kinetics because of clot formation, all experiments were performed in the presence of $0.5 \mu \mathrm{M}$ hirudin. This amount of hirudin was sufficient to prolong the clotting time from 2.5 to more than 10 minutes, and was found not to influence the factor $\mathrm{XI}_{\mathrm{a}}$-catalyzed factor $\mathrm{IX}_{\mathrm{a}}$ generation in plasma (Pieters and Lindhout, unpublished results).

Figure 5 shows factor $\mathrm{IX}_{\mathrm{a}}$ generation curves in the presence of varying amounts of standard heparin. The drawn lines represent the enzyme generation curves as calculated by the fit-procedure. To reduce the number of variable parameters in our mathematical model, the $k_{\mathrm{ca}} / \mathrm{K}_{\mathrm{m}}$ ratio was set at the fixed value of $320 \mathrm{~min}^{-1}{ }_{\mu} \mathrm{M}^{-1}$, as determined earlier (Figure 3). The by the fit-procedure calculated parameter values $k \mathrm{IX}$ and $k \times \mathrm{Xa}_{\mathrm{a}}$ are depicted in Table $\mathbf{I}$.

Whereas the decay constants of inhibition of in situ generated factor $\mathrm{IX}_{\mathrm{a}}$ increased linear with the heparin concentration $\left(6.16 \mathrm{~min}^{-1} /(\mu \mathrm{g} / \mathrm{mL})\right.$, the decay constant of inhibition of factor $\mathrm{XI}_{\mathrm{a}}$ remained the same whether or not heparin was present (see Table I).

The effect of pentasaccharide on factor $\mathrm{IX}_{\mathrm{a}}$ generation and inhibition were analyzed in the very same way. Figure 6 shows the factor $\mathrm{IX}_{\mathrm{a}}$ generation curves in the presence of varying amounts of pentasaccharide. The drawn lines are the

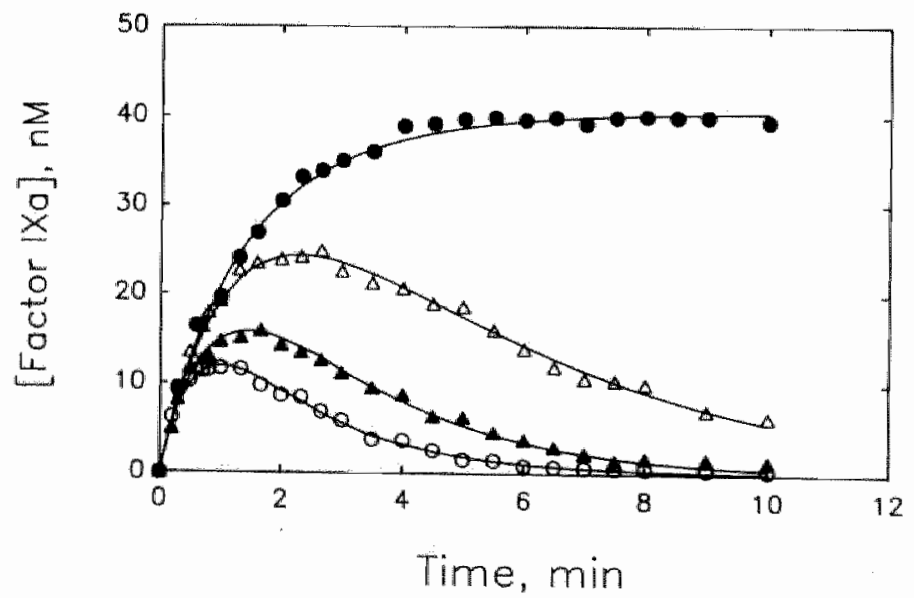

Figure 5: Effect of $0.05 \mu \mathrm{g} / \mathrm{mL}(\Delta), 0.10 \mu \mathrm{g} / \mathrm{mL}(\Delta)$ and $0.175 \mu \mathrm{g} / \mathrm{mL}(0)$ standard heparin on the generation of factor $X_{\mathrm{a}}$ in plasma. (๑): control, no heparin. 
best fit of the model to the data points. The obtained decay constants of inhibition of factor $\mathrm{IX}_{\mathrm{a}}$ and factor $\mathrm{XI}_{\mathrm{a}}$ are listed in Table $\mathrm{I}$. Inhibition of factor $\mathrm{XI}_{\mathrm{a}}$ is not affected by pentasaccharide. Factor $\mathrm{IX}_{\mathrm{a}}$ inhibition, however, is stimulated by pentasaccharide, and the second order rate constant for in situ factor $\mathrm{IX}_{\mathrm{a}}$ inhibition normalized for the pentasaccharide concentration was $0.70 \mathrm{~min}^{-1}$ per $\mu \mathrm{g} / \mathrm{mL}$, thus about 9-fold slower than for standard heparin (on a weight basis; see Table I).

Effect of Calcium Ions on Heparin-Dependent Inthibition in Situ Generated Factor $L X_{a}$-We recently reported that calcium ions stimulate the inhibition of bovine factor IX $\mathrm{X}_{\mathrm{a}}$ by antithrombin II//heparin (5). To see wether calcium ions have an effect on the heparin-catalyzed inhibition of human factor $\mathbf{I X}_{\mathrm{a}}$ by antithrombin III in plasma, we performed an experiment as was shown in Figure 5. Before heparin was added to the activated plasma, EDTA was added at a final concentration of $10 \mathrm{mM}$. At the heparin concentrations used, up to $0.175 \mu \mathrm{g} / \mathrm{mL}$ standard heparin and $5 \mu \mathrm{g} / \mathrm{mL}$ pentasaccharide no inhibition of factor $I_{X_{a}}$ could be detected. Thus, the drastically increased rate of inhibition of in situ generated factor $\mathrm{IX}_{\mathrm{a}}$ caused by either standard heparin or pentasaccharide was completely abolished when free calcium ions were not present. However, when calcium was added to the plasma to retain a free calcium concentration of $4 \mathrm{mM}$, factor $I_{\text {in }}$ was inactivated at about the same rate constants as found by analysis of the factor $\mathrm{IX}_{\mathrm{a}}$ generation curves in heparinized plasma. Because these independently

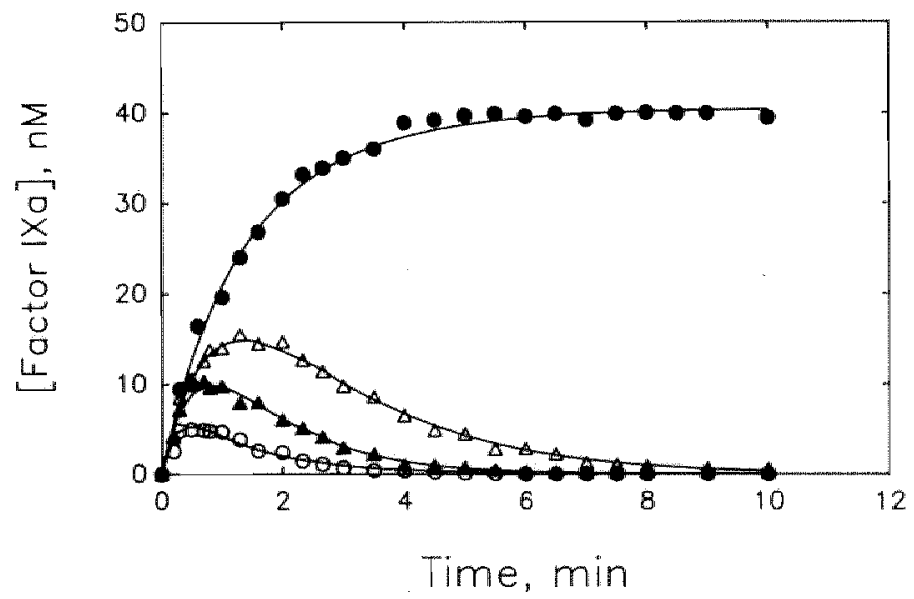

Figure 6: Effect of $5 \mu \mathrm{g} / \mathrm{mL}(\mathrm{O}), 2.5 \mu \mathrm{g} / \mathrm{mL}(\Delta)$ and $I \mu \mathrm{g} / \mathrm{mL}(\Delta)$ pentasaccharide on the generation of factor ${ }_{X} X_{\mathrm{a}}$ in plasma. (๑): control, no pentasaccharide. 
Table I. Pseudo first order rate constants for the inhibition of factor $X I_{\mathrm{a}}$ and factor $I X_{\mathrm{a}}$ in plasma, containing heparin or pentasaccharide as indicated.

\begin{tabular}{|c|c|c|}
\hline [Standard Heparin], $\mu \mathrm{g} / \mathrm{mL}$ & $k \times \operatorname{xa}_{3} \min ^{-1}$ & $k \mathrm{Tx} a, \min ^{-1}$ \\
\hline 0 & 0.35 & 0 \\
\hline 0.05 & 0.39 & 0.30 \\
\hline 0.10 & 0.30 & 0.64 \\
\hline 0.175 & 0.30 & 1.21 \\
\hline \multicolumn{3}{|l|}{$[$ Pentasaccharide], $\mu \mathrm{g} / \mathrm{mL}$} \\
\hline 1.0 & 0.34 & 0.70 \\
\hline 2.5 & 0.39 & 1.51 \\
\hline 5.0 & 0.38 & 3.49 \\
\hline
\end{tabular}

determined decay constants of factor $\mathrm{IX}_{\mathrm{a}}$ are in good agreement with those obtained from the fit-procedure, we conclude that plasma factor $I_{\mathrm{a}}$ generation curves can be acceptably described by the mathematical model.

\section{Discussion}

The purpose of this study was to determine the kinetics of factor $\mathrm{XI}_{\mathrm{a}}$-catalyzed factor IX activation in whole plasma and to investigate the effect of heparin on factor $\mathrm{XI}_{\mathrm{a}}$ and factor $\mathrm{IX}_{\mathrm{a}}$ during factor $\mathrm{IX}$ activation. 
We preferred the use of a factor $\mathbb{I X}_{\mathrm{a}}$ activity bioassay, rather than a radiometric assay because it was aimed to examine both the generation and inactivation reactions. Therefore we made use of an assay that measures sensitively and specificly functional factor $\mathbb{I X}_{\mathrm{a}}$ via its ability to activate factor $\mathrm{X}$ in the presence of phospholipid, calcium and activated factor VIII:C.

Our approach to analyze the factor $\mathrm{IX}_{\mathrm{a}}$ generation curves in plasma involved simple Michaelis-Menten kinetics to describe the activation phase of the reaction system and simple first order decay of both factor $\mathbf{X I}_{\mathbf{a}}$ and factor $\mathbf{I} \mathbf{X}_{\mathrm{a}}$. From Figure 3 where factor $\mathrm{IX}_{\mathrm{a}}$ generation curves at different factor $\mathrm{IX}$ concentrations are depicted, it is clear that fitting our mathematical model to the obtained factor $\mathrm{IX}_{\mathrm{a}}$ generation curves is a valid approach for the determination of the catalytic efficiency, $k_{\text {cat }} / K_{\mathrm{m}}$, which was calculated to be $320 \mathrm{~min}^{-1} \mu \mathrm{M}^{-1}$, and the pseudo first order rate constant of inhibition of factor $\mathrm{XI}_{\mathrm{a}}\left(0.35 \pm 0.05 \mathrm{~min}^{-1}\right)$.

Due to the plasma concentration of factor IX, we were not able to determine an independent value for $k_{\text {cat }}$ and $\mathrm{K}_{\mathrm{m}}$. However, the $k_{\mathrm{cat}} / \mathrm{K}_{\mathrm{m}}$ ratio of 320 min ${ }_{\mu}^{1} \mathrm{M}^{-1}$ is in good agreement with the values reported by Walsh et al. (19) and from our laboratory (18) for factor $\mathrm{XI}_{\mathrm{a}}$-catalyzed factor $\mathrm{IX}$ activation in purified systems (471 and $227 \mathrm{~min}^{-1}{ }_{\mu} \mathrm{M}^{-1}$, respectively).

We tried to determine independent values for $k_{\text {cat }}$ and $K_{\mathrm{m}}$, but even at a factor IX concentration as high as $650 \mathrm{nM}$, the initial rate of factor IX activation by factor $\mathrm{XI}_{\mathbf{a}}$ linearly increased with the factor IX concentration. Therefore, as the $\mathbf{K}_{\mathbf{m}}$ for factor $\mathrm{IX}$ activation by factor $\mathrm{XI}_{a}$ in plasma appeared to be in the $\mu$ molar range, the $k_{\text {cat }} / K_{m}$ ratio was used instead of the separate kinetic parameters in order to analyze the factor $\mathrm{IX}_{\mathrm{a}}$ generation curves in the presence of heparin or pentasaccharide.

The value of $0.35 \pm 0.05 \mathrm{~min}^{-1}$ for factor $\mathrm{XI}_{\mathrm{a}}$ inhibition in plasma is in agreement with the value determined by Scott et al (20) for factor $\mathrm{XI}_{\mathrm{a}}$ inhibition by $\alpha_{1-}{ }^{-}$ antitrypsin in plasma. However, Meijers et al (21) showed that in plasma factor $\mathrm{XI}_{\mathrm{a}}$ is mainly inactivated by the concerted action of a1-antitrypsin (24\%), $\mathrm{\alpha z}_{2}$ antiplasmin (25\%) and C1-inhibitor (31\%).

The determination of the effect of heparin on factor $\mathrm{IX}_{\mathrm{a}}$ generation in normal plasma was not possible because clotting of the plasma abolished the heparinstimulated inactivation of factor $\mathrm{IX}_{\mathrm{a}}$. We established that this effect was not due to protection of factor IX $\mathrm{X}_{\mathrm{a}}$ by activated factor VIII:C from inhibition by antithrombin III. This neutralization of heparin activity is related to clot formation, but not to thrombin formation. Whether the generated fibrinogen-degradation products cause the altered inhibition kinetics of factor IX $_{\mathrm{a}}$ by antithrombin III, remains to be established.

In order to prolong the clotting time to over 10 minutes, hirudin was added at a concentration of $500 \mathrm{nM}$ to the plasma. Standard heparin was found to stimulate the inhibition of factor $\mathrm{IX}_{\mathrm{a}}$ with a rate constant normalized for the heparin 
concentration of $6.16 \mathrm{~min}^{-1} / \mu \mathrm{g}$ heparin/mL (Table I). The fact that heparin greatly stimulates factor $\mathrm{IX}_{\mathrm{a}}$ inhibition in plasma is in agreement with previous studies (4).

The effect of pentasaccharide on factor $\mathrm{IX}_{\mathrm{a}}$ generation was quite unexpected. Table I shows that pentasaccharide is capable of stimulating the inhibition of factor $\mathrm{IX}_{\mathrm{a}}$ with $0.70 \mathrm{~min}^{-1} / \mathrm{mg}$ pentasaccharide $/ \mathrm{mL}$. Although little is known about the interaction of factor IX $_{\mathrm{a}}$-heparin-antithrombin III, it is generally assumed that the mechanism of factor $\mathrm{IX}_{\mathrm{a}}$ inhibition resembles that of thrombin inhibition. That is, the inhibition of factor $\mathrm{IX}_{\mathrm{a}}$ by theparin/antithrombin III proceeds via the binding of heparin to factor $\mathrm{IX}_{\mathrm{a}}$. However, pentasaccharide (22) represents the antithrombin III binding sequence of heparin, and thus probably exerts its anti-protease effect not via the binding to the enzyme, but solely via binding to antithrombin III. And indeed, a previous study of the effect of pentasaccharide on the inactivation of (bovine) factor $\mathrm{IX}_{\mathrm{a}}$ in a pure system showed that pentasaccharide, added in high concentrations had no effect at all.

The inhibition of factor $\mathrm{IX}_{\mathrm{a}}$ by antithrombin III/heparin in plasma only occurred in the presence of free calcium ions ( $4 \mathrm{mM}$ ). The addition of EDTA completely abolished the heparin-dependent inhibition of factor $\mathbf{I X}_{\mathrm{a}}$. This is in agreement with the results obtained from studies with bovine factor $\mathrm{IX}_{\mathrm{a}}$ in a purified system (5), but in contrast to the effect of calcium ions in the heparinstimulated inhibition of e.g. thrombin, for which it was found that $\mathrm{Ca}^{2+}$ inhibits the heparin-dependent antithrombin III inhibition (8).

Acknowledgement. The authors wish to thank Drs. Wagevoord and Hendrix for help with the protein purification.

\section{References}

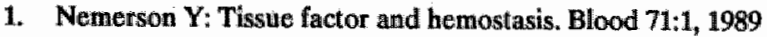

2. Thompson AR: Structure, function and molecular defects of factor IX. Blood 67:565, 1986

3. McNeely T, Griffith MJ: The anticoagulant mechanism of action of heparin in contactactivated plasma: inhibition of factor $X$ activation. Blood 65:1226, 1985a

4. Fuchs HE, Trapp HG, Griffith MJ ${ }_{*}$ Roberts HR, Pizzo SV: Regulation of factor IXa in vitro in human and in mouse plasma and in vivo in the mouse. Role of Endothelinm and the plasma proteinase inhibitors. J Clin Invest 73:1696, 1984

5. Pieters J, Willems $\mathrm{G}$, Hemker $\mathrm{HC}$, Lindhout $T$ : Inhibition of factor $\mathrm{X}_{\mathrm{a}}$ and factor $\mathrm{X}_{\mathrm{a}}$ by antithrombin III/heparin during factior $X$ activation. J Biol Chem, 263(30):15313, 1988 
6. Rosenberg JS, McKenna PW, Rosenberg RD: Inhibition of human factor $\mathrm{LX}_{\text {, }}$ by human antithrombin III. J Biol Chem 250:8883, 1975

7. Holmer $\mathrm{E}$, Kurachi $\mathrm{K}$, Söderström $\mathrm{G}$ : The molecular-weight dlependence of the rateenhancing effect of heparin on the inhibition of thrombin, factor $\mathrm{X}_{\mathbf{3}}$ factor $\mathbf{I X}_{\mathrm{a}}$, factor $\mathrm{XI}_{\mathrm{a}}$, factor XIIa, and kallikrein by antithrombin III. Biochem J 193:395, 1981

8. Speight $\mathrm{MO}$, Griffith $\mathrm{MJ}$ : Calcium inhibits the heparin-catalyzed antithrombin III/thrombin reaction by decreasing the apparent binding affinity of heparin for thrombin. Arch Biochem Biophys 225:958, 1983

9. Morrison SA, Jesty J: Tissue factor-dependent activation of tritium-labeled factor IX and factor $X$ in plasma. Blood 63:1338, 1984

10. Lindhout $T$, Baruch $D_{*}$ Schoen $\mathbb{P}$, Franssen $J$, Hemker HC: Thrombin gentration and inactivation in the presence of antithrombin and heparin. Biochemistry 25:5962, 1986

11. Van Dieijen $G$, Tans $G$, Rosing $J$, Hemker $\mathrm{HC}$ : The role of phospholipid and factor VIIIa in the activation of bovine factor X. I Biol Chem 256:3433, 1981 .

12. Rosing $J$, van Rijn JLML, van Dieijen $G_{3}$ Comfurius $P$, Zwaal RFA:The role of activated platelets in prothrombin and factor $X$ activation. Blood 65:319, 1985

13. Lindhout T, Govers-Riemslag JWP, van de Waart P, Hemker HC, Rosing J: Factor Vafactor $\mathrm{X}_{\mathrm{a}}$ interaction. Effects of phospholipid vesicles of varying composition. Biochemistry $21: 5494,1982$

14. Gill PE, Murray W: SIAM J Num Anal 15:977, 1978

15. Press WH, Flannery BP, Tenkolski SA, Vetterling WT in: Nume rical Recipes, Cambridge University Press, pp 547, 1986

16. Beck JV, Arnold KJ: Parameter estimation in engeneering and science, Johb Willey \& Sons, New York, pp 334, 1977

17. Van der Graaf F, Greengard JS, Bouma BN, Kerbiriou DM, Griffin JH, J Biol Chem $258: 9669,1983$

18. Soons $\mathrm{H}$ : Studies on the inhibition of blood coagulation factor $\mathrm{XI}_{\mathrm{a}}$. Thesis at the University of Limburg, Maastricht, the Netherlands, 1987

19. Walsh PN, Bradford H, Simba D, Piperno JR, Tuszynski GP: Kinetics of the factor $\mathbf{X I}_{a}$ catalyzed activation of human blood coagulation factor IX. I Clin Invest 73:1392, 1984

20. Scott CF, Schapira M, James $\mathbf{H L}$, Cohen $\mathbf{A B}$, Colman RW: Inactivation of factor $\mathbf{X I}_{\mathbf{a}}$ by plasma protease inhibitors: Predominant role of a1-protease inhibitor and protective effect of high molecular weight kininogen. J Clin Invest 68:844, 1982

21. Meijers JCM: Regulation of the blood coagulation mechanism by plasma proteinase inhibitors. Thesis at the University of Utrecht, the Netherlands

22. Choay J, Petitou M, Lormeau JC, Sinay P, Casu P, Gatti G: Structure activity relationships in heparin: a synthetic pentasaccharide with high affinity for antithrombin III and eliciting high anti-factor $\mathrm{X}_{\mathrm{t}}$ activity. Biochem Biophys Res Comm 116:492, 1983 


\section{Chapter VI}

\section{In Situ Generated Thrombin is the Only Enzyme that Effectively Activates Factor VIII:C and Factor V in Plasma ${ }^{0}$}

\section{Abstract}

We investigated the activation of the non-enzymatic protein cofactors factor VIII:C and factor V in plasma when coagulation was initiated by thromboplastin. Using sensitive bio-assays we were able to measure specifically the generation of factor VIII: $\mathrm{C}_{\mathrm{a}}$ and factor $\mathrm{V}_{\mathrm{a}}$ in plasma.

Our results showed that when plasma was triggered with a relative high concentration of thromboplastin, factor VIII:C and factor V were completely activated at the clotting time of plasma. However, when the generation of thrombin, but not that of factor $X_{a}$ was delayed by adding hirudin to the plasma, factor $V_{a}$ was only generated at the time thrombin generation overcame the hirudin inhibition. Also the generation of factor VIII: $\mathrm{C}_{\mathrm{a}}$ correlated with the thrombin generation, and not with factor $X_{a}$ generation. Furthermore, addition of high amounts of factor $X_{a}$ to hirudinized plasma did not show any factor VIII:C or factor $\mathrm{V}$ activation.

a Based on: Pieters J, Hemker HC, Lindhout T, submitted 
We concluded that in plasma, activated with thromboplastin, the enzyme responsible for the activation of factor $\mathrm{V}$ and factor VIII:C is thrombin, and not factor $X_{a}$.

\section{Introduction}

Clotting of plasma is the result of a series of enzymatic reactions acting in a staged cascade system (1). Starting either from the intrinsic or extrinsic coagulation pathway, the coagulation system comprises a number of feed-back activation reactions. For example, the generation of thrombin via the intrinsic pathway proceeds only at a considerable rate after the non enzymatic protein cofactors factor $\mathrm{V}$ and factor VIII:C have been activated $(2,3)$. Activated factor VIII:C serves as an essential cofactor for the activation of factor $\mathrm{X}$ by factor $\mathrm{IX}_{\mathrm{a}}$, while factor $\mathrm{V}_{\mathrm{a}}$ plays an important role in the factor $\mathrm{X}_{\mathrm{a}}$-catalyzed conversion of prothrombin into thrombin.

Conversion of factor VIII:C into its activated form is thought to proceed principally through the proteolytic activity of thrombin (4), although factor $\mathrm{X}_{\mathrm{a}}$ is also considered to be a possible important activator of factor VIII:C $(4,5)$. The activation of factor VIII:C by factor IX $\mathrm{a}$ has been demonstrated in a purified system. However, the factor $\mathrm{IX}_{\mathrm{a}}$ concentrations used in this study exceeded the plasma factor IX concentration, making it unlikely that factor $\mathrm{IX}_{\mathrm{a}}$ could be physiologically important for this activation (6).

Activators of factor $V$ include thrombin and factor $X_{a}(7,8)$. However, the thrombin-catalyzed activation of factor $V$ appeared to be a 100-fold faster than factor $\mathrm{X}_{\mathrm{a}}$ on a molar base (8). Proteases present in platelets and endothelial cells have also been shown to activate factor $V$, although it is not clear if these activation reactions occur under physiologic conditions $(9,10$, see reference 11 for a review on factor $\mathrm{V}$ and factor VIII:C)

The relative importance of the above mentioned activators for the in vivo normal haemostasis is not clear. Although a number of enzymes have been described to activate factor VIII:C and factor V in purified systems, the relative catalytic efficiencies of these enzymes in plasma are unknown.

Therefore, we investigated the activation of factor $\mathrm{V}$ and factor VIII:C under more physiological conditions, namely in whole, platelet free, plasma activated with thromboplastin. With the use of very specific bio-assays we were able to follow the generation of factor $\mathrm{V}_{\mathrm{a}}$ and factor VIII: $\mathrm{C}_{\mathrm{a}}$ during coagulation in plasma. With the use of hirudin we separated the thrombin generation from the factor $X_{\mathrm{a}}$ generation, and clearly demonstrated that in this system, thrombin is the only enzyme responsible for the activation of both factor V and factor VIII:C. 


\section{Materials and methods}

Materials- The synthetic peptide substrates Bz-Ile-Glu-(Piperidyl)-Gly-Arg-pnitro-anilide hydrochloride (S-2337) and H-D-Phenylalanyl-L-pipecolyl-L-arginine-p-nitro-anilide dihydrochloride (S-2238) were purchased from AB Kabi Diagnostica, Stockholm. Ovalbumin was a product of Sigma Chemical Co., St. Louis. All reagents used were of the highest grade commercially available.

Human brain thromboplastin was prepared by the method of Owren and Aas (12). It was homogenated in a Potter Elvehjem homogenizer for 3 minutes, centrifugated at $2,000 \mathrm{x}$ g for 15 minutes and stored at $-80^{\circ} \mathrm{C}$. Its concentration was adjusted with Tris-saline to give a prothrombin time of $13 \mathrm{~s}$.

Proteins- Recombinant desulphato-hirudin variant 1 (CGP 39393) was kindly provided by Dr. Wallis, Ciba-Geigy, Horsham, United Kingdom. All bovine clotting factors were prepared and quantitated as previously described $(2,13,14)$.

Phospholipid- Phospholipid vesicles were made from a mixture of phosphatidylserine (PS) and phosphatidylcholine (PC) as previously described (14). Vesicles composed of 25 mole\% PS and 75 mole\% PC were used throughout the experiments.

Preparation of Human Normal Plasma- Blood from healthy donors was collected on $0.13 \mathrm{~mol} / \mathrm{L}$ trisodium citrate; nine parts blood to one part of citrate solution. The blood was then centrifugated twice at room temperature for $15 \mathrm{minu}-$ tes at $3,000 \mathrm{xg}$. A third centrifugation was done at $4^{\circ} \mathrm{C}$ for one hour at $23,000 \mathrm{x}$ g. The obtained platelet free plasma was stored at $-80^{\circ} \mathrm{C}$.

Thromboplastin-Induced Factor $X_{a}$, Factor $V_{a}$, Factor VIII: $C_{a}$ and Thrombin Generation in Platelet Free Plasma- To $0.13 \mathrm{~mL}$ of citrated human plasma, $9 \mu \mathrm{L}$ of a Tris-buffer ( $50 \mathrm{mM}$ Tris, $180 \mathrm{mM} \mathrm{NaCl}, 0.5 \mathrm{mg}$ ovalbumin/mL, pH 7.9 ) with or without hirudin was added and incubated for $4 \mathrm{~min}$ in a flat-bottom plastic tube while stirring. Clotting was initiated by the addition of $11 \mu \mathrm{L}$ of the Tris-buffer containing $0.27 \mathrm{~mol} / \mathrm{L} \mathrm{CaCl} 2$ and human brain thromboplastin. Timed samples $(10 \mu \mathrm{L})$ were removed from incubations and assayed for either factor $V_{a,}$ factor $\mathrm{X}_{\mathrm{a}}$ or thrombin activity.

Factor $V_{a}$ Assay- Factor $\mathrm{V}_{\mathrm{a}}$ was assayed in plasma samples, diluted 1:200 in Tris-buffer ( $\mathrm{pH} 7.9$ ) containing $5 \mathrm{mM} \mathrm{CaCl} 2$ and $0.5 \mu \mathrm{g}$ unfractionated heparin/$\mathrm{mL}$. Ten $\mu \mathrm{L}$ of the diluted sample was added to a cuvette containing $13 \mathrm{pM}$ factor $\mathrm{X}_{\mathrm{a}}, 5 \mathrm{mM} \mathrm{CaCl} 2$ and $50 \mu \mathrm{M}$ phospholipid in Tris-buffer. After 4 min thrombin generation was initiated by the addition of prothrombin $(0.2 \mu \mathrm{M}$ final 
concentration in $125 \mu \mathrm{L}$ ). The reaction was stopped after 2 min by the addition of $325 \mu \mathrm{L}$ Tris-buffer containing $20 \mathrm{mM}$ EDTA. The amount of thrombin was measured in a dual-wavelength spectrophotometer using S-2238 as described previously (15).

Factor VIII:Ca assay-Factor VIII:Ca was assayed in plasma samples diluted $1: 40$ directly into the assay-mixture containing $100 \mathrm{nM}$ bovine factor $\mathrm{IX}_{\mathrm{a}}, 20 \mu \mathrm{M}$ phospholipids and $5 \mathrm{mM} \mathrm{CaCl} 2$ in Tris-buffer $(\mathrm{pH} 7.9$ ) containing $0.5 \mathrm{mg} / \mathrm{mL}$ ovalbumin. The reaction was started after 15 seconds upon the addition of bovine factor $X$ (final concentration $0.5 \mu \mathrm{M}$ ). At 30 and 90 seconds $50 \mu \mathrm{L}$ was taken and assayed for factor $X_{a}$ activity using the chromogenic substrate S-2337. From these two time points the rate of factor $\mathrm{X}$ activation was determined and was linear with the added amounts of factor VIII: $\mathrm{C}_{\mathrm{a}}$.

Factor $X_{a}$ Assay- Factor $X_{a}$ was assayed in plasma samples diluted 1:200 in Tris-buffer ( $\mathrm{pH} 7.9$ ). Ten $\mu \mathrm{L}$ of the diluted sample was added to a cuvette containing $0.6 \mathrm{nM}$ factor $\mathrm{V}_{\mathrm{an}} 50 \mu \mathrm{M}$ phospholipid and $5 \mathrm{mM} \mathrm{CaCl} 2$ in Tris-buffer. After $4 \mathrm{~min}$ prothrombin $(1.5 \mu \mathrm{M}$ final concentration in $50 \mu \mathrm{L})$ was added and the assay was proceeded as described for factor $V_{a}$.

Thrombin Assay- Undiluted plasma samples $(5 \mu \mathrm{L})$ were added to a cuvette containing $495 \mu \mathrm{L}$ Tris-buffer, $20 \mathrm{mM}$ EDTA and $0.25 \mathrm{mM} \mathrm{S}-2238$. The thrombin activity was calculated from the change in absorbance as described previously (15).

\section{Results}

Factor VIII:C Bioassay- In order to be able to determine activated factor VIII:C in plasma, a highly sensitive and specific bio-assay was developed making use of the activity of factor VIII: $\mathrm{C}_{\mathrm{a}}$ as a cofactor in the activation of factor $\mathrm{X}$ by factor $\mathrm{IX}_{\mathrm{a}}$ in the presence of phospholipids and calcium. By judicious choice of the concentrations of the reaction components, we were able to measure factor VIII: $\mathrm{Ca}_{\mathrm{a}}$ without interference of non-activated factor VIII:C. Figure 1 shows the calibration curve constructed from a series of plasma dilutions which were activated with thrombin ( $50 \mathrm{nM}$ ) (Figure 1, closed circles). Assuming that the plasma concentration of factor VIII:C is about $1 \mathrm{nM}(11,16)$, Figure 1 shows that this assay is linear up to $30 \mathrm{pM}$ activated factor VIII:C and concentrations as low as 5 pM can be determined. The intersection at the ordinate represents the activity of 


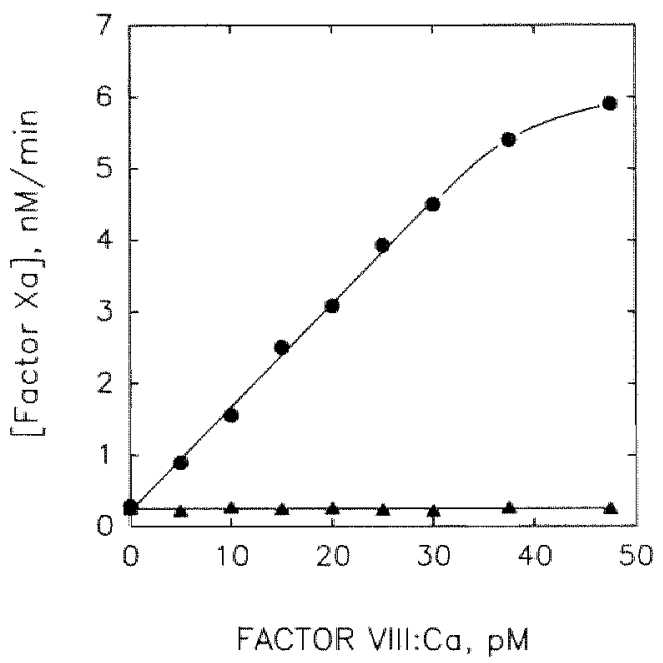

Figure 1: Calibration curve for factor VII: $C_{\mathrm{a}}(\bullet)$. Human normal plasma was diluted to obtain the concentrations factor VIII:C indicated, assuming that the concentration of plasma factor VIII:C is $1 \mathrm{nM}$. The (diluted) plasma samples were activated with $50 \mathrm{nM}$ thrombin, and the activity was determined as described under Materials and Methods. The activity of plasma that was not activated with thrombin was also determined (4).

the assay without factor VIII:C(a). The closed triangles in Figure 1 represent the activity of plasma which was not activated with thrombin. Control experiments in factor VIII:C deficient plasma showed the blanc activity on the assay.

Effect of Hirudin on Thrombin and Factor $X_{a}$ Generation- In order to investigate the relative importance of thrombin and factor $X_{a}$ to the activation of factor $V$ and factor VIII:C, we first had to separate the thrombin generation and factor $\mathrm{X}_{\mathrm{a}}$ generation, as these two are the possible activators of the cofactors $\mathrm{V}$ and VIII:C in our plasma system. To this end, we incubated plasma in the presence of hirudin and activated it using thromboplastin at a final concentration of $1 / 30$ (vol/vol). Thrombin generation and factor $X_{a}$ generation were determined as described under Materials and Methods. Figure 2 shows the effect of the addition of different amounts of hirudin on thrombin and factor $\mathrm{X}_{\mathrm{a}}$ generation. The thrombin generation curve without hirudin is characterized by a very short lag period followed by explosive thrombin formation. The fast inactivation of the formed thrombin, which occurs after the peak at 1 minute, is mainly due to the 


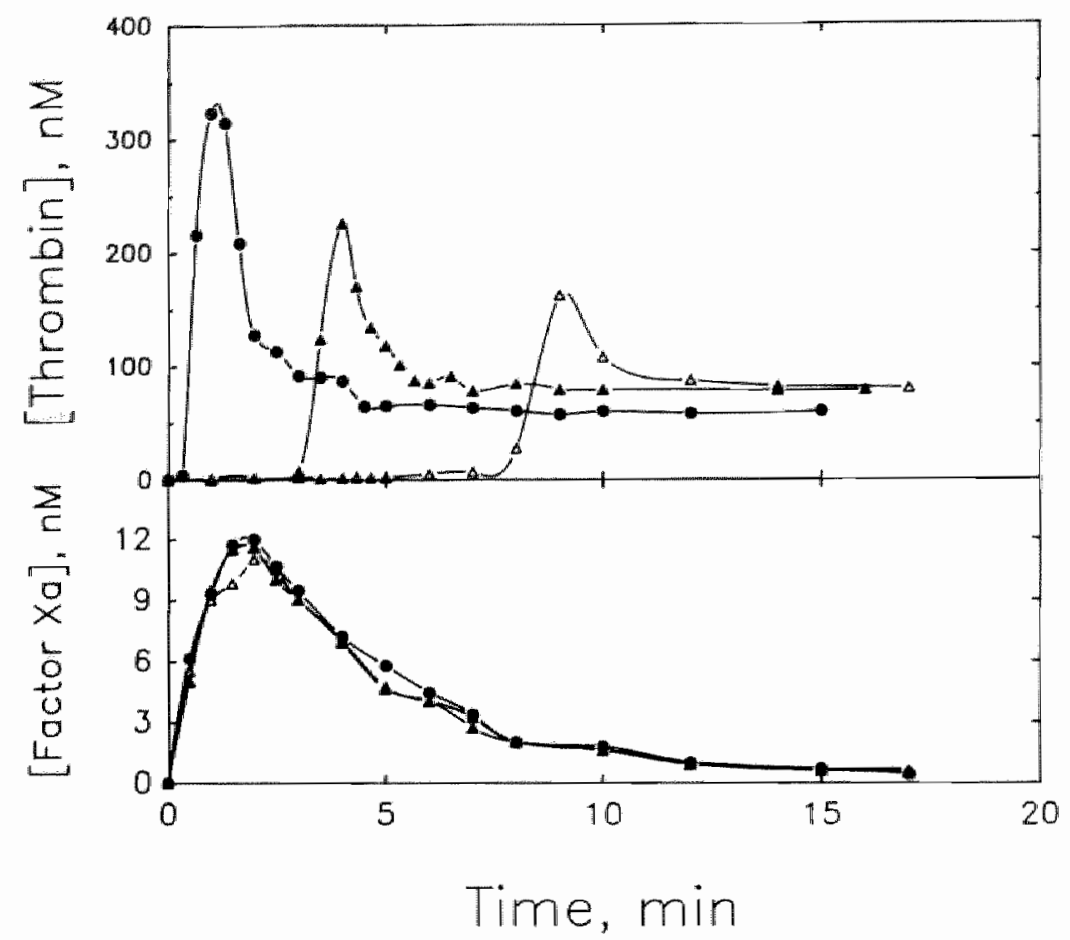

Figure 2: Effect of hinudin on thrombin generation (Panel $A$ ) and factor $X_{\mathrm{a}}$ generation (Panel B) in thromboplastin-activated plasma. The concentrations hirudin used were $0(\bullet), 0.5(\Delta)$ and $0.75(\triangle) \mu M$.

action of antithrombin III and 2-macroglobulin. From Figure 2A it is clear that the more hirudin is present, the more the thrombin generation is delayed, and also the maximal amount of thrombin formed is decreased. The factor $\mathrm{X}_{\mathrm{a}}$ generation, however, is not at all influenced by hirudin.

Effect of Hirudin on Factor $V_{a}$ and Factor VIII: $C_{a}$ Generation- Figure 3 shows factor $V_{a}$ generation curves as they were obtained when plasma was activated with thromboplastin in the presence of varying amounts of hirudin. Apparently,

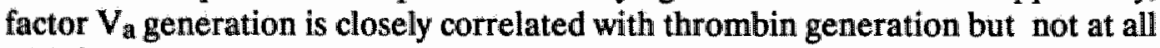
with factor $\mathrm{X}_{\mathrm{a}}$ generation. As in the case of thrombin generation, increasing 


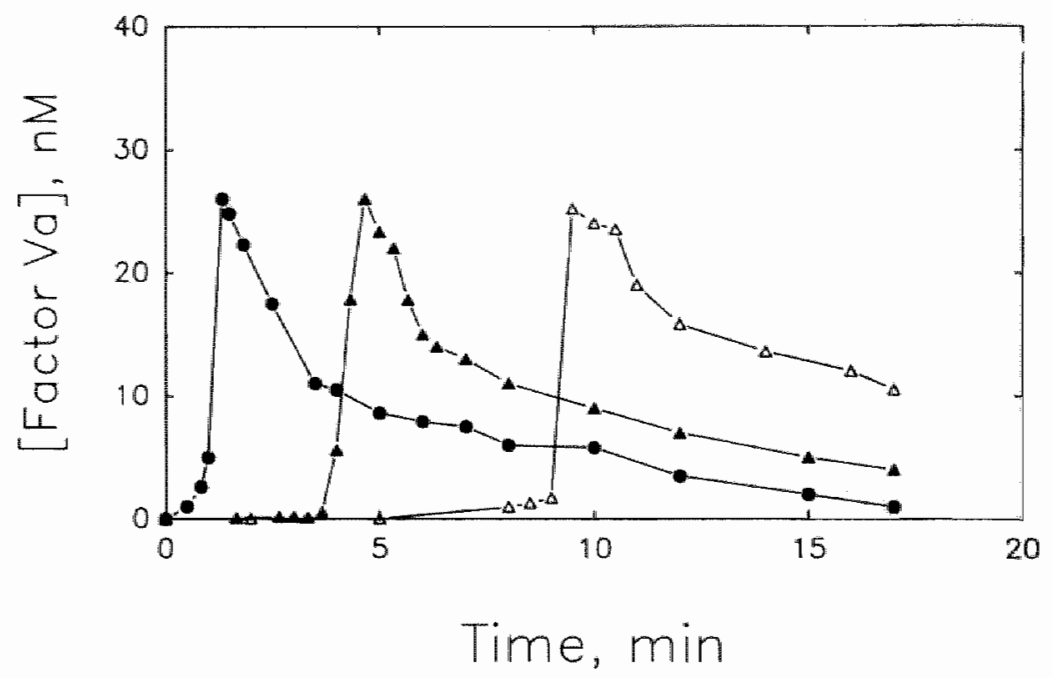

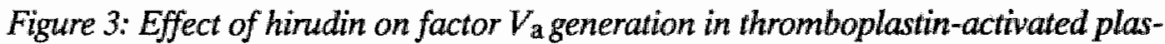
ma. The concentrations hirudin used were $0(\bullet), 0.5(\Delta)$ and $0.75(\Delta) \mu M$.

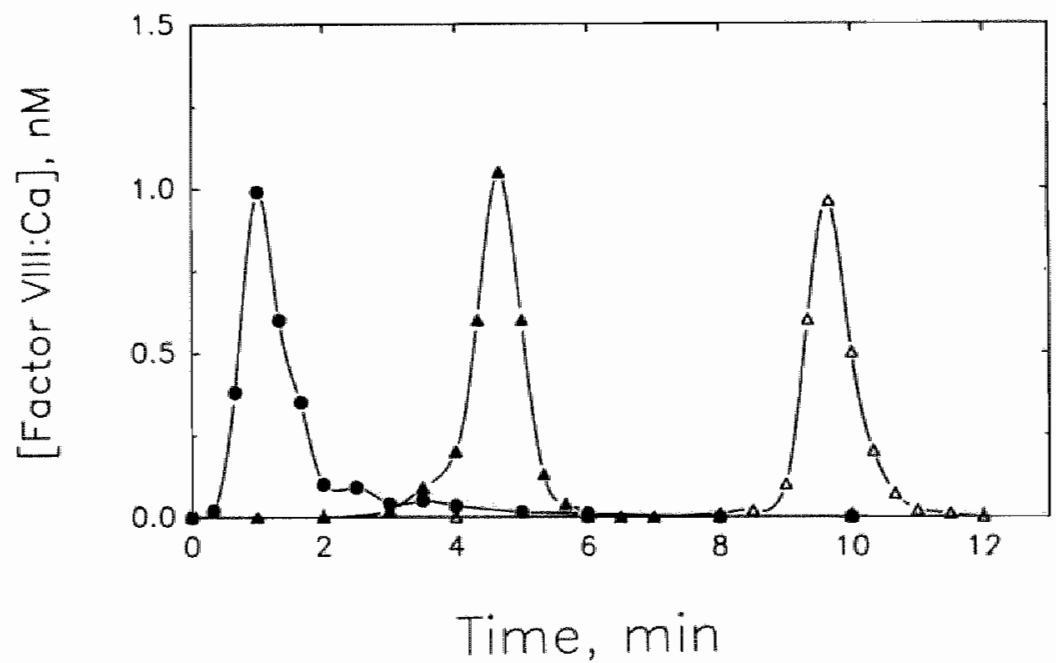

Figure 4: Effect of hirudin on factor VIII: $C_{\text {a generation in thromboplastin-activated }}$ plasma. The concentrations hirudin used were $0(\bullet), 0.5(\Delta)$ and $0.75(\Delta) \mu M$. 
amounts of hirudin caused a prolongation of the lag-phase of factor $V_{a}$ generation. It should be noted that despite a drastic decrease of non-complexed thrombin with increasing hirudin, maximal factor $V_{a}$ activities could be generated. Like the factor $\mathrm{V}_{\mathrm{a}}$ generation curves, the factor VIII: $\mathrm{C}_{\mathrm{a}}$ generation curves (Figure 4) showed a very rapid activation phase followed by a decay of factor VIII:Ca activity. Again, factor VIII: $\mathrm{C}_{\mathrm{a}}$ generation is closely correlated with thrombin generation but not with factor $\mathrm{X}_{\mathrm{a}}$ generation.

Exogerous Factor $X_{a^{-}}$In an attempt to see whether or not factor $V$ and factor VIII: $\mathrm{C}$ could be activated by factor $\mathrm{X}_{\mathrm{a}}$ in plasma at a concentration approaching the amount of factor $\mathrm{X}$ present in plasma, $100 \mathrm{nM}$ of purified human factor $\mathrm{X}_{\mathrm{a}}$ was added to plasma incubated for 8 minutes with thromboplastin (1/30 $\mathrm{vol} / \mathrm{vol}), \mathrm{Ca}^{2+}(20 \mathrm{mM})$ and hirudin $(2 \mu \mathrm{M})$. Prior to the addition of factor $\mathrm{X}_{\mathrm{a}}$, no factor $\mathrm{V}_{\mathrm{a}}$, nor factor VIII: $\mathrm{C}_{\mathrm{a}}$ or thrombin activities could be detected. Factor $\mathrm{X}_{\mathrm{a}}$ level was about $2 \mathrm{nM}$. After the addition of factor $X_{a \text {, samples were taken and }}$ assayed for factor $\mathrm{V}_{\mathrm{a}}$ and factor VIII: $\mathrm{C}_{\mathrm{a}}$. Up to 5 minutes following the addition of factor $\mathrm{X}_{\mathrm{a}}$, no factor $\mathrm{V}_{\mathrm{a}}$ nor factor VIII: $\mathrm{C}_{\mathrm{a}}$ activity could be detected, neither thrombin activity.

\section{Discussion}

A number of investigators have explained their findings on the effects of the anticoagulant drug heparin on the intrinsic pathway of blood coagulation by assuming that trace amounts of factor $\mathrm{X}_{\mathrm{a}}$ are able to activate factor VIII:C and factor $V(17)$. Although thrombin might be the most efficient activator of both cofactors (11), thrombin is also the end product of the coagulation process. Therefore, a (partial) activation of factor $V$ or factor VIII:C by factor $X_{a}$ earlier in coagulation could amplify thrombin generation by inducing small amounts of thrombin which than in turn by a positive feedback mechanism activate factor VIII:C and factor V. However, that indeed factor VIII:C and factor V activation by factor $X_{a}$ is essential to attain "physiological" rates of factor $X_{a}$ and thrombin generation in plasma has, to our knowledge, never been demonstrated.

In this study we determined the relative contribution of factor $X_{a}$ and thrombin to the in situ activation of the non-enzymatic protein cofactors factor VIII:C and factor $V$ in plasma. The plasma was triggered with a high concentration of thromboplastin, thus limiting the activation reactions to the extrinsic pathway (18). Preliminary studies on the intrinsic pathway of blood coagulation revealed that factor $\mathrm{X}_{\mathrm{a}}$ generation was strongly controlled by specific thrombin inhibitors 
like hirudin. As in such a system thrombin and factor $\mathrm{X}_{\mathrm{a}}$ generation cannot be separated, it is extremely difficult to study the relative contribution of thrombin and factor $\mathrm{X}_{\mathrm{a}}$ generation to the activation of factor $\mathrm{V}$ and factor VIII:C (Pieters J, Lindhout $T$, unpublished results). Therefore, thromboplastin-activated plasma was used rather than contact-activated plasma.

We developed a very specific assay to monitor the generation of factor VIII: $\mathrm{Ca}_{\mathrm{a}}$ in plasma, making use of the fact that (human) factor VIII: $\mathrm{Ca}_{\mathrm{a}}$ is able to catalyze (bovine) factor $\mathrm{X}$ activation by (bovine) factor $\mathrm{IX}_{\mathrm{a}}$ in the presence of phospholipids and calcium. A sensitive assay for the determination of factor $V_{a}$ generation in plasma was developed during earlier studies $(18,19)$.

The generation of factor VIII:Ca in thromboplastin-activated plasma follows exactly the generation of thrombin, and shows a maximum around 11 minute. However, at that time point also factor $\mathrm{X}_{\mathrm{a}}$ is generated, so that it is not clear what the relative contribution of thrombin and factor $X_{a}$ is in this system to the activation of factor VIII:C. In order to obtain a thrombin generation, independent from factor $X_{a}$ generation, we added hirudin to the plasma in several concentrations. The thrombin generation curve obtained was indeed dependent on the hirudin concentration used, while the factor $X_{a}$ generation curve was not at all influenced by hirudin. When we determined the generation of factor VIII: $C_{a}$ in this hirudinized plasma, it appeared that this generation paralleled the generation of thrombin but not that of factor $X_{\mathrm{a}}$. Moreover, addition of a high amount of factor $X_{a}$ to thromboplastin-activated plasma containing $2 \mu \mathrm{M}$ hirudin, did not cause any activation of factor VIII:C.

The activation of factor $V$ was investigated in a similar way; thrombin generation and factor $\mathrm{X}_{\mathrm{a}}$ were separated by means of hirudin addition, and factor $\mathrm{V}_{\mathrm{a}}$ generation was determined. Also in this case, generation of factor $V_{a}$ entirely parallels thrombin generation, and addition of a high amount of factor $\mathrm{X}_{\mathrm{a}}$ did not induce factor $V_{\mathrm{a}}$ generation.

The results of this study using plasma as a physiological environment for coagulation, and thromboplastin as a clotting trigger, show that under these conditions thrombin is the only activator of the cofactors factor VIII:C and factor V. The mechanism of plasma clotting evolving from our results is one in which via the TF:factor $\mathrm{VII}_{\mathrm{a}}$ complex factor $\mathrm{X}$ is activated. This initially present factor $\mathrm{X}_{\mathrm{a}}$ is able to convert at a low rate prothrombin into thrombin, which then is able to activate factor VIII:C and factor V. Only then sufficient amounts of thrombin are generated to ensure proper clotting.

The conclusions derived from this study once again emphasizes the central role of thrombin in the overall process of blood coagulation. 


\section{References}

1. Jackson CM, Nemerson Y: Blood coagulation. Ann Rev Biochem $49: 765,1980$

2. Rosing J, Tans G, Gowers-Riemslag JWP, Zwaal RFA, Hemker HC: The role of phospholipids and factor $V_{a}$ in the prothrombinase complex. J Biol Chem 255:274, 1980

3. van Dieijen $G$, Tans $G$, Rosing $J$, Hemker $H C$ : The role of phospholipid and factor VIII in the activation of bovine factor X. J Biol Chem 256:3433, 1981

4. Vehar GA, Davie EW: Preparation and properties of bovine factor VIII (antihemophilic factor). Biochemistry, 19:401, 1980

5. Lollar P, Knutson GJ, Fass DN: Activation of porcine factor VII: $\mathrm{C}$ by thrombin and factor $\mathrm{X}_{\text {a. }}$. Biochemistry 24:8056, 1985

6. Rick M: Activation of factor VIII by factor $1 X_{\mathrm{a}}$. Blood 60:744, 1982

7. Suzuki K, Dahibăck B, Stenflo J: Thrombin-catalyzed activation of human blood coagulation factor V. J Biol Chem 257: 6556, 1982

8. Foster WB, Nesheim ME, Mann KG: The factor $\mathrm{X}_{\mathrm{a}}$-catalyzed activation of factor $\mathrm{V} . \mathrm{J}$ Biol Chem 258:13970, 1983

9. Kane WH, Mruk JS, Majerus PW: Activation of coagulation factor V by a platelet protease. J Clin Invest 70:1092, 1982

10. Rodgers GM, Kane WH: Activation of endogenous factor $V$ by a homocysteine-induced vascular endothelial cell activator. J Clin Invest 77:1909, 1986

11. Kane WH, Davie EW: Blood coagulation factors V and VIII: structural and functional similarities and their relationship to hemorrhagic and thrombotic disorders. Blood 71:539, 1988

12. Owren PA, Aas $K$ : The control of dicoumarol therapy and the quantitative determination of prothrombin and proconvertin. Scand J Clin Lab Invest 3:201, 1951

13. Rosing J, van Rijn JLML, van Dieijen G, Comfurius P, Zwaal RFA: The role of activated human platelets in prothrombin and factor $\mathrm{X}$ activation. Blood 65:319, 1980

14. Lindhout $T$, Govers-Riemslag JWP, van de Waart $P$, Hemker HC, Rosing J: Factor $V_{a-}$ factor $\mathrm{X}_{\mathrm{a}}$ interaction. Effects of phos- pholipid vesicles of varying composition. Biochemistry 21:5494, 1982

15. Lindhout $T$, Baruch $D_{x}$ Schoen $P$, Franssen $J_{y}$ Hemker HC: Thrombin generation and inactivation in the presence of antithrombin. III and heparin. Biochemistry 25:5962, 1986

16. Hoyer $L W:$ The factor VIII complex. Structure and function. Blood $58: 1,1981$

17. McNeely TB, Griffith MJ: The anticoagulant mechanism of action of contact-activated plasma: Inhibition of factor $X$ activation. Blood $65: 1226,1985$

18. Pietters $J$, Lindhout $T$ : The relative importance of factor $X_{a}$ inhibition to the anticoagulant effect of heparin in thromboplastin-activated plasma. Blood, in press

19. Lindhout T, Pieters J, Beguin S, Hemker HC: The mode of action of CY 216 in plasma, in Breddin K, Fareed J, Samama M (eds): Proceedings of the First International Symposium on Fraxiparine, Schattauer Verlag, Stuttgart-New York, 1988, in press 


\section{Chapter VII}

\section{General Discussion}

\section{Introduction}

Over the past decades, a number of proteins were discovered, all forming part of the overall scheme of the blood coagulation system. By means of several purification techniques these factors could be purified to homogeneity, and once they were availlable in a purified form, they could be intensively studied. In that way we gained a great deal of knowledge about structure, function and interactions with other proteins of these coagulation factors (for recent reviews on structures and functions of blood coagulation factors see references $1-3$ ).

Amino acid sequences led to more information about protein structures, and based on these sequences, oliginucleotide probes could be constructed to isolate cDNA clones, coding for these factors (4). Expression of especially those proteins with limited availability (e.g. factor VIII:C) in mammalian cells provided them in large quantities $(5,6)$. Furthermore, the ability to manipulate DNA structures in vitro, thereby creating mutant promotor elements, provides a powerful strategy to define the functionally important regions (7).

However, it became more and more apparent that the interactions between clotting factors, inhibitors and other plasma constituents should be studied under more complex circumstances than only in isolated form. Only then we will get more information about what reactions are really important in the process of coagulation. Also with regard to anticoagulation, the target reactions for the inhibition of clotting should be better determined in plasma. Antithrombotic therapy can then be directed against the relevant reactions in plasma. 
Therefore we initiated the studies described in this thesis, starting with two studies with purified proteins (Chapters II and III), but approaching the physiological situation by reconstituting several proteins in a buffer system. Then we turned to whole plasma in which we were able to measure specifically generation of activated coagulation factors (Chapter IV - VI).

Our goal was to come to a better insight into the interactions of activated blood coagulation factors with antithrombin III and heparin in more complex systems and in plasma.

Antithrombin III is a very important inhibitor of activated clotting factors in plasma, and heparin greatly stimulates this inhibition. Two main topics are treated in the several chapters of this thesis. The first topic deals with the inhibition of activated coagulation factors by antithrombin III/heparin, and the effect of other (plasma) constituents (substrates, cofactors, phospholipids, etc.) on this inhibition. The second topic concerns the determination of the crucial stages in plasma leading to the formation of a fibrin-clot, with the idea in mind that, if those crucial reactions can be controlled by regulatory mechanisms, like the heparin stimulated inhibition by antithrombin III, we might have found a firmer basis for a better antithrombotic therapy. The remaining part of this chapter will discuss the obtained results with respect to the above mentioned topics.

\section{Effect of Heparin/Antithrombin III in Complex Reaction Systems}

\section{Prothrombin activating complex}

In chapter II we describe the effect of prothrombin activation products on the heparin catalyzed factor $\mathrm{X}_{\mathrm{a}}$ inhibition by antithrombin III.

It was known that the antithrombin III dependent inactivation of meizothrombin, a possible major activation product after factor $X_{a}$ catalyzed prothrombin activation, was not stimulated by heparin (9), whereas the inactivation of thrombin is. We showed that (active site blocked) meizothrombin indeed is not able to bind heparin, explaining the absence of a stimulatory effect of heparin on the antithrombin III/meizothrombin reaction (8). Fragment 1.2 and thrombin, however, very clearly showed heparin binding properties. Also after factor $X_{a}$ catalyzed activation of (active site blocked) meizothrombin to give (active site blocked) thrombin and fragment 1.2 these components were not able to neutralize heparin. Only after separation they regained their heparin binding properties.

These results show very clearly that the presence of additional constituents can have important consequences; generation of fragment 1.2 at the sites of prothrombin activation may play an important role in the regulation of blood coagulation by competing with AT III for the available heparin. 


\section{Factor X Activating Complex}

Next we started to investigate what the effect of antithrombin II//heparin on the factor $\mathrm{IX}_{\mathrm{a}}$ catalyzed factor $\mathrm{X}$ activation was in the presence of calcium and phospholipids (Chapter III).

The inactivation of factor $X_{a}$ and factor IX $X_{a}$ by antithrombin III/heparin was already extensively studied (10-12). However, these studies dealt with the inhibition of factor $\mathbf{I X} \mathrm{X}_{\mathrm{a}}$ and factor $\mathrm{X}_{\mathrm{a}}$ in isolated forms. We were able to analyze simultaneously the kinetics of factor $\mathrm{X}_{\mathrm{a}}$ and factor $\mathrm{IX}_{\mathrm{a}}$ inactivation during factor $\mathrm{X}$ activation by factor $\mathrm{IX}_{\mathrm{a}}$. Generation and inactivation curves were fitted to a 3-parameter 2-exponentional model to determine the pseudo first order rate constants of inhibition of factor $\mathrm{LX}_{\mathrm{a}}$ and factor $\mathrm{X}_{\mathrm{a}}$ by antithrombin III/heparin. We showed that the inhibition of factor $\mathrm{X}_{\mathrm{a}}$ by antithrombin III, formed through activation by factor IX $X_{a}$ was 2.5 -fold reduced when compared with factor $X_{a}$ inhibition by antithrombin III in free solution. Phospholipid alone did not show any effect of the inhibition of factor $\mathrm{X}_{\mathrm{a}}$, and this is in contrast to earlier findings $(13,14)$. Further investigations on this phenomenon showed that the protective effect of this so-called "tenase-complex" was due to the presence of phospholipid-bound factor $X$. From the observed effects on factor $X_{a}$ inhibition antithrombin III, two possible explanations evolved from these observations, first, $\beta$ factor $X$ formation at the phospholipid surface (15) could explain the observed inhibition in terms of a competitive enzyme substrate interaction. A second explanation could not be ruled out, i.e. a reduced activity of factor $\mathbf{X}_{\mathrm{a}}$ in the ternary factor $\mathrm{X}$-phospholipid-factor $\mathrm{X}_{\mathrm{a}}$ complex towards antithrombin III, without involvement of the factor $\mathrm{X}_{\mathrm{a}}$ active site. The inactivation of factor $\mathrm{IX}_{\mathrm{a}}$, however was not at all affected by the presence of additional components.

To investigate the effect of heparin on the inhibition of (generated) factor $\mathbf{X}_{\mathrm{a}}$ and factor $\mathbf{I X}_{\mathrm{a}}$, we used two different heparin preparations. First, we used an unfractionated heparin preparation with both high anti-factor $X_{\mathrm{a}}$ and antithrombin activity. As a second heparin preparation we made use of the synthetic pentasaccharide (16), which represents the antithrombin III binding sequence (see Chapter I) in order to explore the reported effects of the non-antithrombin III- binding region of heparin molecules on factor $X_{a}$ and factor $\mathrm{IX}_{\mathrm{a}}(17,18)$. When we compared the effect of pentasaccharide with that of unfractionated heparin, it was clear that an additional sequence to the antithrombin III binding one leads to different inactivation kinetics of factor $X_{\mathrm{a}}$ by antithrombin III, probably because unfractionated heparin and antithrombin III show a greater affinity for factor $\mathrm{X}_{\mathrm{a}}$ than the pentasaccharide-antithrombin III complex. 
Unexpectedly, the heparin catallyzed inhibition of factor IX $\mathrm{a}$ by antithrombin III was stimulated about 6 -fold during factor $\mathrm{X}$ activation as compared to factor $\mathrm{IX}_{\mathrm{a}}$ inhibition in free solution. It appeared that this effect was due to the presence of calcium, probably by inducing structural changes in factor $\mathbb{I X}_{\mathfrak{a}}$ $(19,20)$.

\section{Effect of Heparin/Antithrombin III in Plasma}

From the two first studies described in this thesis (Chapters II and III), it followed that activated coagulation factors behave quite different in more complex systems than was predicted from studies performed in isolated situations, with respect to their inhibition by antithrombin III/heparin. Therefore we decided to continue our research in whole plasma systems.

\section{Importance of Factor $X_{\mathrm{a}}$ Inhibition in Plasma}

As already mentioned in Chapter I, the importance of the anti-factor $\mathrm{X}_{\mathrm{a}}$ effect of heparin to the anticoagulant effect of heparin was not at all clear $(21,22)$. It was found in animal models that heparins with a high anti-factor $\mathrm{X}_{\mathrm{a}}$ over antithrombin ratio were a better antithrombotic than unfractionated heparin, while producing less bleeding tendency (23). Although the so-called low molecular weight heparins clearly show the advantage of a better pharmacokinetic compared with classical heparin, the fact that they give rise to less bleeding problems, while being an as good antithrombotic as unfractionated heparin remained unclear $(23,24)$. Therefore, as described in Chapter IV, we investigated the contribution of factor $\mathrm{X}_{\mathrm{a}}$ inhibition to the overall anticoagulant potency of heparin in plasma. And our results showed, that not factor $X_{a}$ inhibition, but inhibition of the (thrombin-induced) factor $V_{\text {al }}$ generation is of prime importance to inhibit coagulation in thromboplastin-activated plasma. Thus it is our conclusion that the inhibition of thrombin, and not of factor $X_{a}$ is crucial to anticoagulate (thromboplastin-triggered) plasma.

\section{Inhibition of Factor $I X_{\mathrm{a}}$ Generation in Plasma.}

The role of factor $\mathrm{XI}_{\mathrm{a}}$ in the process of blood coagulation is as yet unclear. Factor $\mathrm{XI}_{\mathrm{a}}$ is the product of contact activation, and, under physiological circumstances, it is hard to believe that this contact activation plays an important role (see Chapter I). However, a certain percentage people deficient in factor XI clearly show bleeding problems (in contrast to those deficient in a contact factor). 
Because factor $\mathrm{XI}_{\mathrm{a}}$ is a possible important activator of factor $\mathrm{IX}$ in plasma (25), we decided to studied the kinetics of inactivation (by antithrombin NW/heparin) of the factor $\mathrm{XI}_{\mathrm{a}}$-catalyzed factor $\mathrm{IX}$ activation in plasma.

For the analysis of the factor $\mathrm{LX}_{\mathrm{a}}$ generation curves in the presence of heparin or pentasaccharide in plasma, we used a 3-parameter model, based on the $\mathrm{Mi}$ chaelis-Menten equation and first order kinetics of inactivation to determine $k_{\mathrm{cat}} / \mathrm{K}_{\mathrm{m}}$, and inactivation constants for factor $\mathrm{IX}_{\mathrm{a}}$ and factor $\mathrm{XI}_{\mathrm{a}}$.

The inactivation of factor $\mathrm{XI}_{\mathrm{a}}$ appeared to be fast in plasma, with a pseudo first order rate constant of $0.35 \mathrm{~min}^{-1}$. This inhibition constant was not dependent on the addition of heparin or pentasaccharide, and therefore the inactivation of factor $\mathrm{XI}_{\mathrm{a}}$ is probable not the result of the action of antithrombin III. This inhibition can be explained by the data of Scott et al (26), who found a pseudo first order rate constant for factor $\mathrm{XI}_{\mathrm{a}}$ of $0.59 \mathrm{~min}^{-1}$ by $\alpha 1$-antitrypsin. However, the data of Meijers et al (27) indicate that the inhibition of factor $\mathrm{XI}_{\mathbf{a}}$ in plasma is mainly accomplished by the combined action of $\alpha 1$-antitrypsin, az-antiplasmin and $\mathrm{C} 1$-inhibitor.

Inhibition of the generated factor $\mathrm{IX}_{\mathrm{a}}$ was not observed in normal plasma. However, the addition of heparin caused a dramatic effect on the factor $\mathbf{I X}_{\mathbf{a}}$ inactivation curve $\left(6.16 \mathrm{~min}^{-1}\left(\mu \mathrm{g} / \mathrm{mL}^{-1}\right)\right.$. Moreover, even pentasaccharide, which does not show an effect on factor $\mathrm{IX}_{\mathrm{a}}$ in a purified system, did have a very clear effect on factor $\mathrm{IX}_{\mathrm{a}}$ inactivation, and caused an inactivation of $0.70 \mathrm{~min}$ $1(\mu \mathrm{g} / \mathrm{mL})^{-1}$.

\section{The Central Role of Thrombin in Blood Coagulation}

The general conclusion from Chapter IV, namely the importance of thrombin in the activation of factor $V$ to ensure proper coagulation, already indicates that thrombin plays a key role in the formation of a fibrin-clot. The central role of thrombin in the clotting scheme is also emphasized in Chapter I. From the study described in Chapter IV, the idea developed that in general, thrombin is responsible for the activation of the non enzymatic protein cofactors factor VIII:C and factor $V$ in order to accelerate its own formation. The literature, however, describes studies in which also factor $\mathrm{X}_{\mathrm{a}}$ or factor $\mathrm{IX}_{\mathrm{a}}$ were found to activate factor VIII: $C(28,29)$. Also factor $V$ has been described to be activated by other proteases than thrombin $(30,31)$.

Unfortunately, all these studies deal with investigations done in purified systems. Because we were able to measure all the relevant activated coagulation factors in plasma, we investigated the activation of factor VIII:C and factor V in plasma. Chapter VI describes this study, and we found that in thromboplastin-ac- 
tivated plasma, in situ generated thrombin, but not factor $X_{a}$ catalyzed activation factors VIII:C and V. Even addition of high amounts of factor $X_{a}$ did not result in factor VIII: $\mathrm{Ca}_{\mathrm{a}}$ or factor $\mathrm{V}_{\mathrm{a}}$ formation.

We hope that the investigations presented in this thesis throw some more light on the process of blood coagulation as it nowadays, after more than 300 years of investigations, is thought to proceed. We think that we succeeded at least in pointing out that this process should be investigated $e x$ vivo, or in any case in a physiological more relevant environment as mere buffer. We presented some interesting data on how activated clotting factors behave under more complex conditions (first topic), and we tried to trace out the factor(s) which play a key role in plasma clot-formation (second topic). Our results showed that thrombin is the enzyme that plays a key role in plasma coagulation, and should be the prime target in anticoagulation.

\section{References}

1. Lammle B, Griffin JH: Formation of the fibrin clot: the balance of procoagulant and inhibitory factors. Clinics in Haematology 14:281, 1985

2. Thompson AR: Structure, function and molecular defiects of factor IX. Blood 67:565, 1988

3. Barrowcliffe TW, Thomas DP: Antithrombin III and heparin, in Bloom AL, Thomas DP (eds): Haemostasis and Thrombosis, Second edition, Churchill Livingstone, 1987, pp 849.

4. Rosenberg RD: Regulation of the hemostatic mechanism, in Stamatoyannopoulos $G$, Nienhuis AW, Leder P, Majerus PW (eds): The mollecular basis of blood diseases. Philadelphia, Saunders, 1987, p 534

5. Toole JJ, Knopf JL, Wozney JM, Sultzman LA, Buecker JL, Pittman DD, Kaufman RJ, Brown, $\mathbb{E}$, Shoemaker C, Orr EC, Amphlett GW, Foster WB, Coe ML, Knutson GJ, Fass DN, Hewick RM: Molecular cloning of a CDNA encoding human antihaemophilic factor, Nature 312:342, 1984

6. Vehar GA, Keyt B, Eaton D, Rodriguez $\mathrm{H}_{\text {, }} \mathrm{O}^{3}$ Brien DP, Rotblat $\mathrm{F}$, Oppermann $\mathrm{H}_{\text {, }}$ Keck R, Wood WI, Harkins RN, Tuddenham EGD, Lawn RM, Capon DJ: Structure of human factor VIII. Nature 312:337, 1984

7. Nienhuis AW, Maniatis T: Structure and expression of globin genes in erythroid cells, in Stamatoyannopoulos $G$, Nienhuis AW, Leder $P$, Majerus PW (eds): The molecular basis of blood diseases. Philadelphia, Saunders, 1987, p 28

8. Lindhout $T$, Baruch $D_{n}$, Schoen P, Franssen J, Hemker HC* Thrombin generation and inactivation in the presence of antithrombin III and heparin. Biochemistry 25:5962, 1986

9. Rosing J, Zwaal RFA, Tans G: Formation of meizothrombin as intermediate in factor $X_{\mathrm{a}}$-catalyzed prothrombin activation. J Biol Chem 261:4224, 1986 
10. Jordan RE, Oosta GM, Gardner WT, Rosemberg RD: The kinetics of hemostatic enzyme-antithrombin interactions in the presence of low molecular weight heparin. $J$ Biol Chem 255:10081, 1980

11. Holmer $\mathrm{E}$, Kurachi $\mathrm{K}$, Soderström $\mathrm{G}$ : The molecular - weight dependence of the rate enhancing effect of theparin on the inhibition of thrombin, factor $X_{w}$, factor $L_{k}$, factor $\mathrm{XI}_{\mathrm{a}}$, factor XIIa and kallikrein by antithrombin. Biochem J 193:295, 1981

12. Jesty J: The inhibition of activated bovine coagulation factors $X$ and VII by antithrombin III. Arch Biochem Biophys 185:165, 1978

13. Ellis V, Scully MF, Kalkkar V: Inhibition of prothrombinase complex by plasma proteinase inhibitors. Biochemistry 23:5882, 1984

14. Walker $F J$, Esmon CT: The effects of phospholipids and factor $\mathrm{V}_{\mathrm{a}}$ on the inhibition of factor $X_{\text {a }}$ by antithrombin III. Biochem Biophys Res Comm 90:641, 1979

15. Link RP, Castellino FJ: The activation of bovine factor $\mathbf{X}$ by bovine factor $\mathbf{X}_{\mathrm{a}}$. Arch Biochem Biophys 21:5:215, 1982

16. Choay J, Petitou M, Lormeau JC, Sinay P, Casu B, Gatti G: Structure - activity relationship in heparin: A synthetic pentasaccharide with high affinity for antithrombin III and

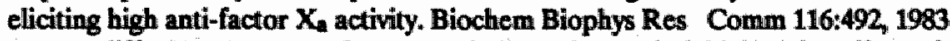

17. Barrowcliffe TW, Havercroft SJ, Kemball-Cook G, Lindahl U: The effect of Ca2+, phospholipid and factor $V$ on the anti-(factor $\mathbf{X}_{\mathrm{a}}$ ) activity of heparin and its high-affinity oligosaccharides. Biochem J 243:31, 1987

18. Kurachi $K_{\text {, Fujilkawa }} \mathrm{K}_{\text {, Schmer }} \mathrm{G}$, Davie EW: Inhibition of bovine factor $\mathrm{XX}_{\text {and fac- }}$ tor $X_{a}$ by antithrombin III. Biochemistry 15:373, 1976

19. Chuang TF, Sargeant RB, Hougie $C$ : The effcet of calcium ions on the properties of factor IX and its activated form. Brit J Haematol 27:281, 1974

20. Amphlett GW, Byrne R, Castellino FJ: The binding of calcium to the activation products of bovine factor IX. J Biol Chem 254:6333, 1979

21. Thomas DP: heparin in prophylaxis and treatment of venous thromboembolism. Sem Haematol 15:1, 1978

22. Ofosu FA, Blajchman MA, Modi GJ, Smith LM, Buchanan MR, Hirsh J: The importance of thrombin inhibition for the expression of the anticoagulant activities of heparin, dermatan sulphate, low molecular weight heparin and pentosan polysulphate. $\mathrm{Br} J$ Haematol 60:695, 1985

23. Carter CJ, Kelton JG, Hirsh J, Cerskus A, Santos AV, Gent M: The relationship between the hemorrhagic and antithrombotic properties of low molecular weight heparin in rabbits. Bllood 59:1239, 1982

24. Thomas DP: Current status of low molecular weight heparin. Thromb Hacmost 56(3):241, 1986

25. Warn-Cramer BJ, Bajaj SP: Intrinsic versus extrinsic coagulation. Kinetic considerations. Biochem J 239:757, 1986

26. Scott $\mathbf{C F}$, Schapira $\mathrm{M}$, James $\mathrm{HL}$, Cohen $\mathbf{A B}$, Colman $\mathbf{R W}$ : Inactivation of factor $\mathrm{XI}_{\mathrm{a}}$ by plasma proteinase inhibitors. Predominant role of $\alpha 1$-protease inhibitor and protective effect of high molecular weight kininogen. J Clin Invest 69:844, 1982

27. Meijers JCM: Regulation of the blood coagulation mechanism by plasma proteinase inhibitors. Thesis at the State University of Utrecht, Utrecht, The Netherlands, 1988

28. Lollar P, Knutson GJ, Fass DN: Activation of porcine factor VIII:C by thrombin and factor X. Biochemistry 24:8056, 1985

29. Rick M: Activation of factor VIII by factor IX. Blood 60:744, 1982

30. Suzuki $\mathbf{K}$, Dahlback B, Stenflo J: Thrombin-catalyzed activation of thuman blood coagulation factor V. J Biol Chem 257: 6556, 1982

31. Foster WB, Nesheim ME, Mann KG: The factor $X_{4}$-catalyzed activation of factor $V$. J Biol Chem 258:13970, 1983

32. Soons $\mathrm{H}$ : Studies on the inhibition of blood coagulation factor $\mathrm{XI}_{\text {. }}$. Thesis at the University of Limburg, Masstricht, the Netherlands, 1987 


\section{Summary}

The work presented in this thesis comprise a number of studies concerning the action of the antithrombin III/heparin system at several levels of the coagulation cascade. Our goal was to gain a better insight into the interactions of activated coagulation factors with the plasma inhibitor antithrombin III and the modulation of this action by heparin.

Heparin is a mucopolysaccharide that greatly accelerates the reaction between antithrombin III and activated coagulation factors. In the clinic, heparin is used in a variety of ways to treat or prevent thrombosis. Its mechanism of action in the patient, however, is not very well understood, because little is known about the effect of heparin on the complex reaction systems that govern blood coagulation in vivo.

Therefore it was our aim to obtain more information on the mechanism of action of heparin in (complex) purified systems and in plasma.

After a general introduction concerning the coagulation process, its initiation and inhibition, it is demonstrated in Chapter II that the prothrombin activation peptides, that are released during the generation of thrombin, are able to neutralize heparin. These results show a possible role for these fragments in the regulation of blood coagulation.

Chapter III describes the effect of antithrombin III and heparin during the enzymatic conversion of factor $\mathrm{X}$ into factor $\mathrm{X}_{\mathrm{a}}$ by factor $\mathrm{IX}_{\mathrm{a}}$ in the presence of phospholipids and calcium. The situation is a complicated one because both the enzyme (factor $\mathrm{IX}_{\mathrm{a}}$ ) and the generated product (factor $\mathrm{X}_{\mathrm{a}}$ ) are inactivated by antithrombin III/heparin. Under these circumstances, that start to approach the complexities of plasma, important differences become apparent with the effect of antithrombin III and heparin on isolated activated coagulation factors.

Chapters II and III clearly show that in more complex systems the activated coagulation factors behave quite different from what would be predicted from studies performed on isolated factors. In order to approach the in wivo situation still further, the investigations were continued in whole (platelet free) plasma. 
To asses the effect of heparin and heparin-analogues on activated coagulation factors in plasma, sensitive and specific bio-assays were developed that can monitor the generation of activated coagulation factors in clotting plasma.

In Chapter IV it is demonstrated that not factor $\mathrm{X}_{\mathrm{a}}$ inhibition, but rather the inhibition of (thrombin-induced) factor $V_{a}$ generation by heparin explains the inhibition of coagulation in thromboplastin-activated plasma.

Using an assay for factor $\mathrm{IX}_{\mathrm{a}}$ the kinetics of inactivation (by antithrombin III/heparin) of the factor $\mathrm{XI}_{\mathrm{a}}$-catalyzed factor $\mathrm{IX}_{\mathrm{a}}$ generation in plasma were studied (Chapter $\mathrm{V}$ ). It was found that the inactivation of factor $\mathrm{XI}_{\mathrm{a}}$ in plasma was fast, and independent of the presence of heparin or heparin analogues. Factor $\mathrm{IX}_{\mathrm{a}}$, generated in plasma by factor $\mathbf{X I}_{\mathrm{a}}$, was not significantly inactivated. However, heparin and pentasaccharide clearly caused inactivation of this factor $\mathrm{IX}_{\mathrm{a}}$.

In Chapter VI, the activation of the non enzymatic protein cofactors VIII:C and $\mathrm{V}$ was studied. It was demonstrated that in thromboplastin-triggered plasma, in situ generated thrombin, but not factor $\mathrm{X}_{\mathrm{a}}$ is responsible for the activation of factors VIII:C and V.

From these studies, it can be concluded that (1) inhibition of activated coagulation factors by antithrombin III/heparin in complex reaction systems is quite different from inhibition of these factors in isolated systems, and (2) thrombin is the enzyme that plays the key role in plasma coagulation. It therefore should be the prime target of antithrombotic therapy by anticoagulation. 


\section{Samenvatting}

In dit proefschrift worden een aantal studies beschreven met betrekking tot de werking van antitrombine III en heparine op verschillende niveaus van de stolcascade. Ons doel was een beter inzicht te verkrijgen in de interacties van geactiveerde stolfactoren met de plasma remmer antitrombine III en heparine.

Heparine is een mucopolysaccharide dat in staat is de reactie tussen antitrombine III en geactiveerde stolfactoren drastisch te versnellen. In de kliniek wordt heparine gebruikt ter behandeling of voorkoming van trombose. Het werkingsmechanisme van heparine in de patiënt is echter slecht begrepen, omdat weinig bekend is over het effect van heparine op de meer complexe reactie systemen die deel uitmaken van de bloedstolling in vivo.

Vandaar dat wij ons ten doel gesteld hebben meer informatie te verkrijgen over het werkingsmechanisme van heparine in (complexe) gezuiverde systemen en in plasma.

$\mathrm{Na}$ een algemene inleiding betreffende het bloedstollingsproces, de initiatie en de remming van dit proces, wordt in hoofdstuk II aangetoond dat de protrombine activeringspeptiden die gevormd worden tijdens de trombine generatie, in staat zijn om heparine te neutraliseren. Deze resultaten tonen een mogelijke rol aan voor deze fragmenten in de regulatie van de bloedstolling.

Hoofdstuk III beschrijft het effect van antitrombine III en heparine gedurende de enzymatische omzetting van factor $\mathrm{X}$ in factor $\mathrm{X}_{\mathrm{a}}$ door factor $\mathrm{IX}_{\mathrm{a}}$ in aanwezigheid van fosfolipiden en calcium. Deze situatie is gecompliceerd omdat zowel het enzym (factor $\mathrm{IX}_{\mathrm{a}}$ ) als het gevormd product (factor $\mathrm{X}_{\mathrm{a}}$ ) geinactiveerd worden door antitrombine 111/heparine. Onder deze omstandigheden, die de complexiteit van het plasma benaderen, worden belangrijke verschillen duidelijk met het effect van antitrombine III en heparine op geïsoleerde stolfactoren.

De hoofdstukken II en III laten zien dat in complexe systemen geactiveerde stolfactoren zich geheel anders gedragen als voorspeld zou worden op basis van studies uitgevoerd met geïsoleerde factoren. 
Om de in wivo situatie nog meer te benaderen, werden de studies voortgezet in vol (plaatjesvrij) plasma.

Om het effect van heparine en heparine analoga op geactiveerde stolfactoren in plasma te bestuderen, werden gevoelige en specifieke bepalingen ontwikkeld om de generatie van geactiveerde stolfactoren in plasma te kunnen volgen.

In hoofdstuk IV wordt aangetoond dat niet de remming van factor $X_{a}$, maar veeleer de remming van de (trombine-afhankelijke) factor $\mathrm{V}_{\mathrm{a}}$ generatie door heparine de remming van de stolling in tromboplastine-geactiveerd plasma verklaard.

Met behulp van een factor IX bepaling, werd de kinetiek van de remming (door antitrombine III/heparine) van de factor $\mathrm{XI}_{\mathrm{a}}$ gecatalyseerde factor $\mathrm{IX}_{\mathrm{a}}$ generatie in plasma bestudeerd (hoofdstuk V). De resultaten laten zien, dat factor $\mathbf{X I}_{\mathbf{a}}$ in plasma snel wordt geremd, en dat deze remming onafhankelijk is van de toevoeging van heparine of heparine analoga. Factor IX $\mathrm{X}_{\mathbf{a}}$, gegenereerd in plasma door factor $\mathrm{XI}_{\mathrm{a}}$, werd niet significant geinactiveerd. Toevoeging van heparine of pentasaccharide veroorzaakte echter een duidelijke remming van factor IX $\mathrm{a}_{\mathrm{a}}$

In hoofdstuk VI werd de activering van de niet enzymatische eiwitcofactoren VIII:C en $V$ bestudeerd, De resultaten tonen aan, dat in tromboplastine-geactiveerd plasma, in situ gegenereerd trombine, en niet factor $X_{a}$, verantwoordelijk is voor de activering van factor VIII: $\mathrm{C}$ en $\mathrm{V}$.

Uit de studies die beschreven worden in dit proefschrif, kan geconcludeerd worden dat (1) inactivatie van geactiveerde stolfactoren door antitrombine III en heparine in complexe reactie systemen grote verschillen vertoond met de remming van deze factoren in geïsoleerde systemen, en (2) dat trombine het enzym is dat een sleutelrol speelt in de stolling van plasma. Vandaar dat trombine de belangrijkste rol zou kunnen spelen als doelwit enzym bij antistolling. 


\section{Dankwoord}

Dit proefschrift is tot stand gekomen dankzij een intensieve samenwerking met vele anderen. Iedereen die hieraan heeft bijgedragen, wil ik graag bedanken.

Mijn promotor, professor H.C. Hemker wil ik bedanken voor de gelegenheid die hij mij geboden heeft om onder zijn leiding dit promotie-onderzoek te verrichten.

Mijn co-promotor en dagelijkse begeleider Dr. T. Lindhout, ben ik veel dank verschuldigd. Ik heb onze samenwerking gedurende de afgelopen jaren steeds als bijzonder positief ervaren. Voor zijn enorme energie, inzet en deskundigheid heb ik grote bewondering.

Hans, Truus, Jo en Pieter bedank ik voor de hulp en steun tijdens de lab-uren.

George Willems wil ik bedanken voor zijn bijdrage aan de wiskundige analyses van onze resultaten.

Rob Wagenvoord en Hans Hendrix stonden altijd klaar om hulp te bieden bij de factor VIII zuiveringen.

Alle medewerkers van de vakgroep Biochemie bedank ik voor de goede werksfeer op het lab gedurende de afgelopen jaren.

Mijn ouders, die mij altijd gestimuleerd hebben en voortdurend interesse toonden, ben ik daarvoor zeer dankbaar.

Tenslotte gaat mijn dank uit naar Chantal, voor haar begrip en steun in de afgelopen tijd. 


\section{Curriculum Vitae}

De schrijver van dit proefschrift werd geboren te Heerlen op 5 januari 1962. Hij behaalde in 1980 het diploma Gymnasium-B aan het Stedelijk Lyceum te Maastricht. Vanaf oktober 1980 studeerde hij aan de faculteit Landbouwwetenschappen van de Katholieke Universiteit Leuven (België), richting scheikunde. Gedurende het laatste studiejaar verrichtte hij onderzoek op het laboratorium virologie van het Rega Instituut te Leuven. In 1985 behaalde hij het ingenieursdiploma in de afstudeerrichting biochemie en microbiologie. Vanaf oktober 1985 is hij werkzaam als wetenschappelijk assistent bij de vakgroep Biochemie van de Rijksuniversiteit Limburg, alwaar hij onder leiding van Prof. Dr. H.C. Hemker en Dr. T. Lindhout het onderzoek verrichtte dat heeft geleid tot dit proefschrift. 